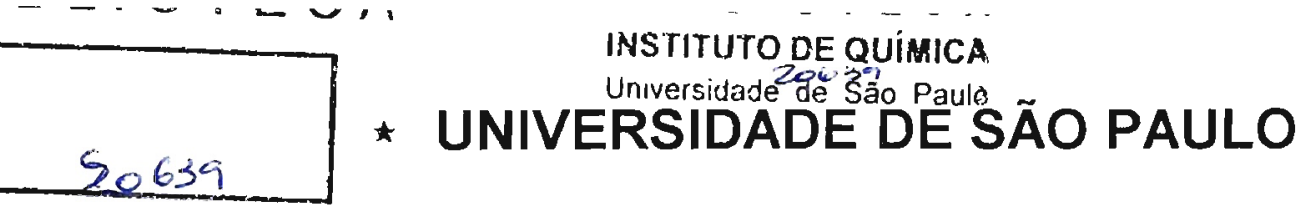

ITUTO DE QUIMICA

Estudos da influência de surfactantes e determinação de cloro em água potável empregando-se TCPO e 2-NPO

Margareth Mie Naķamura Matsuda

Tese de Doutorado

Profa. Dra. Nina Coichev

Orientadora

São Paulo

24 de juriho de 2003 


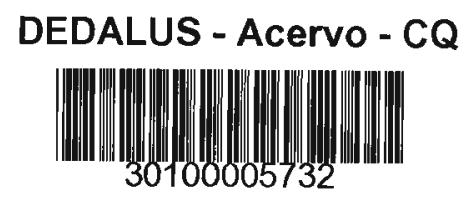

Ficha Catalográfica

Elaborada pela Divisão de Biblioteca e

Documentação do Conjunto das Químicas da USP.

\begin{tabular}{|l} 
Matsuda, Margareth Mie Nakamura \\
Estudos da influência de surfactantes e determinação de \\
cloro em água potável empregando-se TCPO e 2-NPO \\
/ Margareth Mie Nakamura Matsuda. -- São Paulo, 2003. \\
153p. \\
Tese (doutorado) - Instituto de Química da Universidade \\
de São Paulo. Departamento de Química Fundamental. \\
Orientador: Coichev, Nina \\
1. Quimiluminescência: Método óptico: Química analítica \\
2. Cloro : Química inorgânica 3. Surfactante : Físico-química \\
1. T. Il. Coichev, Nina, orientador.
\end{tabular}




\section{"Estudos da influência de surfactantes e determinação de cloro em água potável empregando-se TCPO e 2-NPO"}

\section{MARGARETH MIE NAKAMURA MATSUDA}

Tese de Doutorado submetida ao Instituto de Química da Universidade de São Paulo como parte dos requisitos necessários à obtenção do grau de Doutor em Química - Área: Química Analítica.

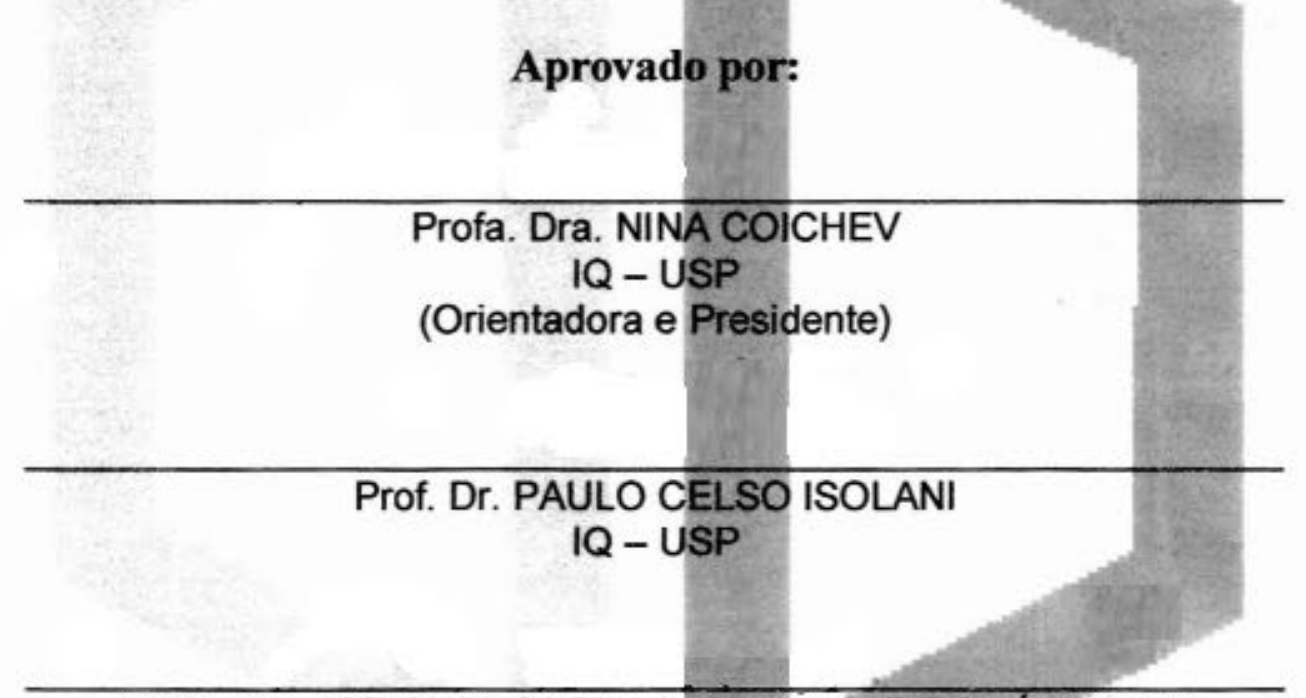

Profa. Dra. MARIA ENCARNACION VAZZUEZ SUAREZ IHA

$$
\text { IQ - USP }
$$

Prof. Dr. ORLANDO FATIBELLO FILHO

UFSCar

\section{Profa. Dra. ADRIANA VITORINO ROSSI \\ IQ - UNICAMP}

SÃO PAULO

16 DE SETEMBRO 2003. B I B L I O TE C A INSTITUTO DE QUIMICA Universidade de Săo Paulo 
Ao Hylton

Por estar sempre presente,

Com muito amor. 


\section{AGRADECIMENTOS}

Aos meus pais, pelo carinho e por sempre me fazer pensar positivamente,

À professora Nina Coichev, pela orientação com objetividade e compreensão,

Ao Prof. Dr. Asano, pelo carinho e pela possibilidade da experiência profissional no Japão,

Aos Profs. Dr. Yamada e Lin, pela orientação na Universidade Metropolitana de Tóquio,

Às professoras Silvia Serrano e Maria Encarnación, pelo carinho,

Ao Laerte, Maria, Rubén, Rodrigo, Luciene e Cristina, pelo dia-a-dia com muita amizade,

Aos funcionários do Instituto de Química, pelo suporte técnico, e

À CAPES e JICA, pelo suporte financeiro aqui e no Japão, respectivamente. 
No presente trabalho, parte dos estudos descritos foi realizada em colaboração com o professor Masaaki Yamada, da Universidade Metropolitana de Tóquio, com suporte financeiro da JICA (Japan International Cooperation Agency).

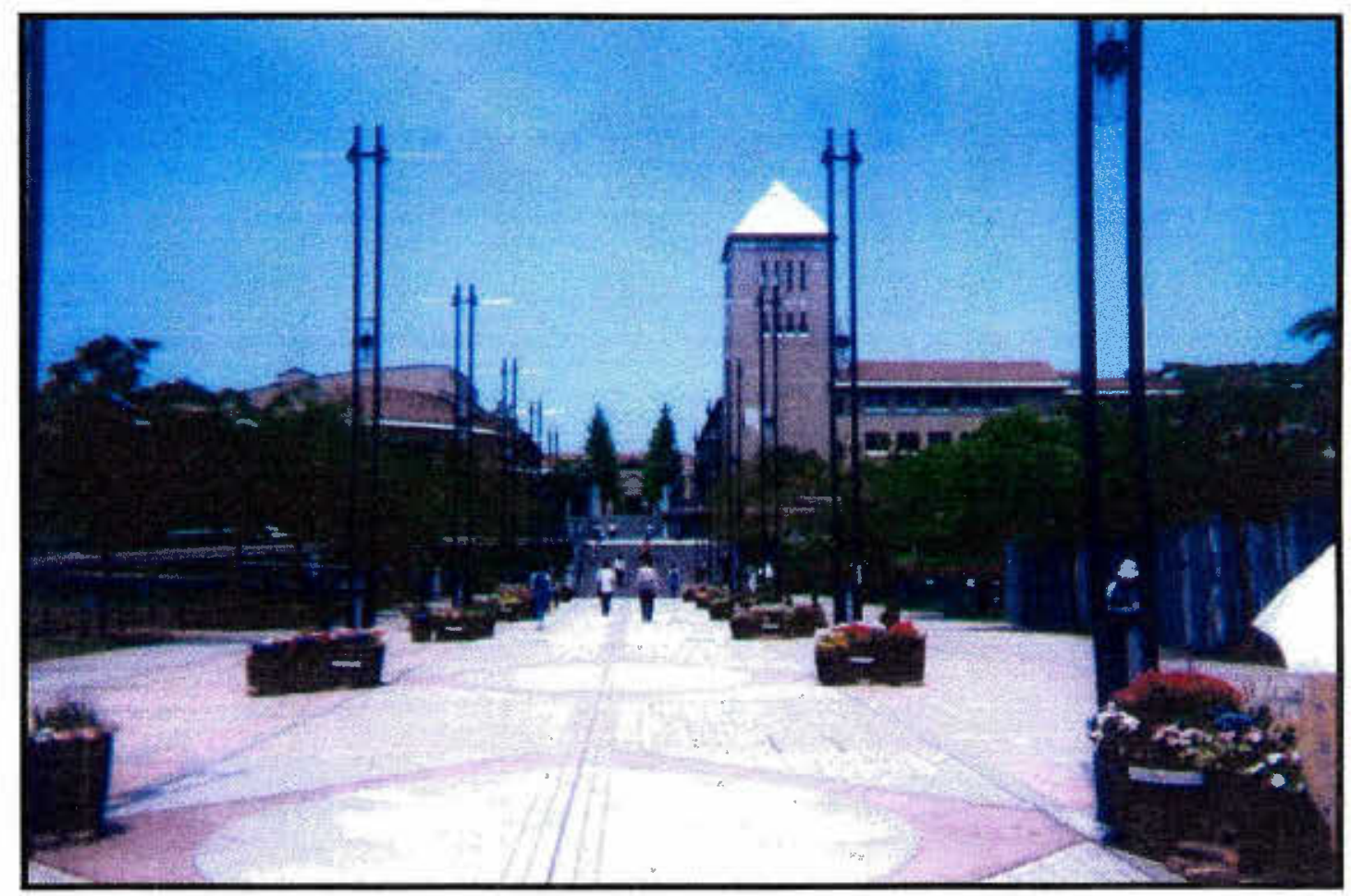

Vista da entrada principal da Universidade Metropolitana de Tóquio - Japão. 
Índice

Página

Resumo

Abstract

ii

Lista de símbolos e abreviações

iii-v

1 - Introdução geral

1

I.1 - Quimiluminescência

1

I.2 - Aparelhagem instrumental

7

1.3 - Breve histórico das reações quimiluminescentes em fase aquosa

10

1.4 - Considerações sobre algumas reações quimiluminescentes mais estudadas e suas aplicações analíticas

II - Quimiluminescência de TCPO e 2-NPO em sistema micelar 25 aquoso

II.1 - Objetivos 26

II.2 - Alguns usos de surfactantes em química analítica

II.2.1 - Considerações gerais sobre surfactantes

11.2.2 - Efeito de micelas em reações químicas

II.2.3 - Algumas aplicações de surfactantes em reações 
quimiluminescentes

II.3 - Estudos da quimiluminescência de TCPO e 2-NPO em sistema 43 micelar aquoso

II.3.1 - Parte experimental

II.3.1.a - Reagentes

II.3.1.a.1 - Soluções estoque

II.3.1.b - Procedimento experimental

II.3.2.1 - Efeito do surfactante na reação de 2-NPO com peróxido de 55 hidrogênio

II.3.2.2 - Comparação do efeito de surfactantes na reação de 2-NPO e 60 TCPO com peróxido de hidrogênio e hidroperóxido de t-butila

II.3.2.3 - Efeito da presença de imidazol

II.3.2.4-Conclusões

III - Desenvolvimento de método analítico para determinação de 70 cloro em água potável

III. 1 - Objetivos

III.2 - Cloração de água potável 
III. 5 - Desenvolvimento de método analítico baseado na reação de TCPO 80 com cloro

III.5.1 - Parte experimental

III.5.1.a-Reagentes

III.5.1.a.3 - Determinação de cloro em amostra de água de torneira, 86 através de método com DPD

III.5.1.b - Procedimento experimental

III.5.1.b.1 - Experimentos no modo estático ("batch")

III.5.1.b. 2 - Experimentos com injeção de amostra em fluxo

III.5.2.1 - Estudos empregando um sistema de injeção em fluxo 
III.5.2.1.d - Efeito das concentrações de TCPO e DFA

III.5.2.1.e - Efeito do volume de amostra

III.5.2.1.f - Efeito da vazão das soluções de TCPO e DFA

III.5.2.1.i - Efeito de $\mathrm{ClO}_{2}^{-}, \mathrm{ClO}_{3}{ }^{-}$e $\mathrm{ClO}_{4}^{-}$

III.5.2.1.j - Curva analítica para determinação de cloro em água de 116 torneira

III.6 - Estudos espectrofotométricos para verificação de hidrólise do 119 TCPO

III.6.1 - Parte experimental 121

III.6.1.a-Reagentes 121

III.6.1.b - Procedimento experimental

III.6.2.b - Estudos espectrofotométricos da reação de TCPO com hipoclorito

III.7 - Conclusões 
IV - Perspectivas futuras 133

V-Referências bibliográficas

134

Curriculum vitae 


\section{RESUMO}

As reações quimiluminescentes de oxalato de bis(2,4,6-triclorofenila) (TCPO) e oxalato de bis(2-ritrofenila) (2-NPO), com fluoranteno como fluoróforo, em sistemas micelares aquosos, foram estudadas na presença de alguns surfactantes. A oxidação destes oxalatos por peróxido de hidrogênio ou por hidroperóxido de $\mathrm{t}$ - butila produz quimiluminescência cuja intensidade depende da acidez e da presença de imidazol. A intensidade de quimiluminescência é maior na presença de alguns surfactantes, especialmente CTAC, OTAC, DDAB, DODAC e $\beta$-ciclodextrina.

A reação de TCPO com cloro $\left(\mathrm{HClO}, \mathrm{ClO}^{-}\right.$e $\left.\mathrm{Cl}_{2}\right)$ na presença de 9,10-difenilantraceno como fluoróforo, em meio de acetonitrila/água, também foi investigada. Um sistema de análise por injeção em fluxo para determinação de cloro com aplicação analitica em água de torneira foi desenvolvido. A faixa linear para a curva analítica de cloro e o limite de detecção foram, respectivamente: $(0,2-3,0) \times 10^{-5}$ e $0,2 \times 10^{-5} \mathrm{~mol} \mathrm{~L}^{-1}$. 


\section{ABSTRACT}

The chemiluminescent reactions of bis (2,4,6-trichlorophenyl) oxalate (TCPO) and bis(2-nitrophenyl) oxalate (2-NPO), with fluoranthene as fluorophore, in aqueous micellar systems, were studied in the presence of surfactants. The oxidation of these oxalates by hydrogen peroxide or t-butyl peroxide produces chemiluminescence, which depends on the acidity and imidazole presence. The chemiluminescent intensity is higher in the presence of some surfactants, especially CTAC, OTAC, DDAB, DODAC and $\beta$-cyclodextrine.

The reaction of TCPO with free chlorine $\left(\mathrm{HClO}, \mathrm{ClO}^{-}\right.$and $\left.\mathrm{Cl}_{2}\right)$, in the presence of 9,10-diphenylanthracene as fluorophore in acetonitrile/water medium, was also investigated. A flow injection analysis system, for free chlorine determination with analytical application in tap water was developed. The linear range for free chlorine and detection limit were, respectively: $(0.2-3.0) \times 10^{-5}$ and $0.2 \times 10^{-5} \mathrm{~mol} \mathrm{~L}-1$. 


\section{LISTA DE SÍMBOLOS E ABREVIAÇÕES}

\begin{tabular}{|c|c|}
\hline 2-NPO & oxalato de bis(2-nitrofenila) \\
\hline $\mathrm{ACN}$ & acetonitrila \\
\hline ANS & ácido 8-anilino naftalenosulfônico \\
\hline AOT & sulfosuccinato de bis(etilexil) e sódio \\
\hline $\mathrm{BL}$ & bioluminescente \\
\hline Brij 35 & éter polioxietileno(23)laurílico \\
\hline Brij 76 & éter polioxietileno(10)estearilico \\
\hline c.m.c. & concentração micelar crítica \\
\hline Cloro livre ou cloro & mistura de hipoclorito, ácido hipocloroso e cloro aquoso \\
\hline CTAB & brometo de cetiltrimetilamônio \\
\hline CTAC & cloreto de cetiltrimetilamônio \\
\hline CTAOH & hidróxido de cetiltrimetilamônio \\
\hline DDAB & brometo de didodecildimetilamônio \\
\hline DFA & 9,10-difenilantraceno \\
\hline DNPO & oxalato de bis(2,4-dinitrofenila) \\
\hline DODAC & cloreto de dioctadecildimetilamônio \\
\hline DPD & $N, N$-dietil-p-fenilenediamina \\
\hline DTAOH & hidróxido de tetradeciltrimetilamônio \\
\hline$A$ & fluoranteno \\
\hline
\end{tabular}


FIA

FMT

$\mathrm{H}_{2} \mathrm{O}_{2}$

I

IMI

METQ

$\mathrm{NaDC}$

NaDDS

Nag

NaSDS

ODI

OTAC

PHA

PO-QL

QL

SB-12

SDS

$\mathrm{t}-\mathrm{bOOH}$

TCP

TCPO

TNS análise por injeção em fluxo ("flow injection analysis")

fotomultiplicadora

peróxido de hidrogênio

altura de pico da curva de intensidade de emissão vs tempo

imidazol

sulfonato de 4,4'-[oxalilbis-[(trifluorometilsulfonil)iminoetileno]

bis(4-metilmorfoliniumtrifluorometano

deoxicolato de sódio

dodecilsulfonato de sódio

número de agregação

dodecilsulfato de sódio

1,1'-oxalildiimidazol

cloreto de octadeciltrimetilamônio

polihidrocarboneto aromático

quimiluminescência de peroxi-oxalatos

quimiluminescente

1-propanosulfonato de 3-dodecildimetilamônio

dodecil sulfato de sódio

hidroperóxido de t-butila

2,4,6-triclorofenol

oxalato de bis(2,4,6-triclorofenila)

2-p-toluidinilnaftaleno-6-sulfonato de potássio 
TRIS

Tween 20

Tween 80

$\Phi$ tris(hidroximetil)aminometano

monolaurato de polioxietileno(20)sorbitano

monooleato de polioxietileno(20) sorbitano

rendimento quântico 


\section{I - INTRODUÇÃO GERAL}

\section{I.1 - Quimiluminescência}

As referências 1 a 18 apresentam um levantamento de uma variedade de usos de métodos analíticos baseados em reações quimiluminescentes. A seguir serão abordados alguns aspectos dessas reações com ênfase em química analítica.

Quimiluminescência é originada quando uma reação química produz uma espécie no estado eletronicamente excitado que, ou emite radiação (Esquema 1 equação 2) e retorna ao estado fundamental, ou transfere sua energia a outra molécula que emite luminescência (esquema 1 - equação 3). Quando a emissão de luz é originada a partir de reações em sistemas biológicos, é denominada de bioluminescência.

A quimiluminescência e a bioluminescência são fenômenos naturais e atraíram a atenção desde os primórdios da vida na terra, porém os mecanismos de produção dessa "luz fria" somente começaram a ser explicados no século passado 17 .

Embora o tempo de vida de estados singletes excitados envolvidos em reações quimiluminescentes $(\mathrm{QL})$ apresente tipicamente duração de nanosegundos, em alguns casos a emissão de luz persiste por vários minutos após o inicio da reação. Uma explicação para esta observação é que, em solução, a emissão de 
luminescência persiste enquanto a reação química ocorre, e é mais um indicativo da cinética da reação do que da fotofísica dos estados eletronicamente excitados formados na reação 8 .

As reações químicas devem obedecer alguns critérios para a produção e emissão de luminescência:8,19,20

- A reação química deve gerar energia suficiente para a produção de espécies no estado excitado;

- Deve existir um caminho de reação favorável para a formação de produtos no estado excitado e,

- As espécies no estado excitado, após uma etapa de transferência de energia, devem apresentar um rendimento quântico de luminescência relativamente alto.

Estes processos podem ser representados pelas equações 2-3 descritas no esquema 1. Em competição com os caminhos de reação que produzem quimiluminescência, exitem vários processos não-qumiluminescentes (esquema 1 equação 1) 18 .

O rendimento quântico é definido como o produto das eficiências dos processos físicos e químicos envolvidos (equação 4) 18 : 


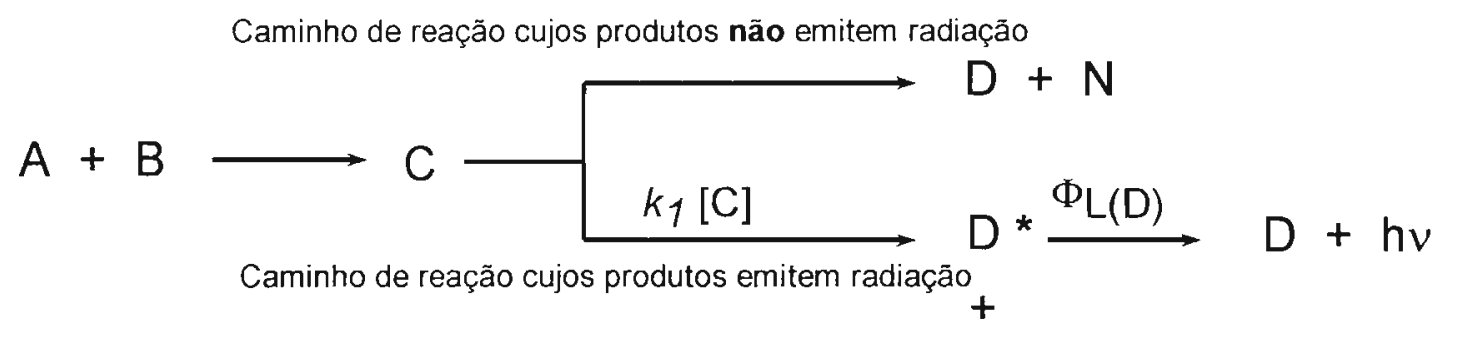

$$
\begin{aligned}
& \text { E } \\
& \text { Etapa de transferência de energia } \\
& E^{*}+D \stackrel{\Phi L(E)}{\longrightarrow} E+h v
\end{aligned}
$$
$A, B$ E $\quad$ : reagentes,
C : intermediário-chave produzido,
$\mathrm{D}, \mathbf{N} \quad$ : produtos,
$D^{*}, E^{*} \quad$ : moléculas no estado excitado,
$\Phi_{L(D),} \Phi_{L(E)}$ : $\quad$ rendimentos quânticos de luminescência das espécies $D$ e $E$.

Esquema 1 - Esquema simplificado para produção e ernissão de luminescência pela reação entre $A$ e $B^{18}$. 


$$
\Phi_{\mathrm{QL}}=\Phi_{\mathrm{R}} \Phi_{\mathrm{E}} \Phi_{\mathrm{L}}
$$

$\Phi_{\mathrm{R}}$ : refere-se ao rendimento quântico quimico ou à fração de moléculas que reagem e formam o intermediário adequado;

$\Phi_{\mathrm{E}}$ : representa a eficiência de produção das espécies no estado excitado, isto é, a probabilidade da decomposição dos intermediários-chave produzir moléculas no estado eletronicamente excitado, e,

$\Phi_{\mathrm{L}}$ : representa a eficiência quântica de fluorescência do emissor.

Nos sistemas envolvendo etapa de transferência de energia para um fluoróforo $(E)$, um termo extra $\Phi_{T E}$, que representa a eficiência desta etapa de transferência de energia, deve ser incluído na equação $4(18)$.

A intensidade de quimiluminescência gerada ( $\mathrm{I}_{\mathrm{QL}}$ ) em cada sistema é função do tempo, e depende do rendimento quântico quimiluminescente ( $\Phi_{Q L}$ ) que corresponde ao número de fótons emitidos por moléculas reagentes de $A$ ou $B$, $e$ também do número de moléculas reagentes por unidade de tempo (equação 5$)^{8,18}$ :

$$
\mathrm{I}_{\mathrm{QL}}=k_{1}[\mathrm{C}] \Phi_{\mathrm{QL}}=k_{1}[\mathrm{C}] \frac{\text { número de fótons emitidos }}{\text { número de moléculas reagente }}
$$

onde $k_{1}[\mathrm{C}]$ refere-se a velocidade de decomposição do intermediário-chave. 
$\Phi_{Q L}$ pode ser medido em função do tempo e geralmente a intensidade máxima é proporcional à concentração do analito. Alternativamente, $\Phi_{Q} L$ pode ser obtido integrando-se a área sob a curva intensidade de emissão versus tempo, em um intervalo de tempo determinado 18.

Em análises empregando-se reações $Q L$, qualquer um dos reagentes $(A, B$ ou $E$, no esquema 1, página 3) pode ser quantitativamente determinado relacionando-se a intensidade de radiação emitida $\left({ }_{Q}{ }_{Q}\right)$ ou medindo-se a variação da velocidade da reação QL com a concentração do componente que está sendo analisado. A quantificação de catalisadores, oxidantes ou redutores da reação também é possivel 18 .

Algumas características do espectro de luminescência como: comprimento de onda da radiação emitida, forma da banda ou tempo de decaimento da luminescência podem ser usadas tanto na análise qualitativa quanto na quantitativa. Essas caracteristicas são freqüentemente dependentes da solvatação, complexação e outros fatores ${ }^{8}$

Ao contrário de outras técnicas envolvendo detecção de emissão de radiação, as medições de quimiluminescência não são sujeitas a interferências de luz espalhada ou de sinal proveniente da fonte de excitação ${ }^{18}$.

Apesar das inúmeras vantagens da utilização de reações $Q L$ em determinações analiticas como: simplicidade da instrumentação necessária, sensibilidade e velocidade de análise, o uso limitado desta técnica provavelmente deve-se à combinação dos seguintes fatores ${ }^{18}$ : 
- Existência de poucas reações QL. Cinco reagentes têm sido principalmente usados em determinaçōes analíticas. Podemos citar os diferentes derivados do luminol, lofina, lucigenina e os derivados de oxalatos de diarila;

- O uso destes reagentes apresenta algumas restrições como: baixa solubilidade em água do reagente ou do intermediário formado, limitações de pH ótimo do meio para a reação, ausência de procedimentos para algumas espécies orgânicas e falta de especificidade da reação;

- Em metodologias que utilizam sistemas de duas ou mais reações combinadas, geralmente as condições da reação que gera o analito não são adequadas àquelas utilizadas na detecção com reação QL.

Além destes fatores, deve-se observar que o objetivo, de grande parte dos trabalhos, tem sido aumentar a eficiência das reações, uma vez que o rendimento quântico de muitos sistemas conhecidos é muito baixo: $\Phi_{Q L} \leq 0,01$. Processos de desativação não-luminescentes e outros processos de supressão da luminescência, juntamente com limitações químicas (baixos rendimentos na produção de espécies no estado excitado) fazem com que a eficiência de algumas reações QL seja baixa 18

Assim, recentemente, pode ser observado que as pesquisas em quimiluminescência na Química Analítica têm caminhado em duas principais direções: 1) a pesquisa para descoberta de novas reações QL e a investigação da aplicabilidade para amostras reais, e 2) o desenvolvimento de sistemas de detecção da quimiluminescência conjugados a técnicas de separação. 
A pesquisa por novas reações QL é um campo muito importante, pois desta forma são abertos novos horizontes para a técnica. Entretanto, alguns trabalhos se limitam apenas ao desenvolvimento de análises químicas. A realização de estudos mais detalhados do mecanismo das reações QL recém-descobertas poderia colaborar na melhoria ou no desenvolvimento de métodos analíticos, e explicar o efeito de interferentes ${ }^{17}$.

\section{I.2-Aparelhagem instrumental}

Inicialmente, a quimiluminescência era registrada fazendo-se a revelação de um filme fotográfico. No início de 1970, a quimiluminescência começou a ser estudada utilizando-se fluorimetros modificados 21 , em que havia perda da sensibilidade. Com o aparecimento de luminômetros para ensaios no modo estático, projetados sem os monocromadores e conjugados a fotomultiplicadoras (FMT) fotoelétricas altamente sensíveis, rendimentos quânticos da ordem de 10-15 passaram a ser detectados, dando um novo impulso aos estudos de reações QL 18.

Os equipamentos empregados constituem de: um sistema para mistura dos reagentes, um detector de radiação, quando necessário, um filtro para isolar um comprimento de onda da radiação emitida e um sistema para aquisição de dados (registrador ou computador "on-line") 8 . 
Por apresentar sensibilidade elevada associada ao uso de uma instrumentação simples, a análise por medição da quimiluminescência despertou interesse. Na prática, em ensaios por quimiluminescência, a concentração mínima detectável de um analito é mais fortememente dependente da intensidade de luz que chega ao detector do que a capacidade dos mesmos em medir a intensidade de radiação emitida, e da pureza dos reagentes ${ }^{8}$.

O rápido decaimento da emissão quimiluminescente requer sistemas efetivos para mistura dos reagentes. O crescimento em qualidade e quantidade de métodos analíticos aconteceu logo após a introdução da análise por injeção em fluxo (FIA $)^{22}$ na área de quimiluminescência e do desenvolvimento de células para fluxo especialmente desenhadas 23 . Desde então, muitos estudos têm sido realizados utilizando-se sistemas em fluxo, para facilitar o manuseio dos reagentes, para a obtenção de resultados reprodutiveis e sensibilidade elevada. Entretanto, em sistemas em fluxo somente uma parte da curva de intensidade de emissão versus tempo é medida e por isso muitas informações sobre a cinética da reação não são obtidas (figura 1). A medição é também afetada por outros parâmetros como: vazão do transportador (carreador) e dos reagentes, volume entre os pontos de mistura e a detecção, e construção da célula de fluxo18.

Como a quimiluminescência é dependente da velocidade de reação, medições da IQL também podem ser usadas para quantificar qualquer espécie cuja concentração determina a velocidade de reação ${ }^{15}$. 


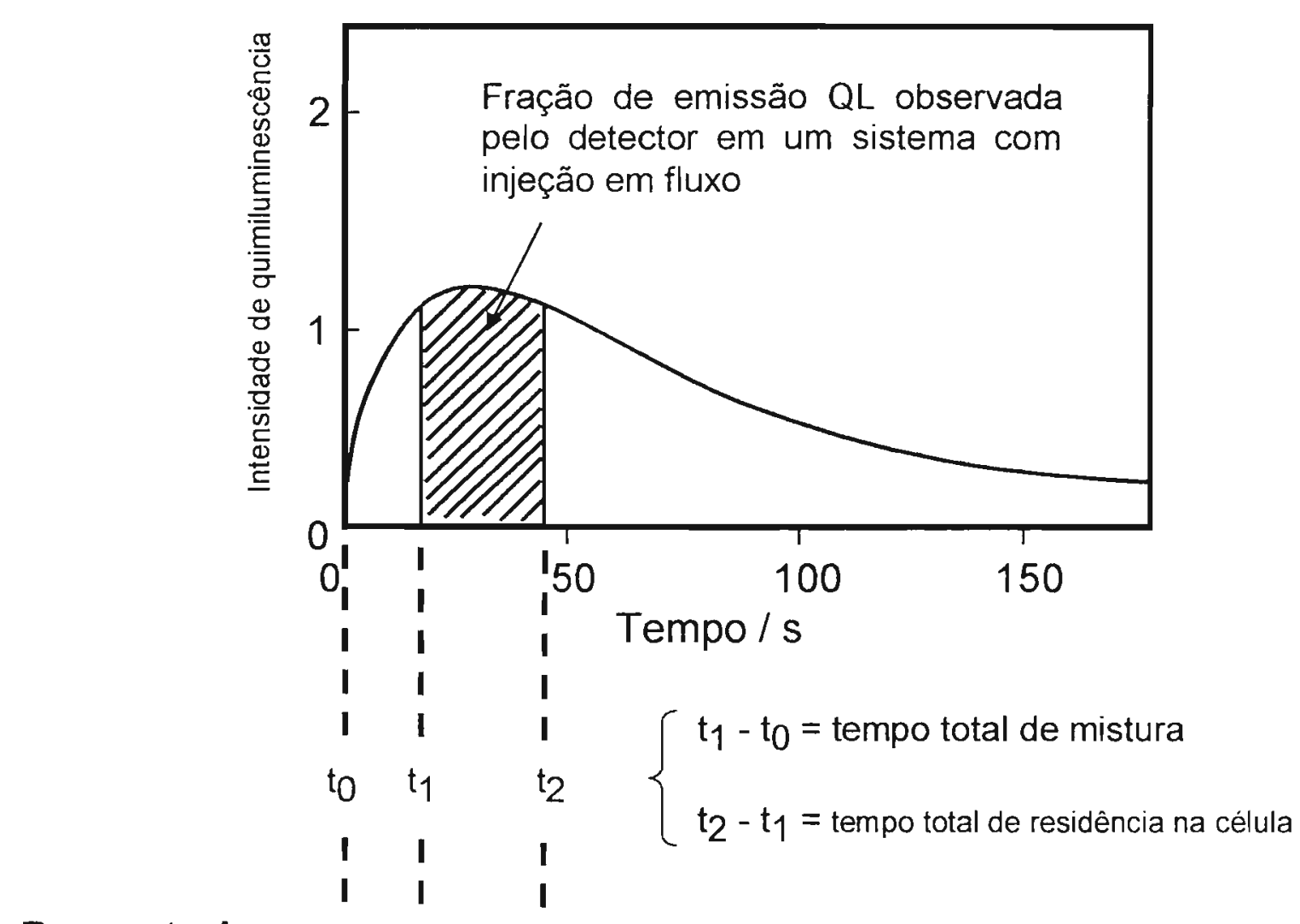

Reagente A

Reagente $B$ misturador

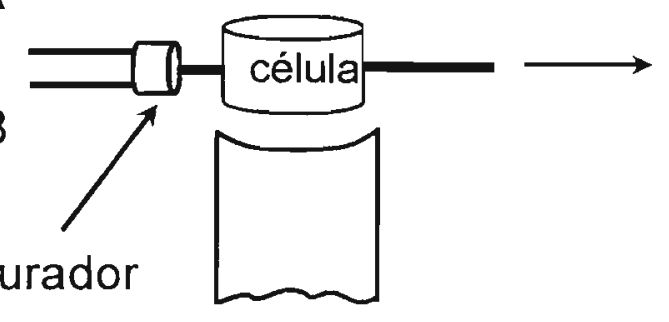

detector

Figura 1 - Esquema da curva de intensidade de quimiluminescência versus tempo e a fração de emissão detectada, em um sistema em fluxo. 


\section{I.3 - Breve histórico das reações QL em fase aquosa}

Vários artigos de revisão relatam aspectos marcantes no desenvolvimento da QL ao longo dos anos ${ }^{1-18,24}$. É dificil atribuir a uma única pessoa a descoberta ou o relato da quimiluminescência, entretanto podem-se identificar algumas observações e experimentos que levaram à definição da quimiluminescência.

Aristóteles (384-322 a.C.) parece ser um dos primeiros a relatar a "luz fria"24. Em 1663 Boyle observou a importância da presença de oxigênio na emissão de luminescência da reação com fósforo. O trabalho de Boyle, "abriu novos horizontes para observação e entendimento das reações QL e BL"25. Em 1877, Radziszewski, realizou o estudo da reação $Q L$ de auto-oxidação da lofina (2,4,5-trifenilimidazol), em meio fortemente alcalino 26 . Em 1888, Wiedemann 27 foi o primeiro a definir a quimiluminescência como a emissão resultante de um processo químico. A primeira publicação em BL foi feita por Dubois 28 que introduziu o termo luciferina-luciferase (estruturas dos reagentes na figura 2).

As aplicações analiticas das reações QL tiveram um aumento significativo a partir do século 20 . Em 1905, $\operatorname{Trautz}^{29}$ publicou a primeira revisão ressaltando a importância do oxigênio nas reações QL. Em 1922, Kautski30 estudou a emissão de radiação da reação de siloxilanos e agentes oxidantes, e em 1927, Mallet atribuiu a excitação de fluoróforos como eosina, fluoresceina, antraceno e quinino à transferência de energia da reação de peróxido de hidrogênio com hipoclorito ${ }^{31}$. Um ano mais tarde, Albrecht estudou a reação $Q L$ do luminol32, que ainda hoje é o 
<smiles>Cn1c(-c2ccccc2)nc(-c2ccccc2)c1-c1ccccc1</smiles><smiles>C=C1NC(=O)c2cc(N)ccc21</smiles>
isoluminol $^{\mathrm{O}}$<smiles>C[n+]1c2ccccc2c(-c2c3ccccc3[n+](C)c3ccccc23)c2ccccc21</smiles><smiles>Nc1cccc2c(=O)[nH][nH]c(=O)c12</smiles>

luminol lucigenina<smiles>O=C(Oc1c(Cl)cc(Cl)cc1Cl)C(=O)Oc1c(Cl)cc(Cl)cc1Cl</smiles>
oxalato de bis(2,4,6-triclorofenila)<smiles>Oc1cccc(O)c1O</smiles><smiles>O=C(O)C1CSC(c2nc3ccc(O)cc3s2)=N1</smiles>
luciferina pirogalol<smiles>[X]c1cccc2c(C(=O)Oc3ccccc3)c3ccccc3[n+](C)c12</smiles>

éster de acridínio

Figura 2 - Substratos mais comumente estudados em reações QL: lofina, luminol, lucigenina, isoluminol, oxalato de bis(2,4,6-triclorofenila), pirogalol, luciferina e éster de acridínio. 
reagente predominante em pesquisas na área.

Outro composto, também estudado extensivamente é a lucigenina, que foi primeiramente relatado por Gley e Petsch, em 1935(33).

As pesquisas iniciais em quimiluminescência e bioluminescência estavam focalizadas principalmente na observação da reação e na investigação do mecanismo. Aplicações analíticas dos fenômenos apareceram na literatura somente no início de 1960.

Chandross estudou a transferência de energia de fluoróforos a partir da reação de peróxido de hidrogênio com oxalatos de diarila34, que logo foram substituídos por ésteres oxálicos de fenóis substituídos em trabalho publicado por Rauhut ${ }^{35}$. A observação foi utilizada com sucesso por Curtis e Seitz, que usaram a reação de peróxido de hidrogênio com DNPO e TCPO para determinar fluoróforos, após separação por cromatografia por camada delgada36. A metodologia foi posteriormente refinada por Kobayashi e Imai 37 , cujo trabalho propôs a detecção de uma grande variedade de moléculas após separação por cromatografia líquida de alta eficiência. Foi verificado que a natureza do fluoróforo influenciou na detecção da quimiluminescência por sistemas peróxi-oxalato.

1.4 - Consideracões sobre alqumas reacões $Q L$ mais estudadas e suas aplicações analíticas 
A oxidação do luminol (5-amino-2,3-diidroftalazina-1,4-diona) por oxigênio ou peróxido de hidrogênio em meio alcalino foi primeiramente estudada em $1928^{(32)}$ e ainda hoje as suas propriedades termodinâmicas e cinéticas continuam sendo intensamente estudadas (esquema 2).<smiles>C=C1N[C@@H](NO)NC(=O)c2c(N)cccc21</smiles>

O

luminol

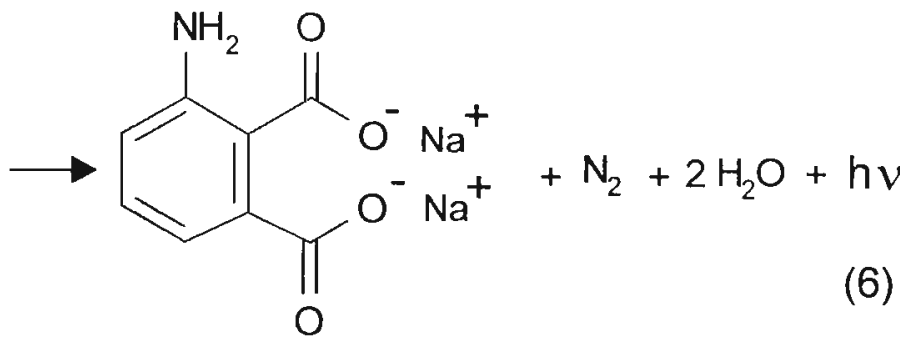

3-aminoftalato

Esquema 2 - Esquema geral da oxidação de luminol (5-amino-2,3-diidroftalazina1,4-diona) por oxigênio ou peróxido de hidrogênio, em meio básico, com geração de quimiluminescência. O luminol é convertido em um ânion duplamente carregado e subsequentemente é oxidado ao estado singlete excitado, que emite radiação $(\lambda=425 \mathrm{~nm})$ ao decompor-se formando o íon 3-aminoftalato 32 
Vários pesquisadores apresentaram propostas mecanisticas $1,9,39,40$ e os possíveis intermediários da reação do luminol com alguns agentes oxidantes como $\mathrm{O}_{2}$ e $\mathrm{H}_{2} \mathrm{O}_{2}$. Algumas descobertas podem ser destacadas, apesar da complexidade da reação:

- a emissão de luminescência está ligada à formação do ion 3-aminoftalato no estado excitado e,

- alguns intermediários propostos para a reação são: diazoquinona, endoperóxido, diânion do ácido ftálico, $\alpha$-hidróxi-hidroperóxido e radical do luminol (estruturas na figura 3$)^{9}$.

As aplicações analíticas do luminol podem ser classificadas em diretas ou indiretas. Nas aplicações diretas, o analito é o "catalisador" ou modificador da reação do luminol. Como exemplos de aplicações diretas destacam-se as determinações de mais de 30 metais de transição ou de supressores de emissão luminescente (compostos orgânicos), com limites de detecção em torno de 10-11 $\mathrm{mol} \mathrm{L}^{-1}$; como aplicação indireta destaca-se a determinação de peróxido de hidrogênio produzido pela oxidação da espécie de interesse por enzimas. Com estas técnicas têm sido analisados substratos de enzimas como amino-ácidos, metanol, açúcares e DNA41.

A detecção da intensidade de quimiluminescência vem sendo aplicada em conjunto com várias técnicas consagradas como: FIA, cromatografia líquida de alta eficiência, cromatografia líquida e a gás, eletroforese, biossensores, entre outras. $\mathrm{Na}$ maioria dos trabalhos publicados, as matrizes de análise são amostras de fluídos biológicos, como: tecidos humanos ou de animais, além de excreções (urina) e 
<smiles>Nc1cccc2c1C(=O)N=NC2=O</smiles><smiles>Nc1cccc2c1C1([O-])N=NC2([O-])OO1</smiles>

endo-peróxido<smiles>Nc1cccc(C(=O)O)c1C(=O)O</smiles>

diânion do ácido ftálico<smiles>Cn1[nH]c(=O)c2c(N)cccc2c1=O</smiles>

radical do luminol<smiles>Nc1cccc2c1C(=O)N=NC2(O)OO</smiles>

$\alpha$-hidróxi-hidroperóxido

Figura 3 - Estruturas de alguns intermediários propostos para a reação QL do luminol 9 . 
sangue (plasma e soro sanguíneo), com ênfase para determinação de glicose, colesterol e cortisona 41 .

A maioria das aplicações da reação QL que utiliza luminol está relacionada à determinação dos mais diversos íons metálicos de transição, com limites de detecção em niveis de $\mathrm{ppb}^{1,12,15,41}$. Estes íons metálicos têm sido comumente denominados de "catalisadores", pois pequenas concentrações são capazes de promover efeito significativo na velocidade da reação.

Entretanto, ainda há controvérsias sobre o real papel destes ions metálicos de transição no mecanismo da reação 42 . Xiao e colaboradores 43 propuseram que os íns metálicos atuariam na decomposição catalitica do peróxido de hidrogênio, produzindo o radical $\mathrm{OH} \bullet$, e também que o ion metálico atuaria na formação e decomposição do intermediário $\alpha$-hidroxi-hidroperóxido (ver estruturas dos intermediários propostos na figura 3). Merényi e colaboradores 40 realizaram estudos focalizados na elucidação mecanistica, e apontaram algumas discordâncias às propostas de Xiao e colaboradores.

Apesar da indefinição sobre os detalhes do mecanismo, a reação QL do luminol apresenta grande potencialidade para aplicações analíticas, o que pode ser verificado pelo grande número de trabalhos publicados nos últimos anos 41

Lucigenina (dinitrato de bis-(N-metilacridinio)) é um dos reagentes $\mathrm{QL}$ mais eficientes, e apresenta uma intensa emissão $(\lambda=525 \mathrm{~nm})$ quando oxidado em meio alcalino 9,33 . Outros derivados da lucigenina também apresentam emissão quando reagem com peróxido de hidrogênio em solução aquosa alcalina. No mecanismo proposto por Rauhult e colaboradores 44,45 (esquema 3 ), o principal produto da 
reação é a $\mathrm{N}$-metilacridona. Como o produto da reação é insolúvel em água, a adição de surfactante, como dodecil sulfato de sódio (SDS), tem sido utilizada para evitar a precipitação ${ }^{18}$. Esta reação foi usada para a determinação de vários íons metálicos, incluindo $\mathrm{Pb}(\mathrm{II})$ and $\mathrm{Bi}(\mathrm{III})$ (que não atuam na reação do luminol), oxidantes (peróxido de hidrogênio) e redutores, como ácido ascórbico 18.<smiles>C[n+]1c2ccccc2c(-c2c3ccccc3[n+](C)c3ccccc23)c2ccccc21</smiles>

lucigenina<smiles>CCOC12c3ccccc3N(C)c3ccccc3C1(Oc1ccccc1)c1ccccc1N2C</smiles>

metilacridona<smiles>Cn1c2ccccc2c(=O)c2ccccc21</smiles>

(7)

Esquema 3 - Reação de lucigenina com peróxido de hidrogênio, em meio básico18 
Uma das reações QL mais eficientes, conhecida como reação quimiluminescente de peróxi-oxalatos (PO-QL) foi primeiramente estudada por Chandross $^{34}$. Consiste na reação de oxalatos de diarila substituídos com peróxido de hidrogênio, na presença de hidrocarbonetos aromáticos fluorescentes (fluoróforos ou ativadores) (esquema 4).

Como outras reações QL, o esquema global para as reações PO-QL pode ser representado por três etapas básicas:

- A primeira etapa envolve a produção de um intermediário-chave contendo a energia necessária para a excitação;

- A segunda etapa envolve a conversão desta energia química em energia de excitação eletrônica e

- Na etapa final a molécula excitada retorna ao estado fundamental, com emissão de luz.

Os oxalatos mais estudados são TCPO (oxalato de bis-(2,4,6-triclorofenila)), METQ (sulfonato de 4,4'-[oxalilbis-[(trifluorometilsulfonil)iminoetileno]bis(4metilmorfoliniumtrifluorometano), 2-NPO (oxalato de bis-(2-nitrofenila)) e DNPO (oxalato de bis-(2,4-dinitrofenila)) (estruturas na figura 4).

Oxalatos que possuem substituintes eletronegativos reagem com peróxido de hidrogênio produzindo rendimentos quânticos maiores ( $\Phi_{Q} \mathrm{~L}$ ). Porém, a escolha do oxalato depende da aplicação da reação e do resultado desejado. Por exemplo, DNPO apresenta cinética de reação mais rápida e intensidade de emissão QL mais elevada que com TCPO. Entretanto, DNPO é menos estável em solução e a reação apresenta maior sinal de fundo que com TCPO 46,47 . 


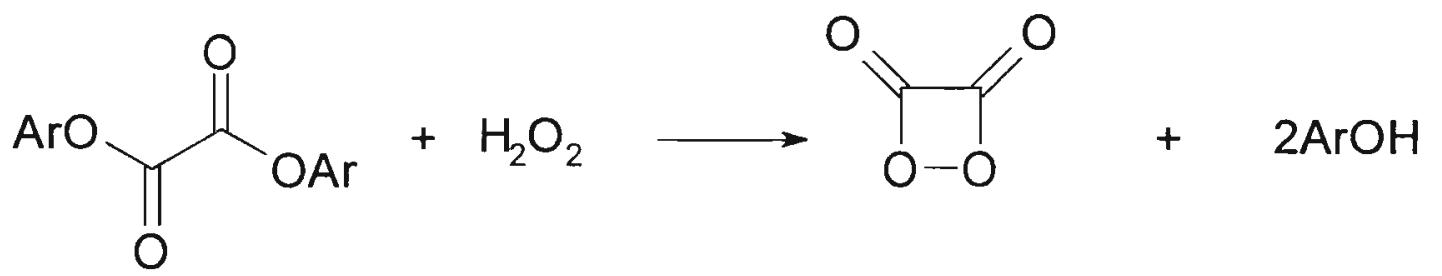

(8)

oxalatos

1,2-dioxetanodiona<smiles>O=C1OOC1=O</smiles>

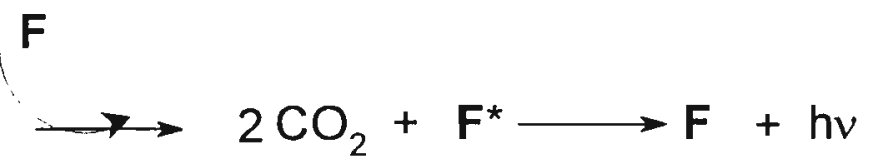

$\mathrm{F}=$ molécula fluorescente (fluoróforo ou ativador)

Esquema 4 - Esquema simplificado da reação PO-QL 34 


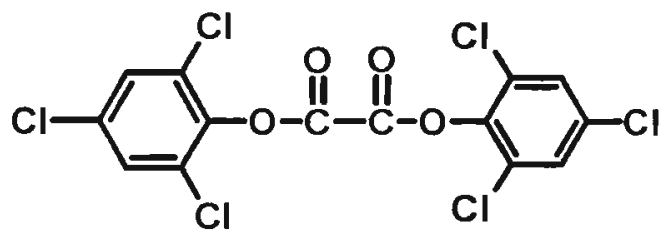

TCPO

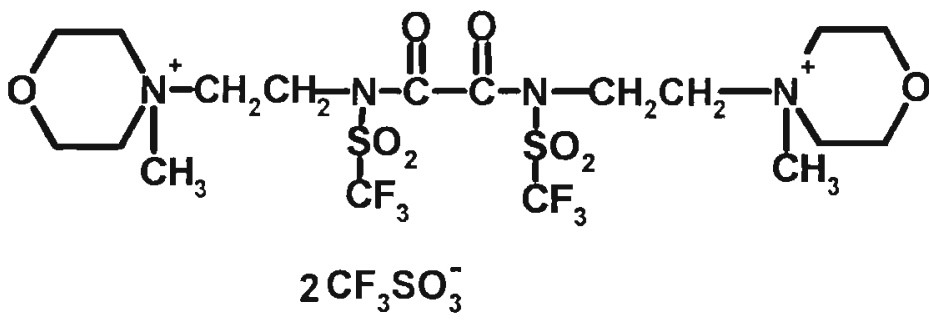

METQ

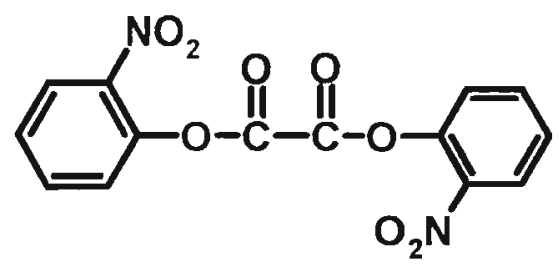

2-NPO<smiles>O=C(Oc1ccc([N+](=O)[O-])cc1[N+](=O)[O-])C(=O)Oc1ccc([N+](=O)[O-])cc1[N+](=O)[O-]</smiles>

DNPO

Figura 4 - Estruturas de alguns oxalatos mais comumente utilizados em reações PO-QL. 
Rauhut e colaboradores 35 foram os primeiros autores a propor a molécula 1,2-dioxetanodiona (esquema 4) como o intermediário-chave da reação. Apesar dos vários estudos mecanísticos que reforçam a idéia da formação deste intermediário, ainda permanece alguma dúvida, pois o suposto intermediário se decompõe formando espécies não identificadas.

Estudos do mecanismo de formação do estado excitado na fase líquida foram inicialmente realizados por Schuster 48 , que propôs uma etapa de excitação química conhecida por CIEEL, ou "chemically initiated electron exchange luminescence" (esquema 5). Em resumo, corresponde à transferência de um elétron da molécula do ativador, (neste trabalho denominado de fluoróforo) para uma molécula orgânica de alto conteúdo energético (peróxido). O rearranjo ou perda de um fragmento neutro, em uma etapa subseqüente, transforma o peróxido reduzido numa espécie altamente redutora (ânion-radical). A aniquilação de carga gera $\bigcirc$ ativador num estado eletronicamente excitado 49

Enquanto a maioria das reações QL envolve a emissão a partir do próprio intermediário-chave, como na reação do luminol ou lucigenina, em sistemas PO-QL a energia química é transferida a uma variedade de moléculas fluorescentes. Este fato permite que a reação PO-QL seja utilizada na determinação de uma grande variedade de fluoróforos em niveis de fmol46,47,50-52 e também de peróxido de hidrogênio, que pode ser inicialmente adicionado, ou pode ser gerado em uma reação paralela, por exemplo, através da ação de enzimas na presença de um substrato apropriado 46,47 . 


\section{Ativador + peróxido $\longrightarrow\left[\right.$ Ativador $^{+\bullet}$ peróxido $\left.^{-\bullet}\right]$}

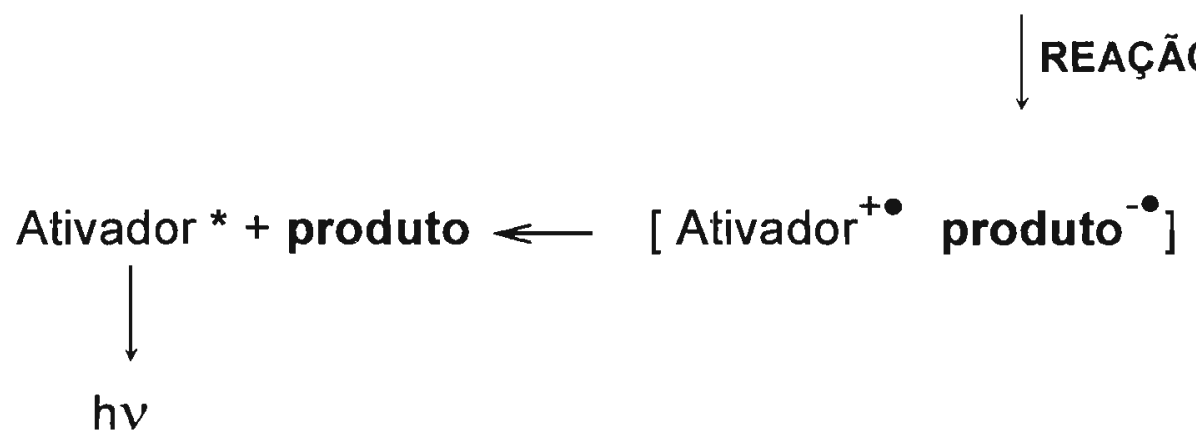

Esquema 5 - Esquema simplificado do mecanismo CIELL "chemically initiated electron exchange luminescence" 48,49

Esta forma de detecção de fluoróforos apresenta duas vantagens principais sobre a espectrofluorimetria clássica: 1) aumento da seletividade resultante do fato de que nem todos os fluoróforos têm a mesma eficiência como aceptor dé-energia e 2) eliminação do espalhamento proveniente da fonte de excitação quando comparada com a detecção fluorescente.

No trabalho realizado por Sigvardson e Birks ${ }^{50}$, no qual os autores utilizaram a reação PO-QL para a determinação de vários poliidrocarbonetos aromáticos (PHA) funcionalizados, os analitos com menores limites de deteç̧ão foram os amino-PHA. Os autores observaram que os compostos com menores potenciais de oxidação foram detectados com maior sensibilidade, o que é um indicativo da possibilidade de uma etapa de transferência de energia no mecanismo, como 
proposto inicialmente por McCapra51. Stevani e colaboradores 52 também observaram correlação linear entre o rendimento quântico e o potencial de oxidação $\left(E_{p / 2}=\right.$ potencial de meia onda em estudos voltamétricos $)$ de fluoróforos mais comumente utilizados como rubreno, perileno, 9,10-difenilantraceno e 2,5-difeniloxazole. Entretanto, os rendimentos quânticos obtidos para 9,10-dimetoxiantraceno e 9,10-dicianoantraceno não puderam ser explicados e demonstraram que alguns detalhes da hipótese do mecanismo CIELL ainda estão para ser elucidados.

A intensidade de emissão de sistemas PO-QL também é afetada pelas condições experimentais, incluindo natureza do solvente, teor de água, concentrações dos reagentes, acidez do meio e natureza do catalisador. Em meio composto por uma mistura de solvente orgânico e água, um dos parâmetros mais significativos parece ser a acidez do meio $46,47,53,54$.

Quando imidazol foi utilizado como catalisador da reação PO-QL53, um aumento marcante na intensidade de radiação emitida foi observado. Baseados em estudos cinéticos, alguns pesquisadores ${ }^{54-57}$ propuseram etapas do mecanismo da reação PO-QL catalisada por imidazol. As contribuições relativas das reações hidrolíticas e dos diferentes caminhos de reação, dependentes da concentração relativa dos reagentes, têm sido discutidas por estes autores, e 1-aroxalilimidazol e 1,1'-oxalildiimidazol (conhecido como ODI) (esquema 6) têm sido sugeridos como os principais intermediários da reação. O mecanismo proposto não é capaz de explicar todos os detalhes da reação catalisada por imidazol, mas propõe a elucidação de algumas etapas. 


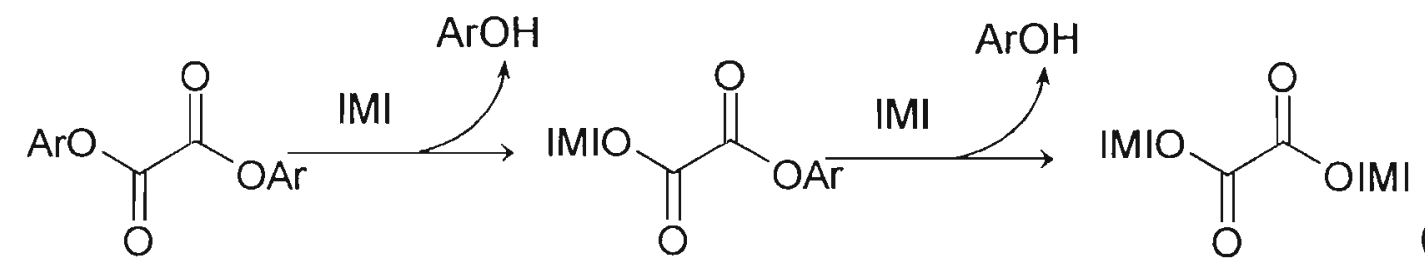

1-aroxalilimidazol

1,1'-oxalildiimidazol (ODI)
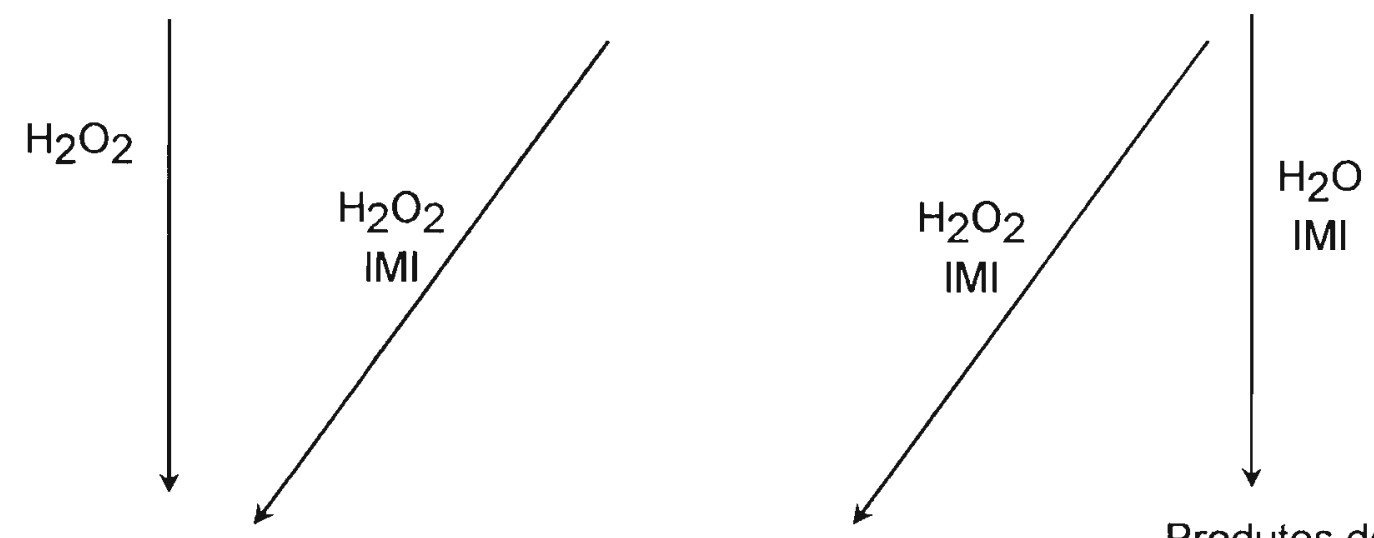

Produtos de hidrólise

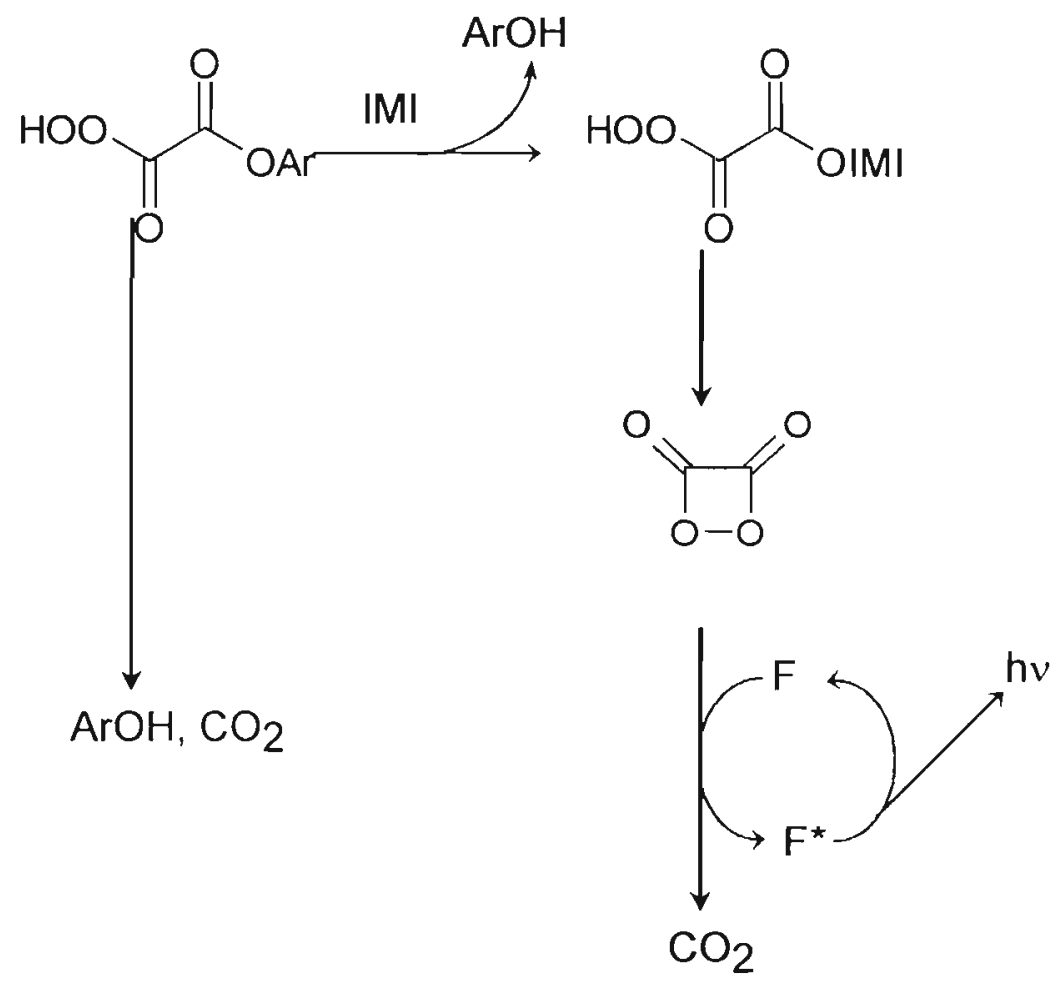

Esquema 6 - Esquema geral ${ }^{56}$ do mecanismo proposto para a reação PO-QL catalisada por imidazol (IMI) em que 1-aroxalilimidazol e 1,1'-oxalildiimidazol (ODI) são os possiveis intermediários da reação que leva à quimiluminescência. 


\section{II - Quimiluminescência de TCPO e 2-NPO}

em sistema micelar aquoso 


\section{$\underline{11.1-\text { Objetivos }}$}

Esta parte do trabalho descreve o estudo do efeito de micelas na reação QL de 2-NPO ou TCPO com hidroperóxido de t-butila (t-bOOH) ou peróxido de hidrogênio, na presença de fluoróforo. O efeito de diferentes tipos de surfactante (não-iônico, catiônico e aniônico) na reação QL foi investigado através do monitoramento da curva de intensidade de emissão versus tempo.

Inicialmente será feita uma introdução sobre aspectos relacionados à utilização de surfactantes em química analitica, a aplicação de sistemas micelares em pesquisas realizadas com reações quimiluminescentes, e especificamente, os aspectos relevantes nos estudos envolvendo sistemas peroxi-oxalato. Subseqüentemente, serão apresentados os resultados de estudos da influência de alguns sistemas micelares aquosos na quimiluminescência de TCPO e 2-NPO no presente trabalho. 


\section{$\underline{11.2 \text { - Alguns usos de surfactantes em química analítica }}$}

A utilização de surfactantes (tensoativos) em quimica analítica está relacionada à formação de ambientes organizados, conhecidos como ambientes micelares, que podem modificar determinadas propriedades reacionais, como: velocidade da reação, equilíbrio químico e em alguns casos a estereoquímica da reação58.

A aplicação de micelas em química analítica tem sido descrita em vários artigos de revisão de Mclntire59, Pelizzetti e Pramauro60, Quina e Hinze61 e Maniasso62.

Pode-se destacar que o emprego de ambientes micelares no desenvolvimento de métodos de análise visa principalmente:

1) a exploração das características do ambiente micelar no meio reacional para a melhoria da sensibilidade elou seletividade, principalmente quando se trata de reações catalisadas, e

2) a utilização de surfactantes em etapas de concentração e/ou separação de reagentes, em substituição às metodologias tradicionais (extração líquido-líquido ou troca iônica) 61 . 


\section{II.2.1 - Consideracōs gerais sobre surfactantes}

Um surfactante possui uma estrutura $R-X$, onde $R$ è uma cadeia de hidrocarboneto com 8-20 átomos (normalmente linear) e X é o grupo-cabeça polar (ou iônico). Dependendo de X, os surfactantes podem ser classificados como: nãoiônicos, catiônicos, aniônicos ou anfóteros 61 .

Um surfactante catiônico possui em geral, a fórmula $R_{n} X^{+} Y^{-}$, onde $R$ representa uma ou mais cadeias hidrofóbicas, $X$ é um elemento capaz de formar uma estrutura catiônica (N, P, S, As, Te, Sb ou Bi) e Y é o contra-ion63-64.

Dentre os surfactantes aniônicos mais frequentemente utilizados estāo os sais de ácidos carboxilicos (graxos) monopróticos ou polipróticos e ácidos sulfúrico, sulfônico ou fosfórico, contendo um hidrocarboneto saturado ou insaturado como substituinte65. Os surfactantes não-iônicos são derivados do polioxietileno e polioxipropileno de alquil fenóis, álcoois, ésteres de ácidos graxos, alquilaminas, amidas ou mercaptanas, ou mesmo polialcoóis, ésteres de carboidratos, amidas de álcoois graxos e óxidos de amidas graxas 66 .

Os surfactantes anfóteros possuem grupos aniônicos e catiônicos, e dependendo da sua estrutura e do pH da solução, podem estar presentes como espécie aniônica, catiônica ou neutra67.

Na Tabela 1 estão representados alguns exemplos de surfactantes, empregados neste trabalho. 
Tabela 1: Estruturas químicas de alguns surfactantes

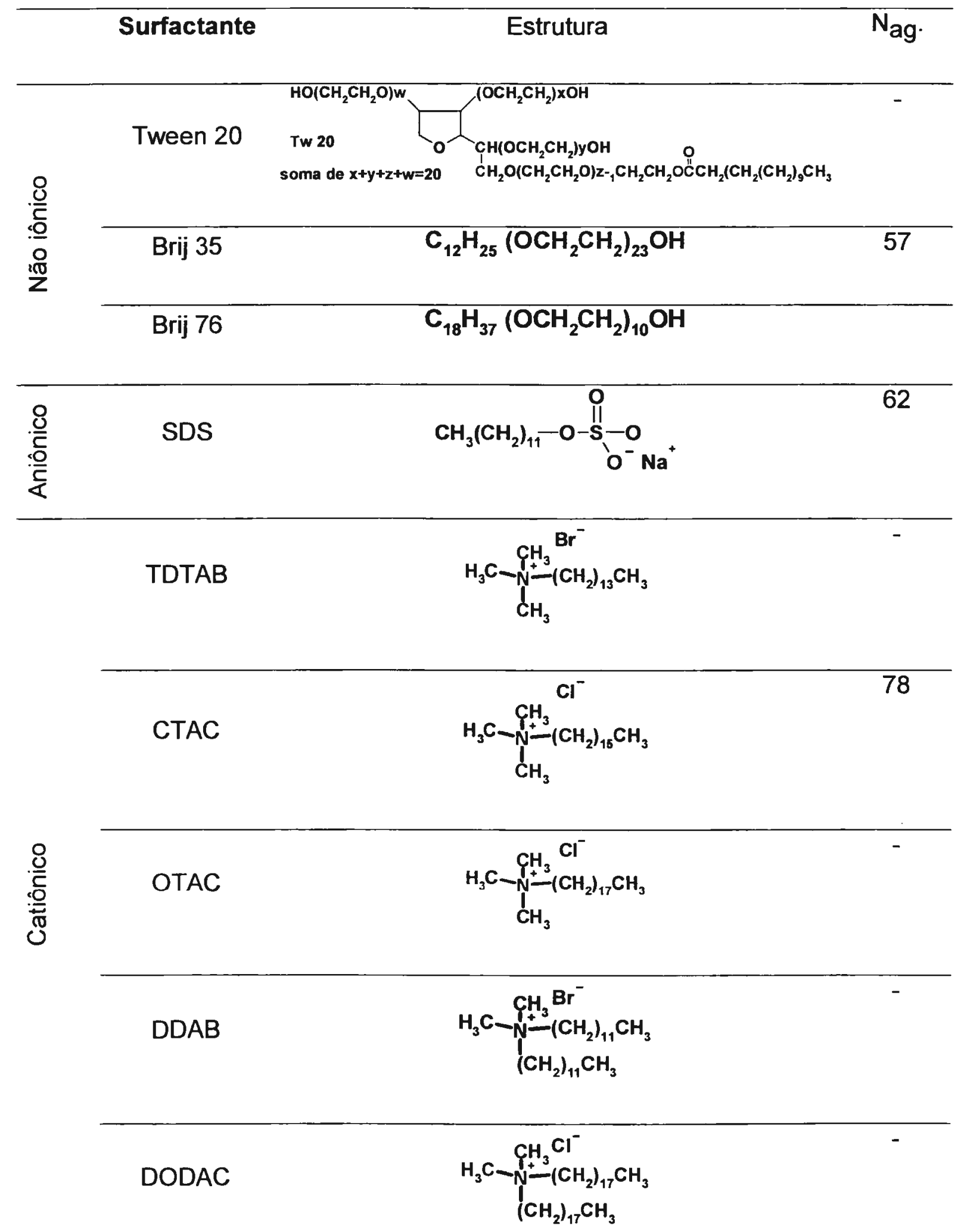

$\overline{N_{a g}}=$ número de agregação 
As micelas são agregados moleculares, que possuem ambas regiões estruturais: hidrofilica e hidrofóbica e arranjam-se espontânea e dinamicamente em solução aquosa, a partir de uma faixa de concentração chamada de concentração micelar crítica (c.m.c.). A c.m.c. é uma propriedade intrínsica e caracteristica do surfactante e depende da sua estrutura (comprimento e número das cadeias hidrocarbônicas, presença de ramificação, duplas ligações ou anéis aromáticos) e das condições experimentais (força iônica, contra-íons, temperatura, etc). Abaixo da c.m.c., o surfactante está predominantemente na forma de monômero; quando a concentração está abaixo, porém próxima a c.m.c., existe um equilibrio dinâmico entre monômeros e micelas. Em concentraçōes acima da c.m.c., as micelas possuem um diâmetro entre 3-6 mm (40-200 monômeros) ${ }^{68}$. Quando a c.m.c. é atingida, ocorre uma variação brusca em determinadas propriedades físico-químicas da solução como: tensão superficial, pressão osmótica, pressão de vapor, espalhamento de luz, ressonânica magnética nuclear, viscosidade, condutividade (surfactantes iônicos), entre outros 68 .

Os fatores que afetam a c.m.c. são68:

- natureza do grupo hidrofóbico. Para surfactantes iônicos, o aumento do número de átomos de carbono em cadeias hidrocarbônicas não ramificadas leva à diminuição do c.m.c.;

- natureza do grupo hidrofílico. Há uma pronunciada diferença entre c.m.c. de surfactantes iônicos e não iônicos; quanto maior a quantidade de gupos iônicos presentes na estrutura, maior o valor de c.m.c., pois haverá repulsão entre as cargas elétricas dificultando a formação da micela; 
- natureza do contra-ion. Surfactantes iônicos que tem o contra-íon trocado por outro de maior polarizabilidade ou valência provocam diminuição de c.m.c.. O tamanho do contra-ion também é um fator determinante; ocorre aumento do c.m.c. com aumento da hidratação;

- efeito de substâncias orgânicas. As micelas atuam como sítios de solubilização de substâncias lipofilicas. Por exemplo, álcoois de cadeia carbônica de tamanho moderado-longo são adsorvidos na parte externa da micela, o que diminui a energia necessária para formação de micelas, e também o valor de c.m.c., e

- efeito da temperatura. A diminuição no valor de c.m.c. de surfactantes iônicos é possivelmente devido à desidratação de monômeros. O aumento na temperatura causa ruptura da estrutura da água localizada em torno dos grupos hidrofóbicos que se opõem a micelização.

Cada micela é composta por um certo número de moléculas de surfactante, denominado por número de agregação $\left(\mathrm{N}_{\mathrm{ag}}\right)$, que rege o tamanho e a geometria do sisterna micelar 68

O termo interface indica o limite entre duas fases imisciveis, e o termo superfície indica uma interface onde uma fase é liquida e a outra é gasosa, (geralmente ar) ${ }^{62}$.

O termo micela normal é utilizado para se referir a agregados de tensoativos em meio aquoso. Na estrutura da micela normal, o grupo cabeça hidrofílico está direcionado para o contato com a solução aquosa formando uma superfície polar, enquanto que a cadeia linear (cauda) está em sentido inverso ao da água, formando 
um núcleo central não polar. Uma fração dos contra-íons permanece ligada aos grupos cabeça, de maneira a reduzir a força repulsiva entre estes grupos. (figura 5) $68-69$.

Com a introdução de um solvente apolar, ocorre formação de microemulsões óleo/água. Em um sistema onde a quantidade de solvente polar é muito grande, há o predominio de estruturas chamadas de microemulsōes água/óleo. Quando estas microemulsōes são muito pequenas, os agregados dos surfactantes são chamados de micelas reversas. Nas micelas reversas, a cabeça polar do surfactante está voltada para o centro da micela, formando um núcleo central hidrofílico 68 .

Na grande maioria de aplicações analíticas, o uso de micelas normais tem sido predominante sobre o uso de micelas reversas.

Uma propriedade importante das micelas é a sua capacidade em solubilizar espécies pouco solúveis, provocando uma significativa alteração na cinética da reação. A solubilização introduz duas novas situações que podem influenciar a velocidade reacional: alterar o local de distribuição do soluto (reagente) e da superficie 62,68

A solubilização dos reagentes na micela é normalmente atribuída ao balanço das interações eletrostáticas e da hidrofobicidade entre os reagentes e o sistema micelar. Para várias reações, aspectos eletrostáticos simples podem ser considerados para explicar os efeitos causados pelas micelas. Entretanto, deve-se salientar que nem todos os incrementos ou inibição de reações podem ser explicados simplesmente considerando-se os efeitos eletrostáticos. Em vários casos, o efeito da interação hidrofóbica é preponderante sobre o efeito eletrostático, sendo necessário levá-la em consideração62,68 


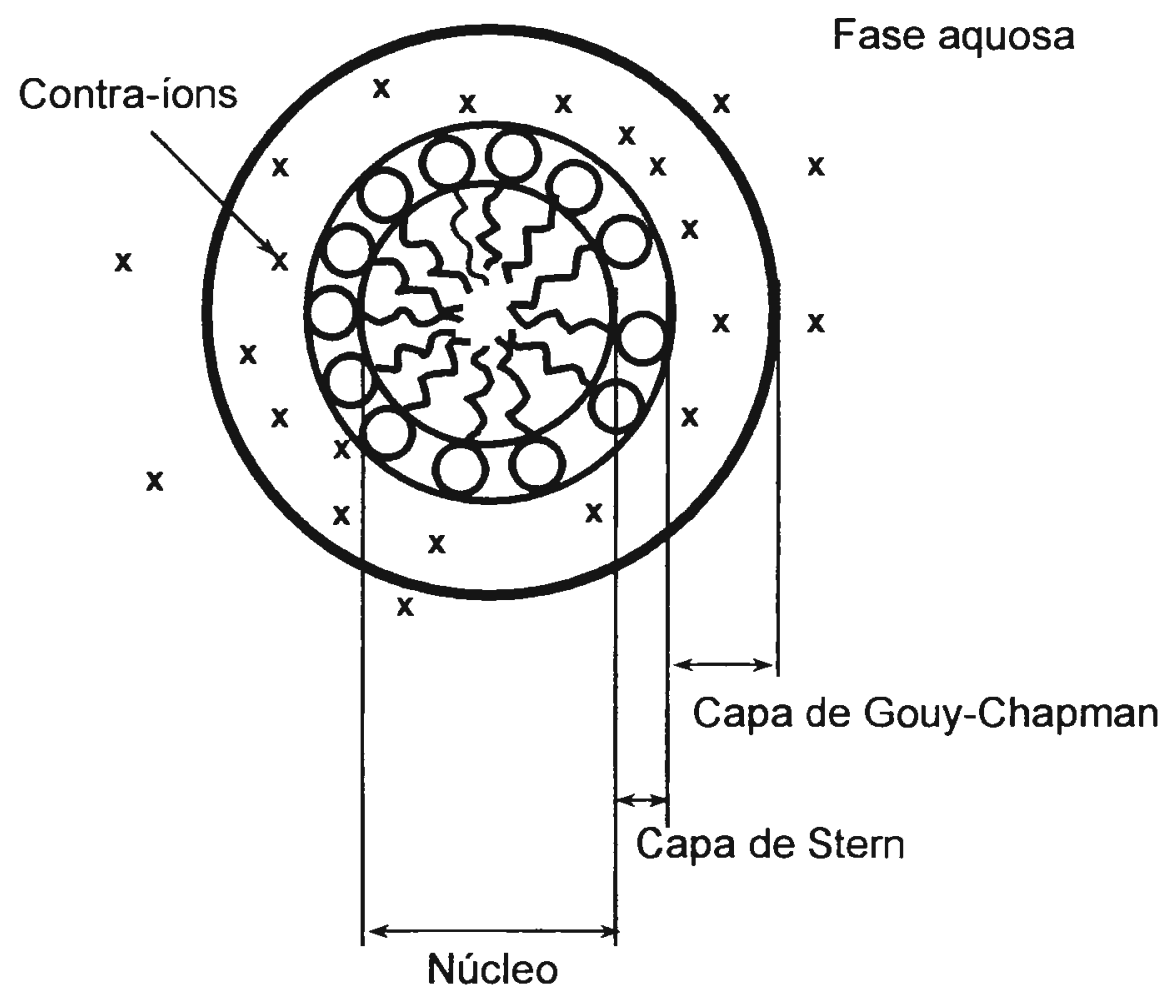

$(\mathrm{X}),(\mathrm{O})$ e $(\sim)$ indicam as localizações relativas dos contra-ions, do grupo cabeça, e das caudas (hidrocarbonetos), respectivamente.

Figura 5 - Representação bidimensional das regiões que formam uma micela iônica normal com estrutura esférica69. 
Em contraste com a micela normal, o efeito catalítico causado pelas micelas reversas é mais complexo que pelas micelas normais, e provavelmente envolve outros fatores além do efeito eletrostático e do hidrofóbico62,68.

Alguns fosfolipídeos sintéticos ou de ocorrência natural também podem fomar sistemas organizados. Os sistemas formados a partir de fosfolipídeos são tipicamente chamados de lipossomas e aqueles formados a partir de surfactantes sintéticos são chamados de vesículas (figura 6a). Dependendo do modo de preparação, da natureza do surfactante (carga e comprimento da cadeia carbônica) e das condições experimentais ( $\mathrm{pH}$, força iônica, contra-íon), um espectro variado de estruturas vesiculares pode ser formado. Vesículas, diferentemente das micelas, uma vez formadas, não são destruidas pela diluição. Adicionalmente, comparadas com as micelas, a região hidrocarbônica das vesículas é mais ordenada. Abaixo da sua temperatura de transição de fase, as vesículas são mais estáticas (menos fluidas e mais rígidas) comparadas com as micelas em fase aquosa. Exemplos de vesículas são DDAB (brometo de didodecildimetilamônio) e DODAC (cloreto de dioctadecildimetilamônio) ${ }^{18}$ (vide tabela 1, página 29).

Ciclodextrinas são moléculas de carboidrato macrocíclicas produzidas por degradação bacteriológica do amido. Elas consistem em arranjos de 6,7 ou 8 monômeros de glucose e são denominadas por $\alpha-$-, $\beta$ - ou $\gamma-$, dependendo do número de monômeros presentes. A junção dos monômeros de glucose através de ligações glicosídicas 1,4 confere às ciclodextrinas uma estrutura cônica molecular rígida, com um interior oco hidrofóbico (figura $6 b$ ). O tamanho do interior da ciclodextrina é dependente do número de monômeros de glucose ${ }^{18}$. 


\section{a)}
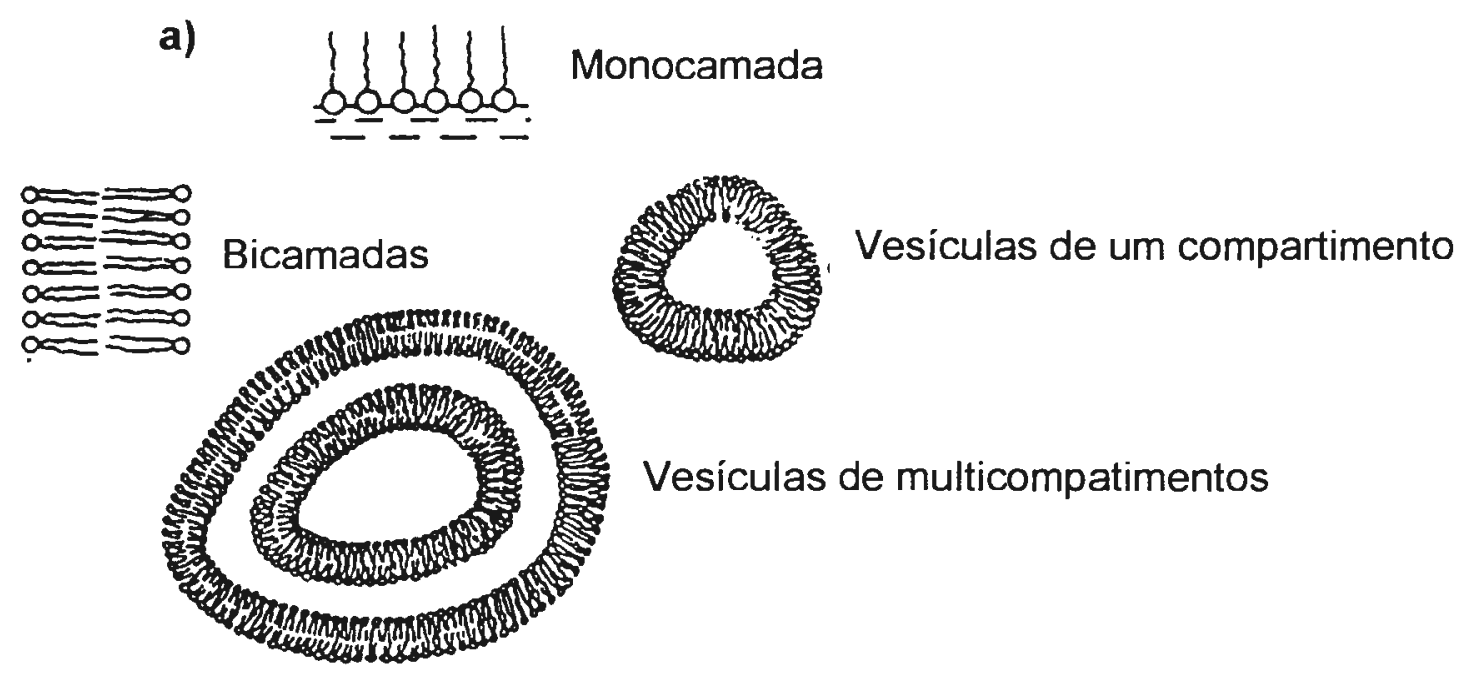

b)

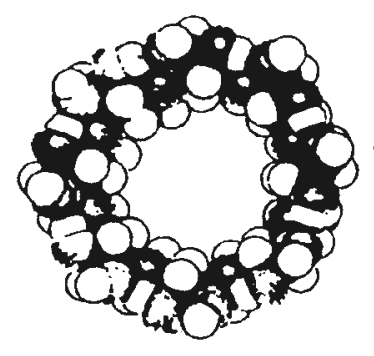

$\alpha$-ciclodextrina

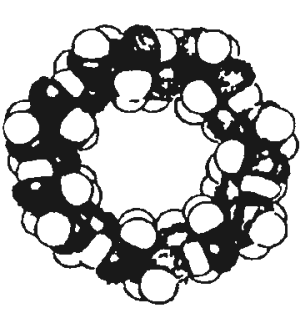

$\beta$-ciclodextrina

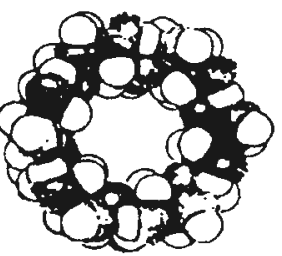

$\gamma$-ciclodextrina

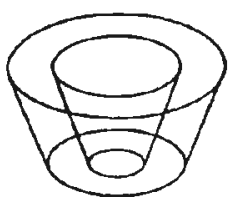

Figura 6 - Representação da estrutura de a) lamelas e vesículas (topo) e b) modelo de ciclodextrinas (abaixo), diagrama esquemático de duas unidades de glucopiranose em uma molécula de ciclodextrina, ilustrando os detalhes da ligação $\alpha-(1,4)$ glicosídica, e o sistema de numeração e ilustração de uma cavidade cônica de $\gamma$-ciclodextrina 68 . 
Na cavidade das ciclodextrinas podem ser aprisionados compostos orgânicos, aminoácidos, pequenos íons ou gases, em um processo dinâmico. Além da entrada e saída do substrato na cavidade, ocorre reorganização das moléculas de água. As forças que regem a formação do complexo entre ciclodextrina e substrato são do tipo: interações de Van der Waals, ligações de hidrogênio, associações hidrofóbicas ou proveniente da energia resultante da saida de moléculas de água ${ }^{18}$.

\section{⒈2.2 - Efeito de micelas em reacões químicas}

O efeito produzido pelas micelas nas reaçōes quimicas tem sido apresentado em estudos realizados durante as últimas décadas, e modelos têm sido propostos para simular os ambientes micelares. Apesar de os sistemas micelares modificarem a velocidade das reações, esta propriedade não tem sido muito explorada na melhoria dos métodos cinéticos de análise $62,68$.

Para que as micelas possam catalisar as reações, é necessário que pelo menos duas condições sejam cumpridas:

- o substrato deve se solubilizar no agregado micelar;

- o centro da solubilização da micela não deve impedir que um dos reagentes (substrato) seja acessivel ao outro reagente (por exemplo, o oxidante ou catalisador). 
Além disso, as interações eletrostáticas podem influir na concentração dos reagentes nas proximidades do centro da reação. Assim, uma micela catiônica pode catalisar a reação entre um ânion nucleofilico e um substrato neutro, mediante o deslocamento da carga negativa, que pode ser gerada numa etapa intermediária, diminuindo a energia de ativação da reação. Esta reação também pode ser catalisada aumentando-se a concentração do ânion nucleófilo na interface micelaágua, perto do centro de reação do substrato. Por outro lado, as interações hidrofóbicas são especialmente importantes, pois determinam a localização do substrato na micela e o grau de incorporação do mesmo.

\section{$\underline{\text { II.2.3 - Algumas aplicacões de surfactantes em reacões quimiluminescentes }}$}

Baseado nos estudos físico-químicos teóricos sobre catálise micelar e considerando as aplicações jả descritas sobre a utilização de agregados micelares nos mais diferentes campos da Química Analitica62,68,69, pode-se dizer que o uso de micelas apresenta grande potencial no desenvolvimento de novos métodos e também na modificação dos métodos analíticos já existentes.

Alguns dos problemas que, em princípio, podem ser solucionados pelo uso de surfactantes são: insolubilidade de reagentes que participam na reação, reações muito lentas, presença de reações paralelas, sensibilidade e/ou seletividade do método insuficiente, etc. 
O uso de micelas também oferece interessantes perspectivas na área dos métodos cinéticos de análises.

Apesar dos resultados de estudos caracterizando os ambientes micelares apresentarem grande potencial analítico, somente recentemente a utilização de micelas tem se tornado popular em métodos baseados nas medições de quimiluminescência.

A seguir serão apresentados alguns exemplos de publicações descrevendo o uso de surfactantes em determinações analiticas baseadas em reações $\mathrm{QL}$.

Lasovsky e Grambal 70 foram alguns dos primeiros pesquisadores a estudar o efeito de sistemas micelares na reação do luminol com peróxido de hidrogênio. Os autores observaram que a presença de surfactantes catiônicos, como CTAB (brometo de cetiltrimetilamônio), aumentou a intensidade de emissão como conseqüência do efeito micelar na eficiência da excitação da reação. Quando fluoresceína foi adicionada, o aumento da sensibilidade na determinação de peróxido de hidrogênio e de íons metálicos como $\mathrm{Cu}(\mathrm{II})$ e Co(II) foi atribuido ao efeito micelar na etapa de transferência de energia da molécula de 3-aminoftalato excitado à molécula de fluoresceina.

O efeito de ciclodextrinas observado por Karatani 71 , na emissão de radição da reação do luminol com peróxido de hidrogênio foi atribuído ao aumento no rendimento quântico da fluorescência e da excitação (equação 4, pág. 4). Acreditase que o complexo formado pelo intermediário da reação hidroperóxido com $\beta$-ciclodextrinas facilita o mecanismo de transferência de energia, o que não ocorre com $\alpha$-ou $\gamma$-ciclodextrinas. 
Visser e Santema observaram que a utilização de sistemas de micela reversa aumentou significativamente a detecção de peróxido de hidrogênio através da reação QL com luminol. Em sistema de micela reversa de CTAC (cloreto de cetiltrimetilamônio), a reação de luminol com peróxido de hidrogênio em meio de $\mathrm{pH}=7-9$, na ausência de quaisquer catalisadores ou co-oxidantes, apresentou emissão de radição intensa. Na ausência de sistema micelar não foi observada luminescência. Este resultado despertou a possibilidade da utilização de reações com enzimas em meio neutro, acopladas à deteç̧ão da luminescência, sem o ajuste da acidez do meio, uma vez que a reação QL com luminol é eficiente em meio básico $(\mathrm{pH} 10-11)^{18}$. Apesar dos esforços, o papel das micelas reversas na reação QL do luminol ainda não está totalmente delineado.

Igarashi e Hinze 72 utilizaram a reação de luminol com peróxido de hidrogênio em meio de micela reversa e observaram que a intensidade de emissão foi fortemente influenciada pelo contra-íon do surfactante: a substituição de íons brometo por cloreto resultou em um aumento de sensibilidade na determinação de peróxido de hidrogênio.

Entre os diferentes tipos de reações quimiluminescentes explorados com propósitos analíticos, a reação com lucigenina ou com um de seus mais conhecidos derivados, o éster de acridínio, está entre os sistemas mais estudados conforme pode ser observado no artigo de revisão de Hinze e colaboradores 18.

Malehorn e colaboradores ${ }^{73}$ realizaram um estudo da reação de lucigenina com peróxido de hidrogênio (esquema 3 , pág. 17), observando um aumento da emissão na presença de surfactantes e ciclodextrinas na seguinte ordem: 
$\beta$-ciclodextrina $\geq \gamma$-ciclodextrina $>$ CTAC $\approx$ Brij $35 \approx$ Triton $\mathrm{X}-100>\mathrm{SB}-12$ (3dodecildimetilamônio-1-propanosulfonato) $\approx \alpha$-ciclodextrina $\approx$ DODAB (brometo de dioctadecildimetilamônio) > solução aquosa > NaDC (deoxicolato de sódio) > NaSDS (dodecilsulfato de sódio) $\approx$ NaDDS (dodecilsulfonato de sódio).

No estudo realizado por Malehorn e colaboradores, a intensidade da emissão de radiação foi dependente da concentração do surfactante. A partir de determinada concentração de Brij 35, a intensidade de emissão da reação se manteve inalterada, e por isso a utilização deste surfactante se mostrou mais adequada. O efeito interferente de alguns ions metálicos foi suprimido pelo uso de surfactantes nãoiônicos. A explicação para este efeito foi que as cadeias de polioxietileno do Brij 35 poderiam ligar-se aos ions metálicos a uma distância que favorece a reação QL. As alterações na intensidade de quimiluminescência, observadas nos diferentes meios micelares, foram explicadas em termos do efeito na velocidade de reação e na eficiência da excitação. O uso de sistema micelar auxiliou a determinação de peróxido de hidrogênio em uma variedade de matrizes 73 .

Em meio básico, a reação da lucigenina com peróxido de hidrogênio (esquema 3) permite a determinação de alguns agentes redutores como ácido ascórbico, ácido úrico, glucose e frutose. O uso desta metodologia, inicialmente limitado pela insolubilidade do produto $\mathrm{N}$-metilacridona em água, foi superado pela adição de sistemas micelares 74 . Na determinação de agentes redutores como frutose ou glucose, em que o equilibrio tautomérico ceto-enólico catalisado por base está envolvido, a presença de sistemas micelares catiônicos ou anfóteros favoreceu a formação da forma enólica, causando aumento da emissão de radiação 74 . O uso de sistemas micelares de $\mathrm{CTAOH}$ (hidróxido de cetiltrimetilamônio), em substituição 
ao correspondente CTAC ou DTAOH (hidróxido de tetradeciltrimetilamônio), que possui o íon cloreto como contra-ion, causou aumento na intensidade de emissão da reação QL da lucigenina na determinação da frutose 68,75 .

Já os sistemas peroxi-oxalato são importantes por apresentarem muitas aplicações analíticas. Inicialmente, estudos do efeito de sistemas micelares foram publicados preferencialmente em patentes e tinham como objetivo aumentar a intensidade e duração da emissão de luz. Somente em 1982, um estudo mais detalhado com METQ, em meio contendo rubreno sulfonado, em sistema micelar não iônico foi publicado ${ }^{18}$. Os aumentos no rendimento quântico de 6 até 13,5 vezes na presença de surfactante não iônico e aniônico/polímero, respectivamente, foram atribuídos ao efeito micelar no mecanismo da reação peroxi-oxalato 18 .

A reação do oxalato de bis-triclorosalicilico butil éster com peróxido de hidrogênio na presença de bis-fenil-etilantraceno em sistema de micela reversa resultou em aumento no tempo de emissão de radiação ${ }^{18}$.

Wolf e Grayeski76 estudaram o efeito de ciclodextrinas na reação de METQ com peróxido de hidrogênio na presença de sulfonato de 2-toluidinilnaftaleno. Em meio de tampão fosfato $(\mathrm{pH}=5,0)$ e $\beta$-ciclodextrina, as intensidades máximas de emissão aumentaram de um fator de 100 a 330 vezes. Os autores atribuíram estes resultados à combinação do aumento na eficiência de excitação, na velocidade da reação e também na eficiência de fluorescência do fluoróforo. Brij 35 aumentou a intensidade da reação de METQ com peróxido na presença dos fluoróforos ANS (ácido 8-anilino naftalenosulfônico) e TNS (2-p-toluidinilnaftaleno 6-sulfonato de potássio). 
Koyo e colaboradores ${ }^{77}$ utilizaram o sistema glucose-glucose oxidase para gerar peróxido de hidrogênio e este então reagir com TCPO em meio de $\gamma$-ciclodextrina e tampão fosfato e determinar compostos contendo grupo dansil em concentração de pmol L-1.

Steijger e colaboradores ${ }^{78}$ compararam a intensidade da reação QL de TCPO com peróxido de hidrogênio na presença de perileno em sistema micelar, com a reação em uma mistura de acetonitrila e tampão fosfato, e sugeriram um método para determinação de compostos fluorescentes com cromatografia líquida de fase reversa. A presença de surfactante não-iônico Arkopal-300 aumentou a solubilidade do TCPO em solução aquosa, porém a estabilidade do reagente não foi tão alterada.

Dan e colaboradores 79 estudaram o efeito de vários tipos de surfactantes e de parâmetros experimentais da reação $Q L$ de $M E T Q$ com peróxido de hidrogênio na presença de fluoróforos, e os resultados foram utilizados na análise de peróxido de hidrogênio. A presença de CTAC, Brij 35 ou SB-12 aumentou a intensidade de emissão em até 130 vezes com relação ao observado em tampão fosfato. Os autores atribuíram o aumento da intensidade de emissão em meio micelar não somente ao aumento da eficiência na fluorescência como também à eficiência na excitação. Posteriormente, Dan e Grayeski 80 estudaram o efeito de micelas reversas CTAC e AOT (sulfosuccinato de bis(etilexil) e sódio) em misturas de solventes contendo 1-butanol/ciclo hexano ou clorofórmio/ciclohexano com quantidades de água variável. $\mathrm{O}$ aumento de até 55 vezes foi atribuído principalmente ao aumento da eficiência de excitação. Um sistema de análise por injeção em fluxo foi desenvolvido para determinação de ANS e de rodamina B. 


\section{3 - Estudos da quimiluminescência de TCPO e 2-NPO em sistema micelar} aquoso

A seguir serão apresentados os estudos da influência de alguns sistemas micelares aquosos na quimiluminescência de TCPO e 2-NPO realizados no presente trabalho.

Procurou-se variar a natureza do surfactante (não iônico, aniônico e aniônico).

\section{II.3.1 - Parte experimental}

\section{II.3.1.a - Reagentes}

Todos os reagentes químicos, de grau analítico, foram usados sem purificação prévia. Soluções aquosas foram preparadas com água destilada e desionizada pelo sistema Milli-Q (Millipore). 


\section{II.3.1.a.1 - Solucões estoque}

- Solução de 2-NPO (preparado de acordo com a ref. 81$)\left(4,5 \times 10^{-4} \mathrm{~mol} \mathrm{~L}^{-1}\right)$ : 2 mg de 2-NPO foram dissolvidos em 10,0 mL de acetonitrila (ACN) (Kanto Chemical Co). A solução foi preparada diariamente.

- Solução de TCPO (Nakalai Chemicals Ltd) $\left(4,5 \times 10^{-4} \mathrm{~mol} \mathrm{~L}^{-1}\right): 2 \mathrm{mg}$ de TCPO foram dissolvidos em 10,0 mL de acetonitrila. A solução foi mantida em banho de ultrassom, até completa solubilização. A solução foi preparada diariamente.

- Solução de fluoranteno (FA) (Nakalai Chemicals Ltd) (1,0×10-3 mol L-1): 2 mg de FA foram dissolvidos em $10,0 \mathrm{~mL}$ de acetonitrila. A solução foi mantida em banho de ultrassom, até completa solubilização.

- Solução de $\mathrm{H}_{2} \mathrm{O}_{2}(1,0 \times 10-2 \mathrm{~mol} \mathrm{~L}-1)$ (Kanto Chemical Co): $10 \mu \mathrm{L}$ de solução de peróxido de hidrogênio $34 \%(\mathrm{v} / \mathrm{v})$ foram diluídos com água desionizada em balão de $10,0 \mathrm{~mL}$. A solução foi preparada diariamente.

- Solução de hidroperóxido de t-butila (t-bOOH) $(1,0 \times 10-2 \mathrm{~mol} \mathrm{L-1)}$ (Kanto Chemical Co): $64 \mu \mathrm{L}$ de solução de hidroperóxido de t-butila $70 \%(\mathrm{v} / \mathrm{v})$ foram dissolvidos com água desionizada, em balão de $10,0 \mathrm{~mL}$. A solução foi preparada diariamente.

- Solução de imidazol (IMI) (Nakalai chemicals Ltd) (1,0×10-3 mol L-1): $34 \mathrm{mg}$ de imidazol foram dissolvidos em $10,0 \mathrm{~mL}$ de acetonitrila. A solução foi preparada diariamente. 
- Solução tampão HTRIS ${ }^{+} / T R I S\left(0,03 / 0,10 \mathrm{~mol} \mathrm{~L}^{-1}\right)$ (Kanto Chemical Co): 0,40 g de TRIS foram dissolvidos em balão de $25,0 \mathrm{~mL}$ contendo $40 \mu \mathrm{L}$ de $\mathrm{HNO}_{3}$ concentrado e o volume foi completado com água desionizada, para preparação de $\left[\mathrm{HTRIS}^{+}\right]=0,03 \mathrm{~mol} \mathrm{~L}^{-1}$ e $[$ TRIS $]=0,10 \mathrm{~mol} \mathrm{L-1}$.

- Solução tampão fosfato $\left(\mathrm{H}_{2} \mathrm{PO}_{4}^{-} / \mathrm{HPO}_{4}{ }^{2-}\right)(0,02 / 0,03 \mathrm{~mol} \mathrm{L-1})$ : Solução de $\left[\mathrm{KH}_{2} \mathrm{PO}_{4}\right]=0,10 \mathrm{~mol} \mathrm{~L}-1$ foi inicialmente preparada pela dissolução de $1,4 \mathrm{~g}$ de $\mathrm{KH}_{2} \mathrm{PO}_{4}$ (Kanto Chemical Co) com água desionizada em balão de 100,0 $\mathrm{mL}$. Solução de $[\mathrm{NaOH}]=0,10 \mathrm{~mol} \mathrm{~L}-1$ foi preparada pela dissolução de 0,40 g de $\mathrm{NaOH}$ (Kanto Chemical Co) com água desionizada em balão de 100,0 $\mathrm{mL}$. Em um balão de $50,0 \mathrm{~mL}$ foram adicionados $25,0 \mathrm{~mL}$ de $\mathrm{KH}_{2} \mathrm{PO}_{4} \quad 0,10$ mol L-1, $15,0 \mathrm{~mL}$ de $\mathrm{NaOH} 0,10 \mathrm{~mol} \mathrm{L-1}$ e o volume foi completado com água desionizada para obter solução tampão $\left[\mathrm{H}_{2} \mathrm{PO}_{4}^{-}\right]=0,02 \mathrm{~mol} \mathrm{L-1}$ e $\left[\mathrm{HPO}_{4}^{2-}\right]=$ $0,03 \mathrm{~mol} \mathrm{~L}-1$.

As soluções estoque dos surfactantes (aproximadamente 10 vezes a c.m.c.) foram preparadas em água desionizada:

- Brij 35 (éter polioxietileno(23)laurilico) (c.m.c. $=1,0 \times 10-4 \mathrm{~mol} \mathrm{~L}-1$ ): $500 \mu \mathrm{L}$ de solução de Brij 35 foram adicionados a balão de $50,0 \mathrm{~mL}$ para preparação de [Brij 35] $=5,0 \times 10-2 \mathrm{~mol} \mathrm{L-1}$. A seguir foi feita diluição desta solução para $1,0 \times 10-4 \mathrm{~mol} \mathrm{~L}-1$ em balão de $25,0 \mathrm{~mL}$.

- Brij 76 (éter polioxietileno(10)estearílico) (c.m.c. $=3,0 \times 10-3 \mathrm{~mol} \mathrm{L-1):} \mathrm{foi}$ preparada solução saturada de Brij 76. 
- Tween 20 (monolaurato de polioxietileno(20)sorbitano) (c.m.c. $=5,0 \times 10^{-5}$ mol $\mathrm{L}^{-1}$ ): $2,8 \mathrm{~mL}$ de solução de Tween 20 foram adicionados a balão de 50,0 $\mathrm{mL}$ para preparação de $[$ Tween 20$]=5,0 \times 10-2 \mathrm{~mol} \mathrm{~L}-1$. A seguir foi feita diluição para [Tween 20] $=5,0 \times 10-4 \mathrm{~mol} \mathrm{L-1}$ em balão de $25,0 \mathrm{~mL}$.

- Tween 80 (monooleato de polioxietileno(20) sorbitano) (c.m.c. $=1,2 \times 10-5$ mol L-1): 0,6 mL de Tween 80 foram adicionados a balão de $25,0 \mathrm{~mL}$ para preparação de solução [Tween 80$]=2,0 \times 10-2 \mathrm{~mol} \mathrm{L-1}$. A seguir foi feita diluição desta solução para [Tween 80$]=1,0 \times 10-4 \mathrm{~mol} \mathrm{L-1}$ em balão de 25,0 $\mathrm{mL}$.

- SDS (dodecil sulfato de sódio) (c.m.c. $=8,0 \times 10-3 \mathrm{~mol} \mathrm{L-1}$ ): $0,16 \mathrm{~g}$ SDS foram dissolvidos com água desionizada em balão de $25,0 \mathrm{~mL}$ para preparação de $[S D S]=2,0 \times 10-2 \mathrm{~mol} \mathrm{~L}-1$.

- TDTAB (brometo de tetradeciltrimetilamônio) (c.m.c. $=3,5 \times 10-3$ mol L-1): foi preparada solução de $[\mathrm{TDTAB}]=3,5 \times 10-2 \mathrm{~mol} \mathrm{L-1}$

- $\operatorname{CTAC}$ (cloreto de cetiltrimetilamônio) (c.m.c. $=1,3 \times 10-3 \mathrm{~mol} \mathrm{~L}-1$ ): $91 \mathrm{mg}$ de CTAC foram dissolvidos com água desionizada em balão de $25,0 \mathrm{~mL}$ para preparação de $[C T A C]=1,0 \times 10-2 \mathrm{~mol} \mathrm{~L}-1$

- OTAC (cloreto de octadeciltrimetilamônio) (c.m.c. = 3,4×10-4 mol L-1): 1,0 g de OTAC foram dissolvidos em 100,0 mL, para preparação de [OTAC] = $3,0 \times 10-3 \mathrm{~mol} \mathrm{~L}-1$.

- $\mathrm{DDAB}$ (brometo de didodecildimetilamônio) (c.m.c. $=1,8 \times 10-4 \mathrm{~mol} \mathrm{L-1}$ ): foi preparada solução de $[D D A B]=2,0 \times 10-3 \mathrm{~mol} \mathrm{L-1}$. 
- DODAC (cloreto de dioctadecildimetilamônio) $(1,0 \times 10-3 \mathrm{~mol}$ L-1): foi preparada solução de $[D O D A C]=1,0 \times 10-2 \mathrm{~mol} \mathrm{~L}-1$.

- cicloheptaamilose ( $\beta$-ciclodextrina) $\quad(1,0 \times 10-2 \quad \mathrm{~mol} \quad \mathrm{~L}-1): 0,7 \mathrm{~g}$ de $\beta$-ciclodextrina foram dissolvidos com água desionizada em balão de $50,0 \mathrm{~mL}$, para preparação de $[\beta$-ciclodextrina $]=1,0 \times 10-2 \mathrm{~mol} \mathrm{~L}-1$.

\section{II.3.1.b - Procedimento experimental}

A sequência de adição das soluções ao tubo de vidro foi: $0,10 \mathrm{~mL}$ de água desionizada ou solução tampão ou solução de surfactante, seguida de $20 \mu \mathrm{L}$ da solução de FA, $20 \mu \mathrm{L}$ da solução de peróxido de hidrogênio ou hidroperóxido de t-butila e $20 \mu \mathrm{L}$ da solução de 2-NPO ou TCPO. O volume final foi de $0,16 \mathrm{~mL}$.

Nos estudos com imidazol, a sequência de adição das soluções ao tubo de vidro foi: $0,10 \mathrm{~mL}$ de água desionizada ou solução tampão ou solução de surfactante, seguida de $20 \mu \mathrm{L}$ da solução de $\mathrm{FA}, 20 \mu \mathrm{L}$ da solução de IMI, $20 \mu \mathrm{L}$ da solução de peróxido de hidrogênio ou hidroperóxido de t-butila e por último $20 \mu \mathrm{L}$ da solução de 2-NPO ou TCPO. O volume final foi de $0,18 \mathrm{~mL}$.

A emissão de radiação iniciou imediatamente após a injeção da solução de 2-NPO ou TCPO, através do septo sob o qual estava posicionado o tubo de vidro contendo o restante das soluções. 
As concentrações das soluções finais após a mistura dos reagentes estão indicadas nas figuras e tabelas relacionadas na parte de resultados e discussões. Quando a solução de surfactante não foi adicionada à reação, o mesmo volume de solução tampão ou água desionizada foi adicionado para manter as concentrações dos outros reagentes inalteradas.

\subsection{1.c - Aparelhagem para realização de testes no modo estático}

Para obter o perfil da emissão quimiluminescente, foram realizados experimentos no modo estático utilizando Lumicounter 600 ou Lumicounter 1000 (esquema 7) (Microtec NITI-ON, Japão) sem discriminação do comprimento de onda de emissão, com a FMT em baixa (LV) ou alta voltagem (HV). Um tubo de vidro de capacidade $1,0 \mathrm{~mL}$ foi colocado no compartimento posicionado em frente à FMT.

As soluções dos reagentes foram adicionadas à célula, sob agitação magnética, através de um septo, por meio de uma seringa Hamilton.

O perfil de emissão foi registrado com um registrador Shimadzu 135. (Shimadzu).

Nas figuras estão representadas as intensidades relativas, pois os experimentos foram realizados em diferentes condições de sensibilidade do equipamento. 


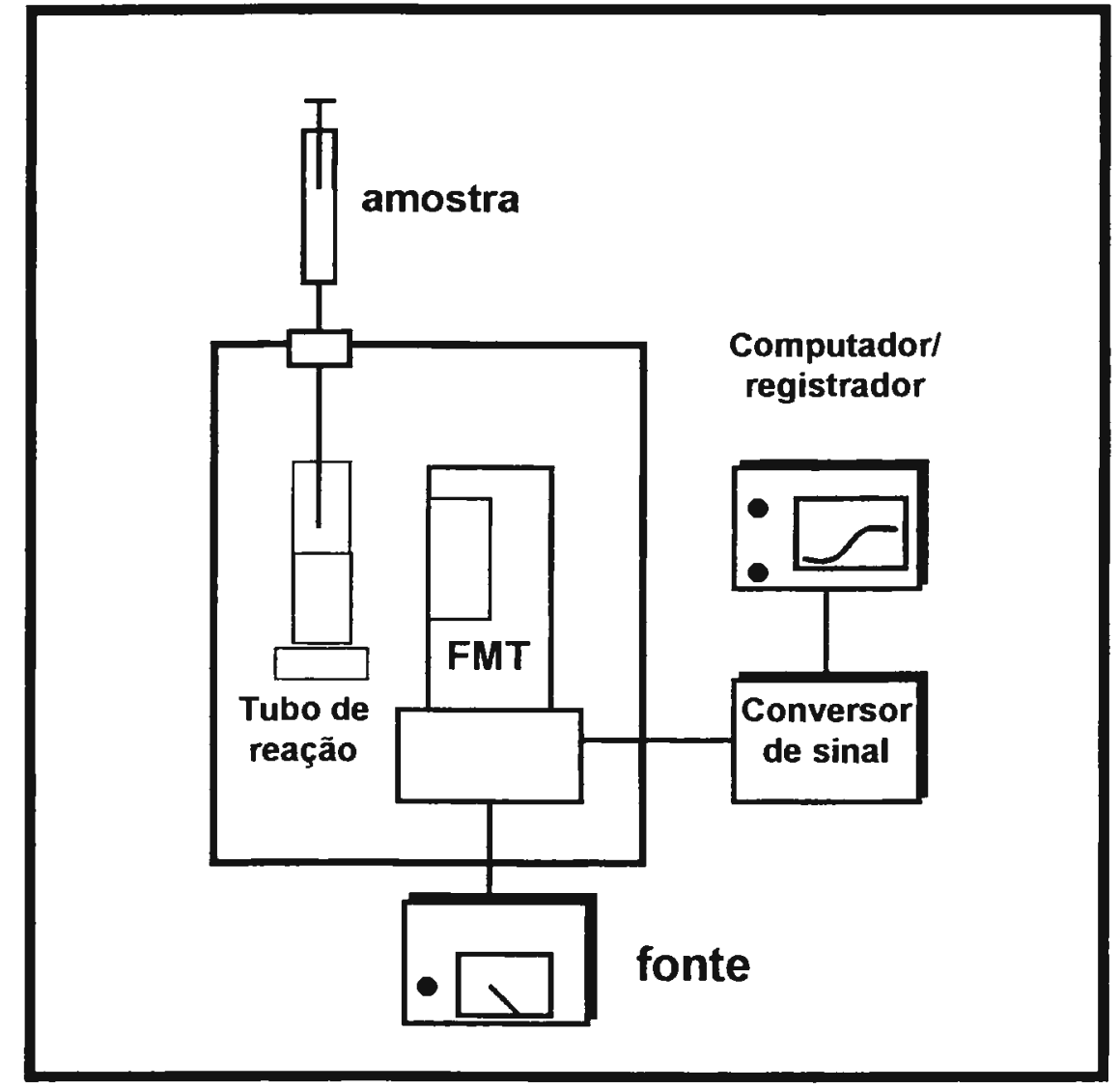

Esquema 7 - Esquema do equipamento Lumicounter 1000 utilizado para realização de testes no modo estático. 


\section{$\underline{\text { II.3.2 - Resultados e discussão }}$}

Esta parte do trabalho descreve o estudo do efeito de micelas na reação QL de 2-NPO ou TCPO com hidroperóxido de t-butila (t-bOOH) ou peróxido de hidrogênio $\left(\mathrm{H}_{2} \mathrm{O}_{2}\right.$ ), na presença de um fluoróforo (estruturas dos reagentes na tabela 2). O efeito de diferentes tipos de micelas (não-iônico, catiônico e aniônico) na reação QL foi investigado através do monitoramento da curva intensidade de emissão vs tempo.

As medições de intensidade de emissão foram feitas no ponto máximo da curva de intensidade de emissão com o tempo. A intensidade de emissão foi representada como altura de pico (I), em unidades relativas de intensidade, e foi obtida pela média de 3 medições. $O$ tempo total ( $t$ ) refere-se à duração da emissão em segundos (s), ou seja, o tempo até o decaimento de cerca de $90 \%$ do sinal. A área integrada sob a curva de intensidade-tempo é um indicativo do rendimento quântico da reação, $\Phi \mathrm{QL}$.

$\mathrm{Na}$ figura 7 estão representadas as intensidades de emissão com $\circ$ tempo da reação de 2-NPO ou TCPO com hidroperóxido de t-butila ou peróxido de hidrogênio na presença de fluoranteno (FA), em meio contendo $75 / 25 \%(\mathrm{v} / \mathrm{v})$ águalacetonitrila. O perfil da emissão de radiação apresentou um rápido aumento de intensidade e um decaimento mais lento.

Pode-se observar que a intensidade de emissão máxima (I) da reação de 2-NPO com $\mathrm{H}_{2} \mathrm{O}_{2}$ (figura $7 \mathrm{~b}$ ) é cerca de 100 vezes maior que com t-bOOH (figura 7a). Rauhut e colaboradores já haviam observado que alguns 
organoperóxidos reagem com os oxalatos, porém com uma eficiência muito menor 81 .

A intensidade de emissão na reação com 2-NPO (figuras $7 a$ e $7 b$ ) é maior do que com TCPO (figuras $7 \mathrm{c}$ e $7 \mathrm{~d}$ ). A figura $7 \mathrm{c}$ mostra que nenhum sinal foi detectado para a reação de TCPO e t-bOOH nas condições indicadas.

Tabela 2 - Estruturas químicas de reagentes utilizados

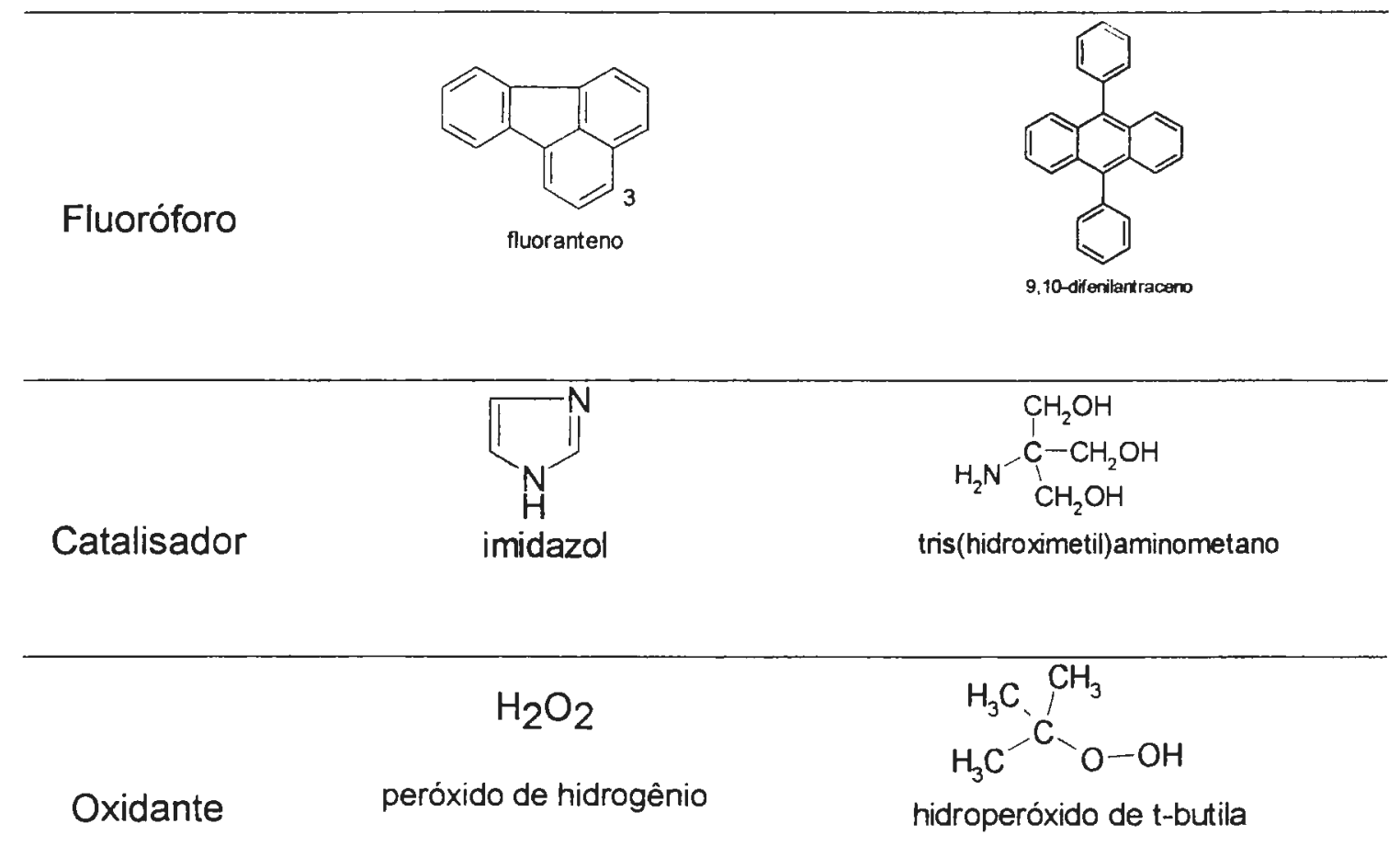




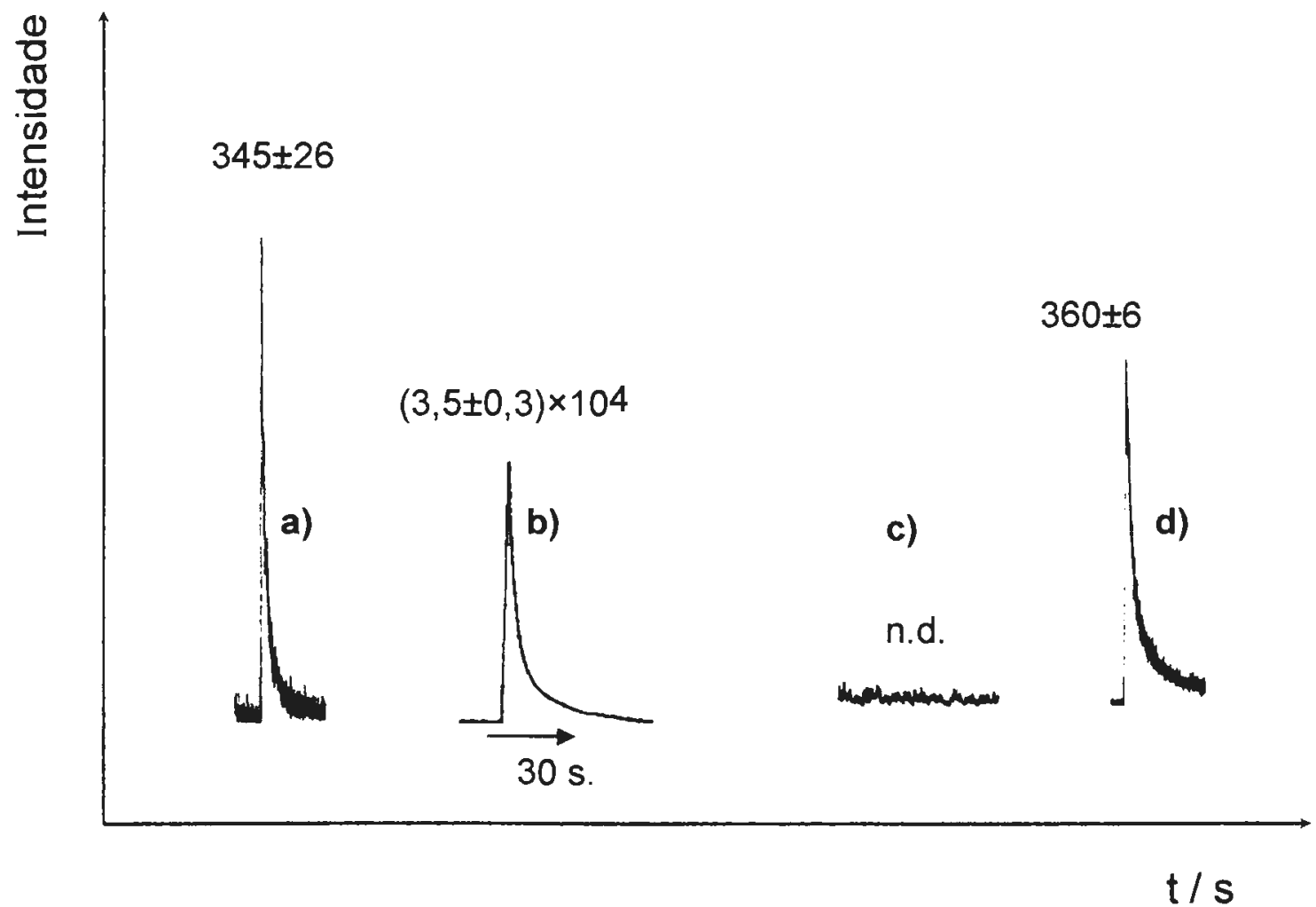

Figura 7 - Intensidade relativa da emissão de radiação da reação de: a) 2-NPO e hidroperóxido de t-butila, b) 2-NPO e peróxido de hidrogênio, c) TCPO e hidroperóxido de t-butila e d) TCPO e peróxido de hidrogênio.

$[2-\mathrm{NPO}]=[\mathrm{TCPO}]=5,6 \times 10-5,\left[\mathrm{H}_{2} \mathrm{O}_{2}\right]=[\mathrm{t}-\mathrm{bOOH}]=1,2 \times 10-3,[\mathrm{FA}]=1,2 \times 10-4$

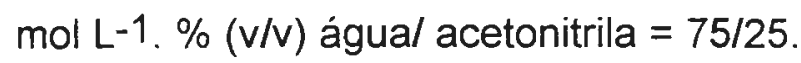

Obs.: Como os experimentos foram realizados em diferentes condições de sensibilidade do equipamento, os números indicados nas figuras referem-se às intensidades relativas. 
Quando a acidez do meio de reação de 2-NPO e peróxido de hidrogênio foi controlada pela adição de tampão HTRIS $^{+} /$TRIS $(p H=8,3)$ ou tampão fosfato $(\mathrm{pH}=8,4)$ (condições experimentais: $[2-\mathrm{NPO}]=3,5 \times 10-5,\left[\mathrm{H}_{2} \mathrm{O}_{2}\right]=7,7 \times 10-4,[\mathrm{FA}]=$ $7,7 \times 10-5 \mathrm{~mol} \mathrm{~L}-1$ e $\%$ (v/v água/acetonitrila) $=85 / 15 \%)$, o tempo de emissão foi reduzido para 3 segundos e a intensidade de emissão aumentou para 1,0×105 e $6,0 \times 104$, respectivamente (dados aqui não representados). O tempo de emissão sofreu redução significativa com a adição de solução tampão, o que pode ter sido causado pela basicidade do meio e também pelo efeito catalítico dos reagentes utilizados para tamponar o meio de reação.

Por exemplo, alguns estudos verificaram o efeito catalitico de TRIS na reação de TCPO (a ser discutido no próximo capítulo). Para um mesmo pH do meio, $\Phi_{\mathrm{QL}}$ depende também da natureza do tampão.

Alguns trabalhos têm demonstrado que o perfil de emissão de sistemas POQL é fortemente afetado pelos reagentes, que podem atuar como catalisadores da reação. Alguns autores ${ }^{82}$ evidenciaram a ação de algumas bases (piridina, imidazol ou salicilato) como catalisadores. No presente trabalho, a TRIS também pode também atuar como um catalisador.

Atualmente, o catalisador da reação peroxi-oxalato mais popular é o imidazol. Estudos da reação catalisada por imidazol confirmaram formação do intermediário 1,1'-oxalildiimidazol (ODI) através de catálise nucleofílica (esquema 6) 55-57.

Lee e colaboradores 82 observaram perfis de emissão de radiação diferenciados e dependentes da natureza e da concentração da base (piridina, imidazol ou salicilato) utilizada na reação de DNPO (oxalato de bis-(2,4-dinitrofenila)) 
com peróxido de hidrogênio na presença de antraceno ou 1-aminoantraceno ou perileno. Em meio contendo baixas concentrações de base, dois picos foram observados; em altas concentrações de base, o segundo pico foi suprimido. Os autores atribuíram a existência de caminhos múltiplos para a reação de DNPO (oxalato de bis(2,4-dinitrofenila)) com $\mathrm{H}_{2} \mathrm{O}_{2}$, o que foi ratificado pelos estudos de Stevani e colaboradores 55 , Neuvonen 56 e Hadd e colaboradores 57 para a sistema PO-QL catalisada por imidazol (esquema 6, página 24). H. Neuvonen83 atribuiu o decaimento rápido do pico à interação entre o intermediário da reação e a base, via catálise ácido-base (ao invés da catálise nucleofílica catalisada por base).

Os efeitos causados pelas bases, que atuam como catalisadores, no rendimento quântico da reação $\mathrm{PO}-\mathrm{QL}$ são: formação de complexo entre a base e o reagente oxálico, catálise na decomposição do intermediário formado, hidrólise básica dos reagentes e também permite a utilização de meio de reação semiaquoso 84

A função do catalisador é promover e acelerar a reação produzindo intensidade de emissão maior. A maneira de aumentar a eficiência catalítica é usar um nucleófilo mais forte, mas o conceito de nucleofilicidade para ésteres não obedece a uma regra simples, e é dependente de diversas propriedades como basicidade, polaridade, habilidade em formar pontes de hidrogênio, solvatação, estabilização da ressonância de elétrons e efeitos estéricos 84 .

Jonsson e colaboradores 84 também realizaram experimentos para verificar a influência de diversas bases ( $\mathrm{pK}_{\mathrm{a}}$ variando de $7-11$ ) na reação de TCPO com peróxido de hidrogênio. Sugeriram que a presença de bases ativa o ácido oxálico 
tornando-o mais sensivel ao meio reacional básico e fazendo com que os possíveis intermediários se decomponham mais rapidamente.

\section{॥.3.2.1 - Efeito do surfactante na reação de 2-NPO com peróxido de hidrogênio}

O efeito de diferentes tipos de surfactantes com diferentes comprimentos da cadeia hidrocarbônica (não-iônico, catiônico e aniônico) na reação de 2-NPO com peróxido de hidrogênio foi investigado através do monitoramento da curva intensidade de emissão - tempo.

Os resultados relativos à luminescência produzida pela reação de 2-NPO com peróxido de hidrogênio, em meio de fluoranteno, estão descritos na tabela 3. Alguns perfis de emissão QL (curva de intensidade de emissão vs tempo) estão representados na figura 8 .

Nas primeiras linhas das tabelas que se seguem estão as intensidades de emissão (IR) (altura do pico) na ausência de surfactante. Os aumentos relativos causados pela adição de surfactante estão representados em relação ao sinal obtido na ausência de surfactante:

\footnotetext{
I surfactante $=$ fator de aumento $\times$ I ausência de surfactante
} 
e)

$$
(1,7 \pm 0,1) \times 105
$$

$\frac{0}{0}$
$\frac{0}{0}$
$\frac{0}{0}$
$\frac{5}{0}$
$\frac{1}{5}$

d)

$(9,5 \pm 0,1) \times 104$

c)

b) $\quad(4,5 \pm 0,7) \times 104$

a) $\quad(3,5 \pm 0,5) \times 104$

$(2,2 \pm 0,1) \times 104$
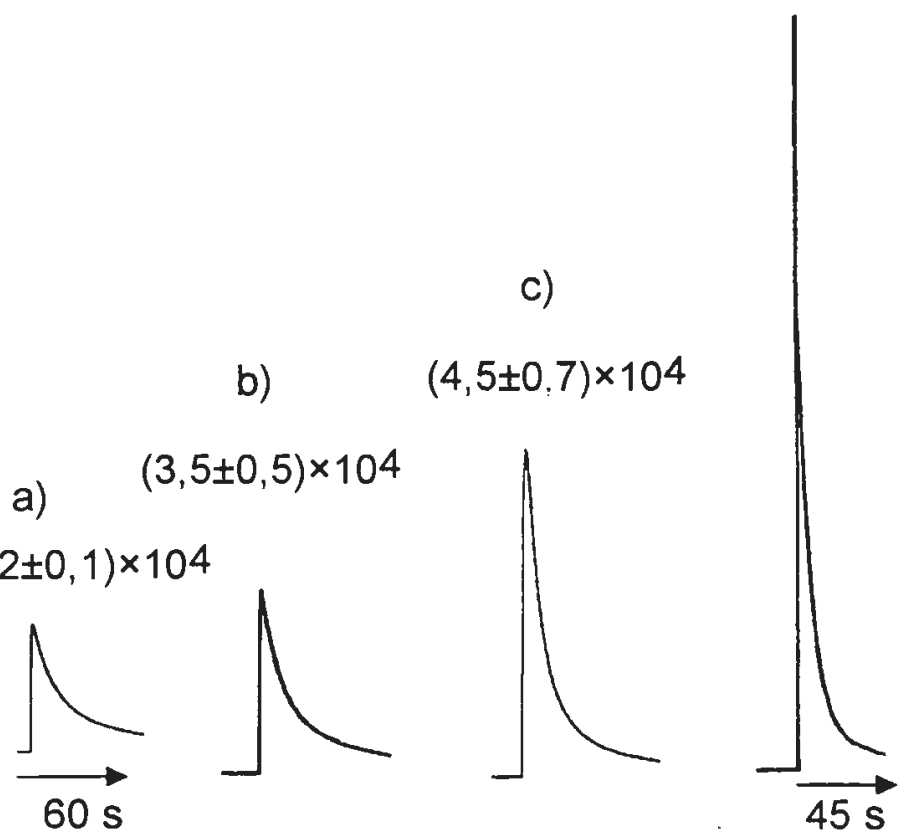

f)

$(1,8 \pm 0,4) \times 104$

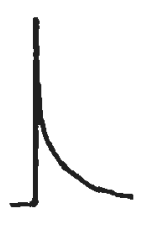

$t / s$

Figura 8 - Intensidade relativa da emissão da reação de 2-NPO e peróxido de hidrogênio, em meio de fluoranteno e surfactante. Surfactantes:

a) Brij 35; b) Brij 76; c) SDS; d) DDAB e) DODAC e f) TDTAB.

$[2-\mathrm{NPO}]=5,6 \times 10-5,\left[\mathrm{H}_{2} \mathrm{O}_{2}\right]=1,2 \times 10-3,[\mathrm{FA}]=1,2 \times 10-4 \mathrm{~mol} \mathrm{~L}-1 . \%(\mathrm{v} / \mathrm{v}$ águal acetonitrila) $=75 / 25 \%$. 
Através da tabela 3 pode-se concluir que surfactantes catiônicos são mais eficientes em aumentar a IR (até 6 vezes no caso de OTAC) que aniônicos e nãoiônicos. Além disso, o tempo de reação foi duas vezes maior do que na ausência de surfactante. Para a reação de 2-NPO com peróxido de hidrogênio, os surfactantes catiônicos que causaram maior aumento na intensidade máxima seguem a seqüência: OTAC > DODAC > CTAC > DDAB > TDTAB.

A comparação entre as $I_{R}$ produzidas em meio de surfactante catiônico permitiu verificar que o aumento na cadeia carbônica do surfactante acarretou aumento na intensidade máxima.

TDTAB e DDAB têm como contra-íon o íon brometo, o qual pode reagir com o peróxido de hidrogênio em solução; mesmo assim DDAB (que possui uma maior cadeia hidrofóbica) causou um efeito positivo na intensidade de quimiluminescência.

DDAB e DODAC são dialquil surfactantes catiônicos, capazes de formar agregados do tipo vesículas (figura 6). Estas estruturas exibem maior organização, estabilidade e rigidez do que micelas do tipo TDTAB ou OTAC. Yamada e colaboradores $^{85-87}$ têm utilizado surfactantes capazes de formar vesículas, e tem observado que várias reações QL ocorrem mais eficientemente nestes ambientes que em micelas normais, porque as estruturas são cineticamente "mais estáveis" e são capazes de proporcionar um microambiente mais protegido para os intermediários no estado excitado, o que resulta em aumento da emissão de luz. 
Tabela 3 - Efeito de surfactantes na emissão QL da reação de 2-NPO com peróxido de hidrogênio.

$[2-\mathrm{NPO}]=5,6 \times 10-5,\left[\mathrm{H}_{2} \mathrm{O}_{2}\right]=1,2 \times 10-3,[\mathrm{FA}]=1,2 \times 10-4$ mol L-1, [surfactante $]=10$ vezes a c.m.c. do surfactante, $\%$ (v/v) água/acetonitrila: $75 / 25 \%$.

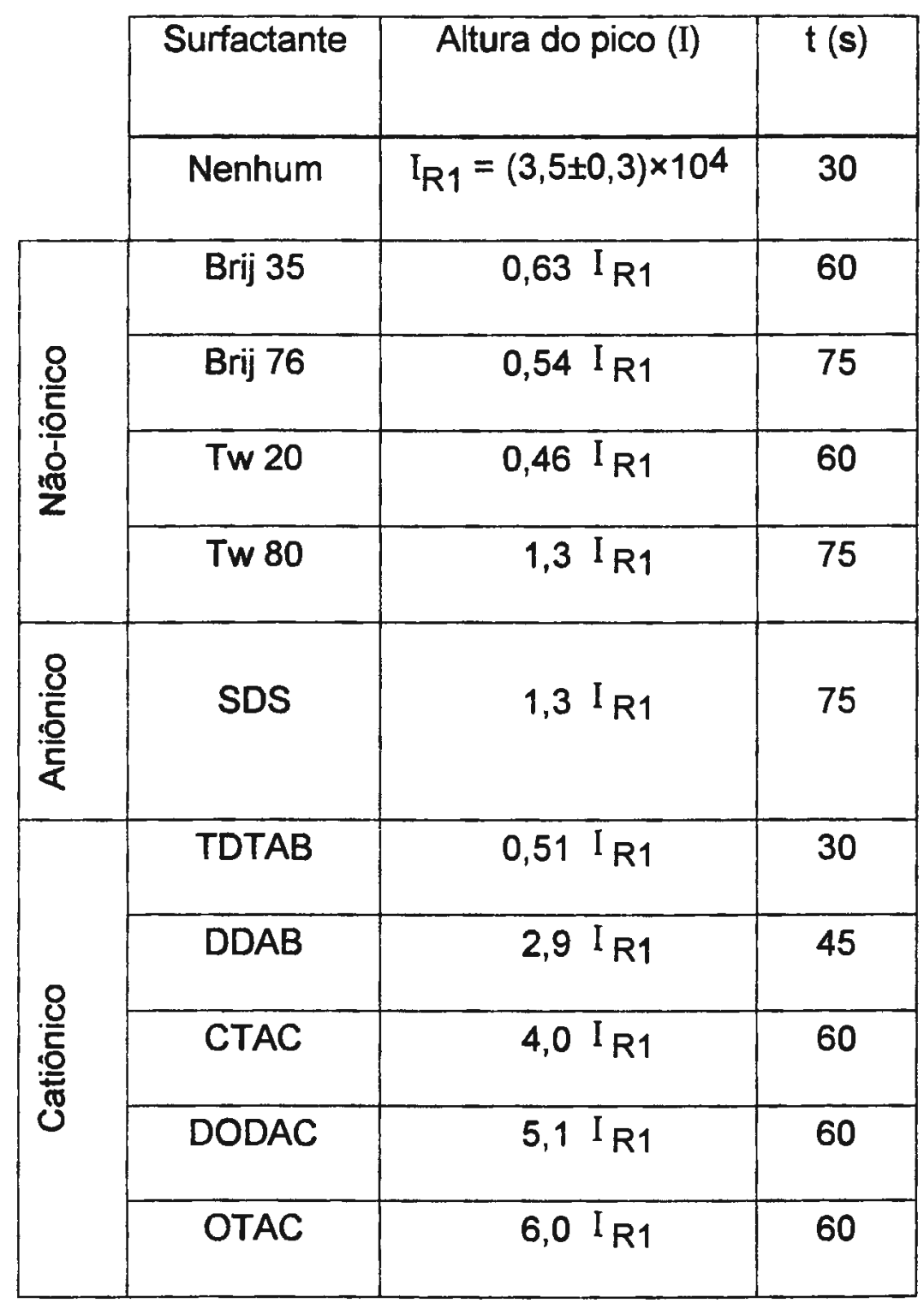


É possível que as micelas estabilizem produtos ou intermediários da reação. Peróxido de hidrogênio, presente na fase aquosa deve migrar para as proximidades da capa da micela para reagir com 2-NPO ou TCPO, dando origem ao suposto intermediário da reação, 1,2-dioxetanodiona (esquema 4, página 19), um composto polar, e interagir com fluoranteno, que possui cadeia hidrofóbica e provavelmente deve estar presente no núcleo da micela. Além disso, ânions hidratados são maiores que ânions $\mathrm{OOH}^{-}$. Com isso a penetração de $\mathrm{OH}^{-}$deve ser mais lenta e mais difícil de maneira que a hidrólise do oxalato diminui e a intensidade de emissão aumenta. O aumento da cadeia hidrofóbica do surfactante pode estar favorecendo a estabilidade dos ésteres oxalatos frente à hidrólise 78 .

A reação QL foi favorecida por surfactantes de cadeias hidrocarbônicas maiores. Entretanto, a intensidade de emissão da reação de 2-NPO com peróxido de hidrogênio na presença de SDS, foi similar àquela observada na presença de TW 80. Apesar de SDS apresentar cadeia carbônica (12 carbonos) menor que TDTAB (14 carbonos), o primeiro causou maior aumento na IR, indicando que além do tamanho da cadeia carbônica do surfactante, outros fatores podem estar influenciando na emissão de radiação.

Brij 35, Brij 76 e TW 20 suprimiram parcialmente a intensidade de emissão (tabela 3). A intensidade de emissão da reação de 2-NPO com peróxido de hidrogênio é afetada pela acidez do meio e a natureza do tampão. Alguns experimentos foram realizados empregando-se $[2-\mathrm{NPO}]=3,5 \times 10-5 \mathrm{~mol} L-1$, $\left[\mathrm{H}_{2} \mathrm{O}_{2}\right]=7,7 \times 10-4 \mathrm{~mol} \mathrm{~L}-1$ e $[\mathrm{FA}]=7,7 \times 10-5 \mathrm{~mol} \mathrm{~L}-1$ na presença de Brij 76 (10 vezes c.m.c.) nos tampões HTRIS+/TRIS $\left(\mathrm{pH}_{\text {medido }}=8,3\right)$ e fosfato $\left(\mathrm{pH}_{\text {medido }}=\right.$ 8,5). Na presença de Brij 76 e tampão HTRIS ${ }^{+} / T R I S$, a intensidade máxima (Imax) 
foi o dobro daquela obtida em tampão fosfato. No entanto, na ausência ou na presença de surfactante o valor de $I_{\max }$ é praticamente o mesmo. Nesse caso, a natureza do tampão é mais importante que a presença de Brij 76.

A influência de sistemas micelares não-iônicos na reação TCPO e $\mathrm{H}_{2} \mathrm{O}_{2}$ foi investigada por Steijger e colaboradores 78 . Os autores verificaram que a presença de Arkopal-300, um surfactante não-iônico com 55 grupos de polioxietileno, produziu intensidade de emissão similar à intensidade de emissão em meio tampão fosfatolacetonitrila. Foi verificado que a intensidade de emissão aumentou com o tamanho da cadeia de polioxietileno da série de Arkopal. Sabe-se, entretanto, que a variação no comprimento da cadeia hidrocarbônica dos surfactantes pode alterar o tamanho das micelas e o grau de penetração dos reagentes. Com base neste fato, os autores 78 sugeriram que a diminuição do número de agregação foi responsável pelo decréscimo no tamanho do núcleo hidrofóbico da micela, o que facilitou a aproximação do fluoróforo à capa hidratada de polioxietileno do surfactante não iônico e resultou em reação cuja emissão de radiação ocorreu com maior intensidade.

11.3.2.2 - Comparacão do efeito de surfactantes na reacão de 2-NPO e TCPO com ${ }_{2} \underline{\underline{O}} \underline{2} \underline{\text { e t-bOOH }}$

Experimentos similares foram realizados para verificar o efeito de surfactantes catiônicos (TDTAB, DDAB, CTAC, OTAC e DODAC) na reação de 2-NPO e TCPO 
com peróxido de hidrogênio ou hidroperóxido de t-butila em presença de fluoranteno (figuras 9 e 10).

Os dados apresentados na tabela 4 mostram que a reação de 2-NPO é muito mais eficiente que TCPO, na presença ou ausência de surfactante.

O tempo total da reação de 2-NPO é mais influenciado pela presença de surfactantes catiônicos que a reação com TCPO.

A reação de 2-NPO ou TCPO com peróxido de hidrogênio produziu um sinal cerca de 100 vezes maior que com hidroperóxido de t-butila.

Na presença de surfactantes catiônicos (especialmente OTAC e DODAC), um pico mais intenso foi observado para a reação de 2-NPO ou TCPO.

Brij 35, um surfactante não iônico, praticamente suprimiu a intensidade de emissão da reação de 2-NPO com hidroperóxido de t-butila (figura 9, gráfico a)).

\section{$\underline{11.3 .2 .3 \text { - Efeito da presenca de imidazol }}$}

O efeito catalítico do imidazol (IMI) na reação de TCPO e peróxido de hidrogênio foi investigado por vários autores $55-57$. Os possiveis intermediários, para a reação $\mathrm{PO}-\mathrm{QL}$ catalisada por imidazol, têm sido extensivamente estudados (esquema 6). 


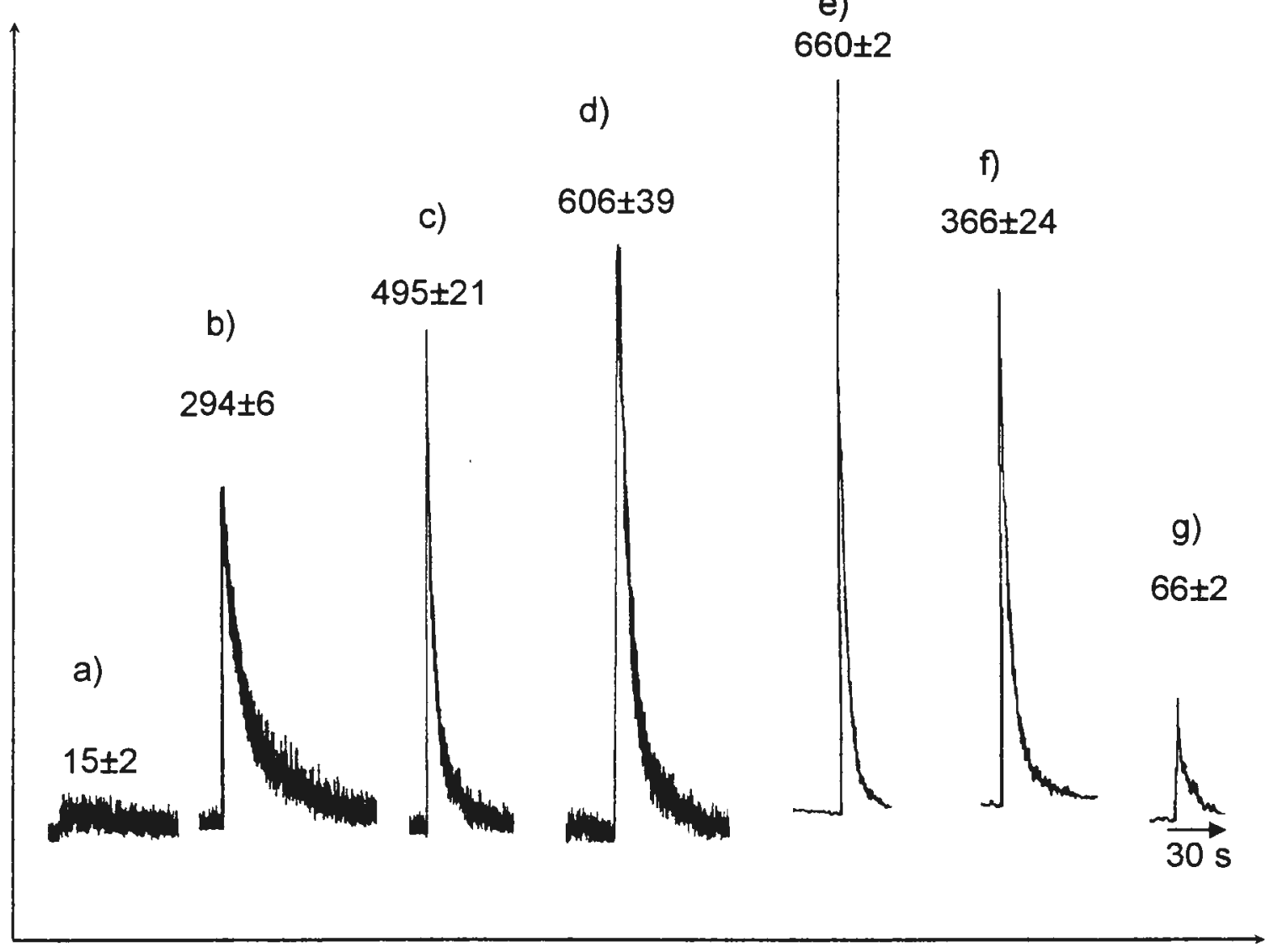

$t / s$

Figura 9 - Intensidade relativa da emissão da reação de 2-NPO e hidroperóxido de t-butila, em meio de fluoranteno e surfactante. Surfactantes:

a) Brij 35; b) Brij 76; c) TW 80; d) SDS; e) CTAC, f) DDAB e g) TDTAB.

$[2-N P O]=5,6 \times 10-5,[t-b O O H]=1,2 \times 10-3,[F A]=1,2 \times 10-4 \mathrm{~mol} \mathrm{~L}-1 . \%(v / v)$ águal acetonitrila $=75 / 25 \%$. 
a)

$(1,6 \pm 0,1) \times 104$

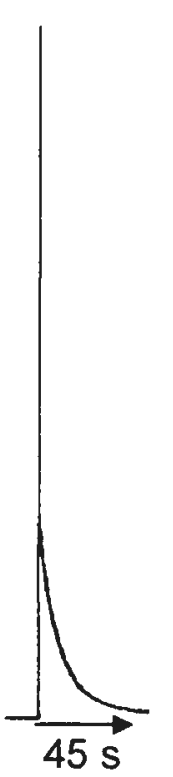

b)

$(7,5 \pm 0,7) \times 103$

c)

$(1,9 \pm 0,3) \times 103$

d)

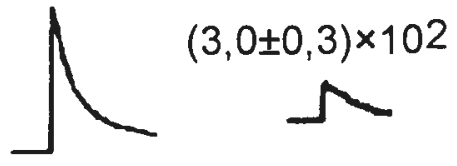

$t / s$

Figura 10 - Intensidade relativa da emissão da reação de TCPO e peróxido de hidrogênio, em meio de fluoranteno e surfactante. Surfactantes:

a) OTAC; b) CTAC; c) DDAB e d) TDTAB.

$[\mathrm{TCPO}]=5,6 \times 10-5,\left[\mathrm{H}_{2} \mathrm{O}_{2}\right]=1,2 \times 10-3,[\mathrm{FA}]=1,2 \times 10-4 \mathrm{~mol} \mathrm{~L}-1 . \%(\mathrm{v} / \mathrm{v})$ águal acetonitrila $=75 / 25 \%$. 
Tabela 4 - Efeito de surfactantes cationicos na reação QL de 2-NPO ou TCPO com peróxido de hidrogênio ou hidroperóxido de t-butila.

$[2-\mathrm{NPO}]=[\mathrm{TCPO}]=5,6 \times 10-5,\left[\mathrm{H}_{2} \mathrm{O}_{2}\right]=[\mathrm{t}-\mathrm{bOOH}]=1,2 \times 10-3,[\mathrm{FA}]=1,2 \times 10-4$ mol L-1. $\%(v / v)$ águal acetonitrila $=75 / 25 \%$, [surfactante]: 10 vezes c.m.c. do surfactante. n.d.: não detectado.

\begin{tabular}{|c|c|c|c|c|c|}
\hline \multirow{3}{*}{ Surfactante } & \multirow{3}{*}{ Peróxido } & \multicolumn{4}{|c|}{ Oxalato } \\
\hline & & \multicolumn{2}{|l|}{ 2-NPO } & \multicolumn{2}{|l|}{ TCPO } \\
\hline & & I & $t(s)$ & I & $t(s)$ \\
\hline \multirow[b]{2}{*}{ Nenhum } & $\mathrm{H}_{2} \mathrm{O}_{2}$ & $\mathrm{IR} 2=(3,5 \pm 0,3) \times 104$ & 30 & $\mathrm{IR} 4=(3,6 \pm 0,1) \times 102$ & 40 \\
\hline & $\left(\mathrm{CH}_{3}\right)_{3} \mathrm{COOH}$ & $\mathrm{IR} 3=(3,4 \pm 0,3) \times 102$ & 30 & n.d. & n.d. \\
\hline \multirow[b]{2}{*}{ TDTAB } & $\mathrm{H}_{2} \mathrm{O}_{2}$ & 0,51 I R2 & 30 & 1,3 IR4 & 45 \\
\hline & $\left(\mathrm{CH}_{3}\right)_{3} \mathrm{COOH}$ & 0,19 IR3 & 30 & 15 & 15 \\
\hline \multirow[b]{2}{*}{ DDAB } & $\mathrm{H}_{2} \mathrm{O}_{2}$ & 2,9 I R2 & 45 & 5,3 IR4 & 45 \\
\hline & $\left(\mathrm{CH}_{3}\right)_{3} \mathrm{COOH}$ & 1,1 I R3 & 40 & - & - \\
\hline \multirow[b]{2}{*}{ CTAC } & $\mathrm{H}_{2} \mathrm{O}_{2}$ & 4,0 I R2 & 60 & 20 IR4 & 45 \\
\hline & $\left(\mathrm{CH}_{3}\right)_{3} \mathrm{COOH}$ & 1,9 I R3 & 60 & - & - \\
\hline \multirow[b]{2}{*}{ OTAC } & $\mathrm{H}_{2} \mathrm{O}_{2}$ & 6,0 I R2 & 60 & 33 IR4 & 45 \\
\hline & $\sqrt{\left(\mathrm{CH}_{3}\right)_{3} \mathrm{COOH}}$ & - & - & 85 & 45 \\
\hline \multirow[b]{2}{*}{ DODAC } & $\mathrm{H}_{2} \mathrm{O}_{2}$ & 5,1 I R2 & 60 & 50 IR4 & 60 \\
\hline & $\sqrt{\left(\mathrm{CH}_{3}\right)_{3} \mathrm{COOH}}$ & - & - & 90 & 60 \\
\hline
\end{tabular}


Na figura 11 estão representados os resultados obtidos para a reação de 2-NPO ou TCPO com peróxido de hidrogênio ou hidroperóxido de t-butila na presença de imidazol.

A figura 12 apresenta o efeito de surfactantes catiônicos e $\beta$-ciclodextrina na reação de TCPO com hidroperóxido de t-butila na presença de imidazol. O efeito catalítico do imidazol na intensidade de emissão e tempo de emissão estão descritos na tabela 5. Somente DODAC e $\beta$-ciclodextrina causaram aumento na QL da reação de 2-NPO e TCPO, sendo que $\beta$-ciclodextrina produziu um aumento de intensidade mais significativo.

O uso de $\alpha$-, $\beta$ - e $\gamma$-ciclodextrinas foi sugerido por Koyo e colaboradores 77 para obter um aumento de sensibilidade no método analítico para determinação de ácido dansil na reação de TCPO com peróxido de hidrogênio gerada pela ação da enzima glucose oxidase na oxidação da glucose.

Woof e Grayeski76 observaram que os aumentos na intensidade de emissão foram causados pela combinação de variaçōes na eficiência do fluoróforo, eficiência na excitação e na velocidade de reação. Os autores sugeriram que a cavidade da ciclodextrina (figura 6 , página 35) poderia estar estabilizando o intermediário de hidroperóxido formado na reação. 


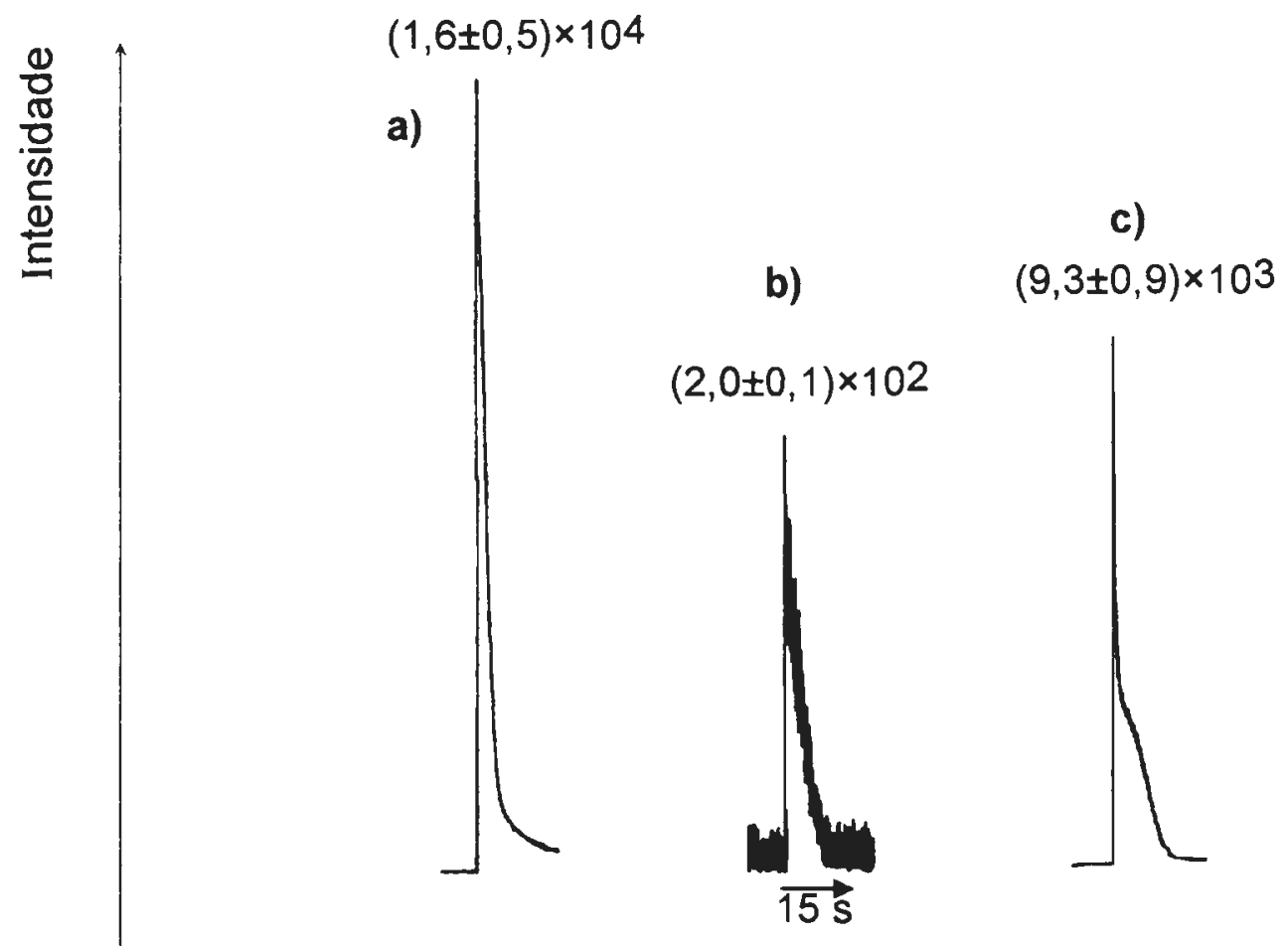

$t / s$

Figura 11 - Intensidade relativa da emissão da reação de: a) 2-NPO e peróxido de hidrogênio, b) TCPO e hidroperóxido de t-butila e c) TCPO e peróxido de hidrogênio, na presença de imidazol.

$[2-\mathrm{NPO}]=[\mathrm{TCPO}]=5,0 \times 10-5,\left[\mathrm{H}_{2} \mathrm{O}_{2}\right]=[\mathrm{t}-\mathrm{bOOH}]=1,1 \times 10-3,[\mathrm{IMI}]=1,1 \times 10-4$, $[F A]=1,1 \times 10-4 \mathrm{~mol} \mathrm{~L}-1 . \%(\mathrm{~V} / \mathrm{V})$ águal acetonitrila $=67 / 33 \%$. 


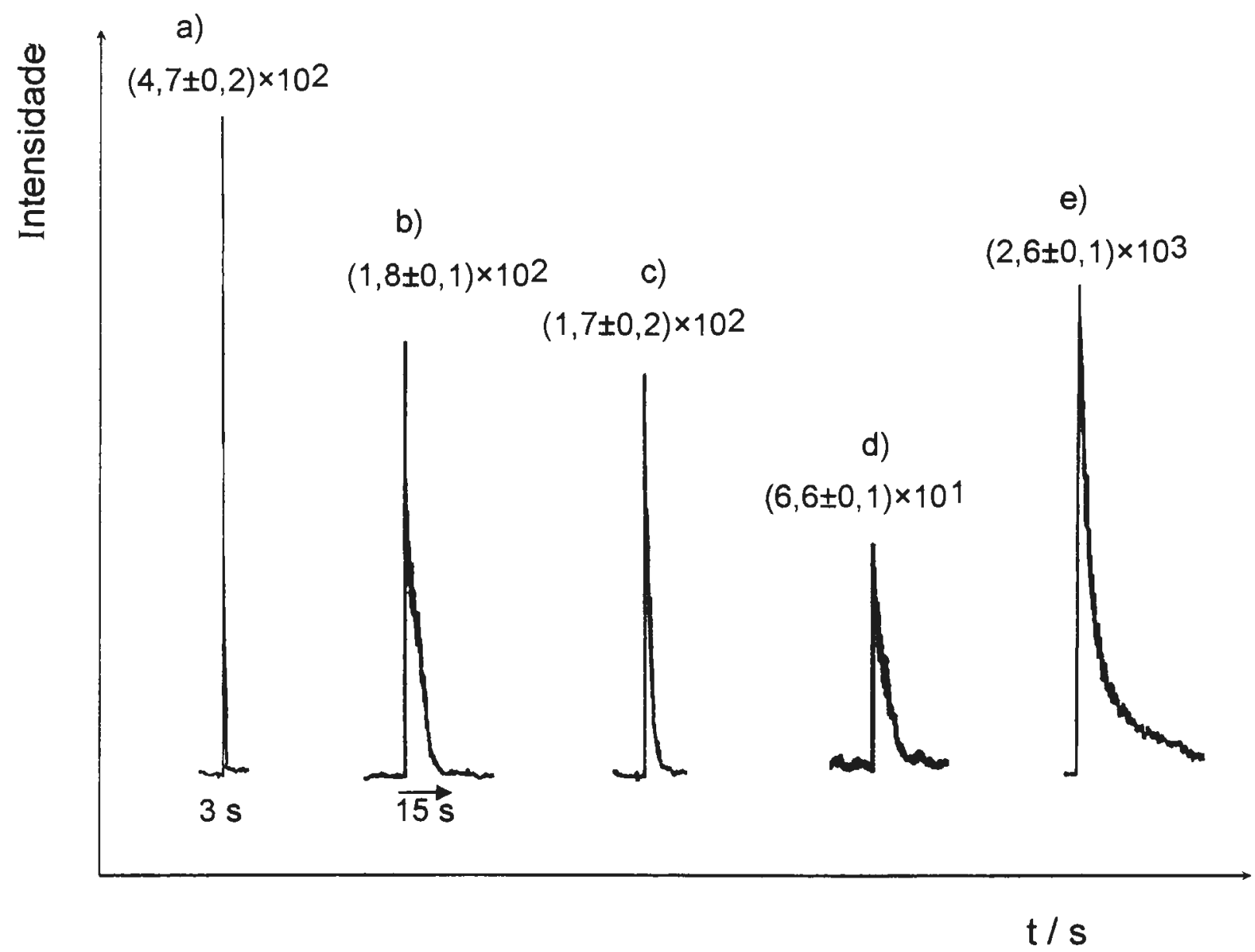

Figura 12 - Intensidade relativa da emissão da reação de TCPO e hidroperóxido de t-butila, na presença de imidazol, em meio de fluoranteno e surfactante. Surfactantes:

a) DODAC; b) CTAC, c) DDAB; d) TDTAB e d) $\beta$-ciclodextrina $[\mathrm{TCPO}]=5,0 \times 10-5,[\mathrm{t}-\mathrm{bOOH}]=1,1 \times 10-3,[\mathrm{IMI}]=1,1 \times 10-4,[\mathrm{FA}]=1,1 \times 10-4 \mathrm{~mol} \mathrm{~L}-1$. $\%(v / v)$ águal acetonitrila $=67 / 33 \%$. 
Tabela 5 - Efeito de surfactantes catiônicos na reação QL de TCPO com hidroperóxido de t-butila, na presença de imidazol.

$[\mathrm{TCPO}]=5,5 \times 10-5,[\mathrm{t}-\mathrm{bOOH}]=2,2 \times 10-4,[\mathrm{IMI}]=1,1 \times 10-3,[\mathrm{FA}]=5,0 \times 10-6 \mathrm{~mol} \mathrm{~L}-1$. $\%(v / v)$ água/acetonitrila $=67 / 33 \%$, [surfactante] $=10$ vezes a c.m.c.. n.d.: não detectado.

\begin{tabular}{|c|c|c|c|c|}
\cline { 2 - 5 } \multicolumn{1}{c|}{} & \multicolumn{3}{c|}{ Imidazol } \\
\cline { 2 - 5 } \multicolumn{1}{c|}{} & \multicolumn{2}{c|}{ Ausência } & \multicolumn{2}{c|}{ Presença } \\
\hline Surfactante & I & $t(s)$ & I \\
\hline Nenhum & n.d. & n.d. & $I_{\mathrm{R} 4}=(2,0 \pm 0,1) \times 102$ & 15 \\
\hline TDTAB & 15 & 3 & 0,32 I $_{\mathrm{R} 4}$ & 9 \\
\hline DDAB & - & - & 0,30 I R4 $_{\mathrm{R}}$ & 6 \\
\hline CTAC & - & - & 0,87 I $_{\mathrm{R} 4}$ & 15 \\
\hline OTAC & 85 & 30 & 0,6 I $_{\mathrm{R} 4}$ & 9 \\
\hline DODAC & 90 & 45 & 2,3 I $_{\mathrm{R} 4}$ & 3 \\
\hline$\beta$-ciclodextrina & 150 & 30 & 12,2 I $_{\mathrm{R} 4}$ & 60 \\
\hline
\end{tabular}




\section{II.3.2.4-Conclusões}

As reações quimiluminescentes de oxalato de bis(2,4,6-triclorofenila) (TCPO) ou oxalato de bis(2-nitrofenila) (2-NPO) com peróxido de hidrogênio ou hidroperóxido de t-butila utilizando o fluoróforo fluoranteno em sistemas micelares aquosos foram estudadas no modo estático, fazendo-se o acompanhamento da intensidade de emissão com o tempo. A reação produz quimiluminescência cuja intensidade depende da acidez, da natureza do tampão e da presença de imidazol.

A reação de 2-NPO ou TCPO com peróxido de hidrogênio produziu emissão maior do que com hidroperóxido de t-butila. Na presença ou ausência de surfactante, a reação de 2-NPO com os peróxidos é mais eficiente do que com TCPO, ou seja, a intensidade máxima para a reação com 2-NPO é relativamente maior. Entretanto, o aumento de emissão devido à presença de surfactante é maior na reação com TCPO (fator de aumento maior)

Os surfactantes CTAC, OTAC, DDAB, DODAC e $\beta$-ciclodextrina aumentaram a intensidade de emissão, influenciando também o tempo de reação. O tempo da reação com 2-NPO é mais fortemente influenciado pela presença de surfactante que a reação com TCPO. Foi observado que quanto maior a cadeia hidrocarbônica do surfactante, maior a intensidade de emissão. Há uma tendência de aumento do sinal analítico com a diminuição das concentrações micelares crítica dos surfactantes. 
III - Desenvolvimento de método analítico para determinação de cloro em água potável 


\section{III.1 - Objetivos}

A seguir serão descritas algumas considerações sobre as possiveis espécies presentes em solução após a cloração da água, que é submetida a tratamento e posteriormente usada no abastecimento de cidades.

Uma das preocupações em Química Analítica é o desenvolvimento de métodos que possibilitem a determinação das espécies: $\mathrm{ClO}^{-}, \mathrm{ClO}_{2}^{-}, \mathrm{ClO}_{3}^{-}$e cloroaminas, em uma única amostra.

No presente trabalho, foi desenvolvido um método para a determinação de cloro livre $\left(\mathrm{Cl}_{2}, \mathrm{HClO}\right.$ e $\left.\mathrm{ClO}^{-}\right)$em água de torneira. $\mathrm{O}$ método é baseado na detecção da intensidade de radiação emitida na reação de TCPO com cloro na presença de 9,10-difenilantraceno.

\section{III.2 - Cloração da áqua potável}

A cloração da água utilizada no abastecimento de cidades é realizada em estações de tratamento e visa principalmente destruir ou desativar microrganismos causadores de doenças, além de propiciar melhoria da qualidade da água potável pela reação de cloro com amônia, ferro, manganês, sulfeto e algumas substâncias 
orgânicas. Entretanto, a cloração também pode produzir efeitos adversos quando é realizada em águas que contém fenóis e outros compostos orgânicos, intensificando odor e o gosto e formando compostos clorados potencialmente carcinogênicos 88 .

O cloro é adicionado à água na forma molecular, e sofre desproporcionamento formando hipoclorito, ou é adicionado como hipoclorito.

No presente trabalho, cloro livre ou simplesmente cloro é a denominação dada à mistura das espécies de cloro aquoso $\left(\mathrm{Cl}_{2}\right)$, ácido hipocloroso $(\mathrm{HClO})$ e hipoclorito $\left(\mathrm{ClO}^{-}\right)$. A proporção relativa destas formas de cloro livre depende da acidez e da temperatura. No $\mathrm{pH}$ da maioria das águas potáveis $(\mathrm{pH} \approx 6,0)$, 0 ácido hipocloroso $\left(\mathrm{pK}_{\mathrm{a}}=7,40\right)(89)$ é a forma predominante de cloro livre88. A decomposição de hipoclorito pode levar a formação de clorito e clorato (equações 18 e 19), que podem causar danos à saúde.

O cloro reage com a amônia e certos compostos nitrogenados para formar o "cloro combinado". Cloro reage com amônia formando cloraminas: monocloramina (equação 11), dicloramina (equação 12), e tricloroamina ou tricloreto de nitrogênio (equação 13) 90 . Cloro e cloro combinado podem estar presentes simultaneamente e a concentração dessas formas combinadas depende principalmente da acidez, temperatura, proporção relativa inicial de cloro e do composto nitrogenado, e tempo de reação.

$$
\mathrm{HOCl}+\mathrm{NH}_{3} \longrightarrow \mathrm{NH}_{2} \mathrm{Cl}+\mathrm{H}_{2} \mathrm{O}
$$




$$
\begin{aligned}
& \mathrm{HOCl}+\mathrm{NH}_{2} \mathrm{Cl} \rightarrow \mathrm{NHCl}_{2}+\mathrm{H}_{2} \mathrm{O} \\
& \mathrm{HOCl}+\mathrm{NHCl}_{2} \rightarrow \mathrm{NCl}_{3}+\mathrm{H}_{2} \mathrm{O}
\end{aligned}
$$

O cloro pode ser adicionado à água, em estações de tratamento, como cloro livre ou como um desinfetante "cloroaminado". No processo de tratamento de água, geralmente, o cloro é adicionado até que uma concentração de cloro residual seja mensurável, indicando que um nível de desinfecção foi alcançado. Em processos de tratamentos de água, baseados em compostos cloroaminados, a amônia é introduzida previamente, seguida da adição de cloro para que ocorra a formação da monocloroamina que, então, age como desinfetante 88 . Entretanto, como $\circ$ cloro pode reagir com materiais orgânicos presentes na água e formar trihalometanos, que apresentam risco à saúde humana, tem havido um certo interesse na utilização de dióxido de cloro $\left(\mathrm{ClO}_{2}\right)$ como agente de desinfecção no tratamento de água potável. Dióxido de cloro pode sofrer desproporcionamento ou uma série de reações com cloro (quando ambos são utilizados), e formar clorito, clorato e hipoclorito, principamente 91 .

Portanto, é essencial que procedimentos apropriados para a determinação destes compostos, em diferentes niveis de concentração em uma mesma solução sejam desenvolvidos. Dessa forma, a determinação analítica poderia levar a um procedimento que permita que a cloração seja efetuada de maneira a cumprir o seu propósito, minimizando também os efeitos adversos 88 . 


\section{IIl.3 - Equilíbrios envolvidos na decomposicão do íon hipoclorito}

A reação de desproporcionamento do cloro é termodinamicamente favorável em meio básico. O equilibrio químico pode ser escrito como 92 :

$\mathrm{Cl}_{2(\mathrm{aq})}+2 \mathrm{OH}_{(\mathrm{aq})} \rightleftharpoons \mathrm{ClO}_{(\mathrm{aq})}^{-}+\mathrm{Cl}_{(\mathrm{aq})}^{-}+\mathrm{H}_{2} \mathrm{O}_{(\mathrm{I})} \quad \mathrm{K}=7,5 \times 10^{15}(14)$

Em solução ácida, a reação de desproporcionamento é muito menos favorável92.

$\mathrm{Cl}_{2(\mathrm{aq})}+\mathrm{H}_{2} \mathrm{O}_{(\mathrm{l})} \rightleftharpoons \mathrm{HClO}_{(\mathrm{aq})}+\mathrm{H}^{+}(\mathrm{aq})+\mathrm{Cl}^{-}(\mathrm{aq}) \quad \mathrm{K}=3,9 \times 10^{-4}$

O mecanismo desta reação (equação 15) de desproporcionamento envolve o ataque da molécula de $\mathrm{H}_{2} \mathrm{O}$ ao $\mathrm{Cl}_{2}{ }^{92}$ :

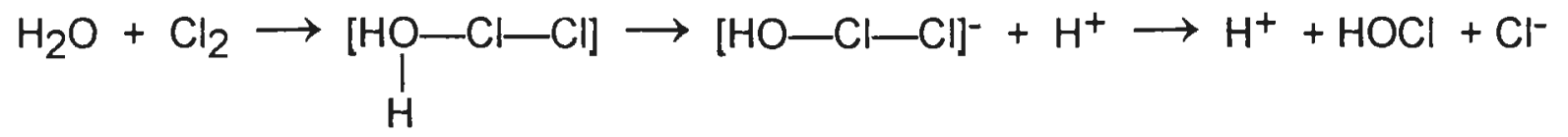

Uma importante conclusão obtida a partir deste mecanismo é que apesar da reação ser formalmente denominada como reação redox (devido à variação do número de oxidação do cloro), pode ser mecanisticamente considerada uma reação nucleofílica92. 
Estudos da cinética e mecanismo da decomposição do hipoclorito, em meios de diferentes faixas de $\mathrm{pH}$, foram realizados por Lister 93 , Yokoyama e colaboradores $^{94}$ e Adam e colaboradores 89,95 , que permitiram estabelecer a seguinte estequiometria para a reação:

$3 \mathrm{ClO}^{-} \rightarrow \mathrm{ClO}_{3}^{-}+2 \mathrm{Cl}^{-} \quad \mathrm{K}=1,5 \times 10^{27(90)}$ quando $\left[\mathrm{ClO}^{-}\right]>\left[\mathrm{H}^{+}\right]$

Adam e colaboradores 89 sugeriram que na decomposição do hipoclorito ocorre transferência de oxigênio entre duas moléculas de hipoclorito para formação do ion clorito $\left(\mathrm{ClO}_{2}^{-}\right)$(equação 18) que, então, reage rapidamente com excesso de hipoclorito produzindo o ion clorato $\left(\mathrm{ClO}_{3}^{-}\right)$(equação 19).

$$
\begin{aligned}
& \mathrm{ClO}^{-}+\mathrm{ClO}^{-} \longrightarrow \mathrm{ClO}_{2}^{-}+\mathrm{Cl}^{-} \\
& \mathrm{ClO}^{-}+\mathrm{ClO}_{2}^{-} \rightarrow \mathrm{ClO}_{3}^{-}+\mathrm{Cl}^{-} \quad \text { (rápida) }
\end{aligned}
$$

Como a reação de consumo de clorito (equação 19) é mais rápida que a reação de formação (equação 18), a concentração de clorito se mantém relativamente baixa. Os ions clorito são formados a niveis apreciáveis somente em meio de pH acima de 10. Em uma solução de $\mathrm{HClO} 0,0233 \mathrm{~mol} \mathrm{~L}^{-1}$ de $\mathrm{pH}$ inicial 7,1, após decomposição parcial de até $35 \%$ de hipoclorito, não foi detectada a presença de íons clorito 95. 
A velocidade de decomposição da solução de hipoclorito é mínima quando o pH está entre 11 e 14, atinge o máximo quando o pH é 6,89 e diminui significantemente em meio de $\mathrm{pH}$ menores ${ }^{89}$. Dependendo da acidez do meio, há maior contribuição da espécie $\mathrm{HClO}(\mathrm{pH}<7,40)$ ou $\mathrm{ClO}^{-}(\mathrm{pH}>7,40)$ (equação 20).

$$
\mathrm{HClO} \rightleftharpoons \mathrm{H}^{+}+\mathrm{ClO}^{-} \quad \mathrm{pK}_{\mathrm{a}}=7,40(89)
$$

Adam e Gordon95 observaram variaçōes na velocidade inicial de decomposição de $\mathrm{HClO}$, quando o estudo foi realizado em meio de solução tampão, e atribuíram as variações na velocidade inicial ao efeito da força iônica, causada pela alta concentração do tampão presente, e também à interação do tampão com as espécies envolvidas.

Uma reação paralela em soluções puras de hipoclorito é a decomposição levando à formação de oxigênio (equação 21) 95-97.

$$
\mathrm{ClO}^{-}+\mathrm{ClO}^{-} \longrightarrow \mathrm{O}_{2}+2 \mathrm{Cl}^{-} \quad \text { (muito lenta) }
$$

A reação de formação de oxigênio é catalisada por impurezas de metais de transição como $\mathrm{Ni}(\mathrm{II}), \mathrm{Mn}(\mathrm{II})$ e $\mathrm{Fe}(\mathrm{III})$. As velocidades de reação são afetadas não somente pela temperatura, mas também pela força iônica e a presença e intensidade de radiação UV95-96. 


\section{IIl.4 - Alguns métodos para determinacão de cloro}

Alguns procedimentos para análise de cloro em águas naturais, tratadas e de efluentes (esgoto) estão descritos no "Standard Methods 88 ": 1) método iodométrico, 2) titulação amperométrica e 3) titulação com DPD ( $N, N$-dietil-p-fenilenediamina).

O método oficial para a determinação da concentração de cloro residual, como cloro livre $\left(\mathrm{Cl}_{2}, \mathrm{HClO}\right.$ e $\left.\mathrm{ClO}^{-}\right)$e combinado (cloraminas, $\mathrm{ClO}_{2}$ ) recomendado pela American Public Health Association, é um procedimento em que $\mathrm{N}, \mathrm{N}$-dietil-pfenilenodiamina (DPD) é utilizado como indicador de um procedimento titrimétrico com sulfato ferroso amoniacal. O método é baseado na formação do complexo de ferro- $N, N$-dietil-p-fenilenodiamina, cujo limite de detecção para cloro é de $50 \mu g \mathrm{~L}^{-1(98)}$.

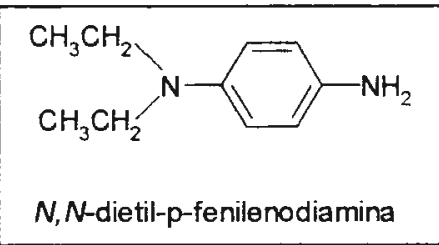

No método DPD, existe um procedimento para estimar a concentração de frações de mono-, dicloraminas e cloro combinado. Quando altas concentrações de monocloramina e manganês estão presentes, a interferência causada na determinação de cloro pode ser evitada adicionando-se tioacetamida. Muitos agentes oxidantes como: bromo, iodo, dióxido de cloro, peróxido de hidrogênio e permanganato interferem. A determinação da concentração de cloro total pelo método DPD é bastante utilizada por ser realizada em condições de $\mathrm{pH} \cong 7(98)$.

O método iodométrico é adequado para determinação de cloro total maior que $1 \mathrm{mg} \mathrm{L} \mathrm{L}^{-1}$. A titulação em meio neutro minimiza o efeito interferente de ions $\mathrm{Fe}(\mathrm{III}) \mathrm{e}$ também de íons nitrito, porém a titulação em meio ácido é preferivel porque algumas formas de cloro combinado não reagem em meio de $\mathrm{pH}=7^{(88)}$. 
A titulação amperométrica permite determinações de cloro total a níveis de $0,2 \mathrm{mg} \mathrm{L}^{-1}$ e é pouco afetada por agentes oxidantes comuns, temperatura, turbidez e cor, porém perdas de cloro podem ocorrer se uma agitação rápida for realizada durante a análise 88 .

Vários métodos espectrofotométricos $99-106$, potenciométricos ${ }^{107-108}$, amperométricos $^{109}$ e cromatográficos $110-112$ foram desenvolvidos para determinação de cloro em amostras aquosas.

Os métodos espectrofotométricos mais utilizados são baseados nas reações de oxidação de aminas aromáticas, como o-toluidina99-101, DPD102-104, tiocetona105 e 4-nitrofenilhidrazina106, que levam à formação de compostos coloridos. Apesar da alta reatividade desses reagentes ao cloro, os principais problemas analiticos são: a instabilidade dos produtos coloridos, o que acarreta em um rápido descoramento, a necessidade de controle rigoroso das condições experimentais, e a dificuldade em estabelecer procedimentos para diferenciar cloro livre de suas formas combinadas.

Ponomarenko, em 1955, foi um dos primeiros autores a sugerir a determinação de hipoclorito através de técnica de detecção da quimiluminescência113. Babko e colaboradores investigaram e indicaram a possibilidade de usar a técnica para determinação de cloro em água potável. Nesta época, a detecção foi feita fotograficamente e a sensibilidade foi de $0,5 \mu \mathrm{g}$ de hipoclorito 113

A reação $\mathrm{QL}$ entre luminol e hipoclorito na presença de peróxido de hidrogênio foi investigada por Isaccson e Wettermark 113,114 e Marino e Ingle 115 
quando foi relatado limite de detecção para hipoclorito de $16 \mu \mathrm{g} \mathrm{L}^{-1}$. Seitz ${ }^{116}$ verificou que mesmo na ausência de peróxido de hidrogênio, hipoclorito reage com luminol e produz emissão de radiação, com limite de detecção de $0,5 \mu \mathrm{g} \mathrm{L}^{-1}$. Marino e Ingle 117 otimizaram as condições de reação de luminol para determinação de hipoclorito na ausência de peróxido de hidrogênio, e também realizaram estudo de interferências de mais de 60 espécies, obtendo limite de detecção de hipoclorito de $0,2 \mu \mathrm{g} \mathrm{L}^{-1}$. Gord e colaboradores 118 desenvolveram método para determinação de cloro livre, através da medição de quimiluminescência da reação de hipoclorito com a lofina por FIA, e o limite de detecção foi de $75 \mu \mathrm{g} \mathrm{L}-1$ como $\mathrm{Cl}_{2}$.

Um método baseado na reação QL de luminol e cloro, em meio óleo-água, foi proposto por Yamada e colaboradores ${ }^{119}$. A curva analítica foi obtida na faixa de $10^{-7}-10^{-4} \mathrm{~mol} \mathrm{~L} \mathrm{~L}^{-1}$. Os autores sugeriram a formação "in situ" do oxidante hipoclorito de 2-propila.

Yamada e colaboradores 120 e Nakagama e colaboradores ${ }^{121}$ publicaram trabalhos para determinação de cloro livre através da reação com corantes xanteno, tais como: eosina $\mathrm{Y}$, eosina $\mathrm{B}$, pironina $\mathrm{B}$ e rodamina $6 G$ (estrutura ao lado). A maior vantagem do sistema é não apresentar sensibilidade a cloraminas e compostos oxoclorados.

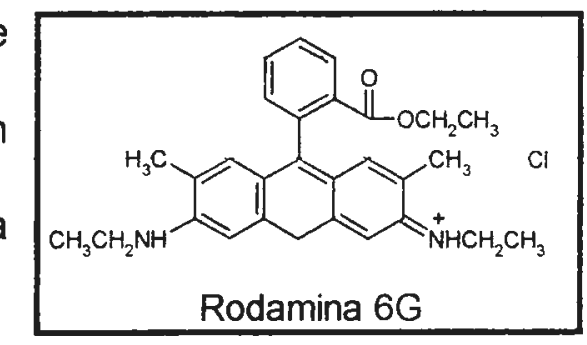

Nakagama e colaboradores 121 estudaram a reação da rodamina $6 G$ com cloro para determinação de cloro na faixa de $10^{-7}-10^{-5}$ mol L-1. Baseados em alguns resultados experimentais, Irons e Greenway 122 propuseram um mecanismo sugerindo que o ácido hipocloroso é o responsável pela oxidação do grupo éster da 
rodamina $6 G$ a um peroxiácido, que se decompõe formando oxigênio singlete que sensibiliza o fluoróforo.

Alguns dos principais métodos para a determinação de cloro estão listados na Tabela 6.

III.5 - Desenvolvimento de método analítico baseado na reação de TCPO com cloro

A reação QL de oxalato de bis-(2,4,6,triclorofenila) (TCPO) com peróxido de hidrogênio tem sido amplamente usada para detecção de diferentes flororóforos em niveis de fentomol e de peróxido de hidrogênio. A maioria das aplicações analíticas desse sistema se refere a métodos indiretos para determinação de espécies, por exemplo, pela ação de enzimas que produzem peróxido de hidrogênio na presença de um substrato apropriado46,47. Ao contrário de reações QL como aquelas envolvendo luminol, lucigenina e ésteres de acridínio, as reações com TCPO são realizadas em pH neutro. A intensidade de emissão é afetada pelas condições experimentais incluindo solvente, conteúdo de água, acidez, concentrações dos reagentes e natureza de catalisadores. Entre estes, a acidez do meio parece ter um efeito significantivo na mistura de água/solvente orgânico46,47. A seleção das condições experimentais deve ser feita de maneira que a medição do sinal analítico não seja tão fortemente influenciada pelo sinal de fundo e por variação da cinética da reação. 
Tabela 6 - Alguns métodos para determinação de cloro e seus respectivos limites de deteç̧ão e interferências

\begin{tabular}{|c|c|c|c|}
\hline Método & $\begin{array}{c}\text { L.D } \\
\left(\mu g \mathrm{~L}^{-1}\right)\end{array}$ & Interferências & Referência \\
\hline Titulação iodométrica & 40 & $\mathrm{Fe}^{2+}, \mathrm{Mn}^{2+}, \mathrm{NO}_{2}$ & 88 \\
\hline Titulação amperométrica & 25 & $\begin{array}{c}\mathrm{Ag}^{+}, \mathrm{NH}_{2} \mathrm{Cl}, \mathrm{NHCl}_{2}, \mathrm{NCl}_{3}, \\
\mathrm{ClO}_{2}\end{array}$ & 88 \\
\hline $\begin{array}{c}\text { Titulação com DPD e } \\
\mathrm{Fe}^{2+}\end{array}$ & 50 & $\mathrm{Cu}^{2+}, \mathrm{NH}_{2} \mathrm{Cl}, \mathrm{MnO}_{4}^{-}$ & 88 \\
\hline Colorimétrico com DPD & 50 & $\mathrm{Cu}^{2+}, \mathrm{NH}_{2} \mathrm{Cl}, \mathrm{MnO}_{4}^{-}$ & 88 \\
\hline $\begin{array}{c}\text { Colorimétrico com } \\
\text { o-toluidina }\end{array}$ & 10 & $\mathrm{Br}_{2}, \mathrm{I}_{2}, \mathrm{NH}_{2} \mathrm{Cl}, \mathrm{ClO}_{2}, \mathrm{MnO}_{4}^{-}$ & 88 \\
\hline $\begin{array}{l}\text { Colorimétrico com } \\
\text { o-toluidina-arsenito }\end{array}$ & 10 & $\mathrm{Br}_{2}, \mathrm{I}_{2}, \mathrm{ClO}_{2}, \mathrm{MnO}_{4}^{-}$ & 88 \\
\hline $\begin{array}{l}\text { Luminol - na presença } \\
\qquad \text { de } \mathrm{H}_{2} \mathrm{O}_{2}\end{array}$ & 4 & $\mathrm{Fe}^{3+}, \mathrm{Co}^{2+}, \mathrm{I}^{-}$ & 115 \\
\hline $\begin{array}{c}\text { Luminol - na ausência de } \\
\qquad \mathrm{H}_{2} \mathrm{O}_{2}\end{array}$ & 0,2 & $\begin{array}{c}\mathrm{Fe}^{3+}, \mathrm{Fe}^{2+}, \mathrm{NHCl}_{2}, \mathrm{ClO}_{2} \\
\mathrm{MnO}_{4}^{-}, \mathrm{Ca}^{2+}, \mathrm{Mg}^{2+}\end{array}$ & 117 \\
\hline Lofina & 75 & - & 118 \\
\hline Rodamina $6 \mathrm{G}$ & 90 & - & 122 \\
\hline $\begin{array}{l}\text { QL, TCPO/CIO- } \\
\text { Presente método }\end{array}$ & 52 & $\mathrm{NH}_{2} \mathrm{Cl}, \mathrm{ClO}_{2}^{-}$ & 123 \\
\hline
\end{tabular}

L.D.: limite de detecção 
No presente trabalho, pela primeira vez está descrito o uso de cloro livre como oxidante de TCPO. O objetivo foi investigar a reação QL de TCPO com cloro livre na presença de um fluoróforo e desenvolver um método analítico alternativo, por análise por injeção em fluxo (FIA), para a determinação de cloro livre em água da torneira.

\section{III.5.1- Parte Experimental}

\section{III.5.1.a - Reagentes}

\section{III.5.1.a.1 - Soluções estoque}

- Solução de TCPO (Nakalai Chemicals Ltd) $(5,0 \times 10-4 \mathrm{~mol} \mathrm{L-1})$ : $11 \mathrm{mg}$ de TCPO foram dissolvidos em $50,0 \mathrm{~mL}$ de acetonitrila. A solução foi mantida em banho de ultrassom, para completa solubilização. A solução foi preparada diariamente.

- Solução de 9,10-difenilantraceno (DFA) (Nakalai Chemicals Ltd) $(1,0 \times 10-3$ mol L-1): $17 \mathrm{mg}$ de DFA foram dissolvidos em 50,0 mL de acetonitrila. A solução foi mantida em banho de ultrassom, para completa solubilização. 
- Solução de antraceno (Nakalai Chemicals Ltd) (1,0×10-3 mol L-1): 9 mg de antraceno foram dissolvidos em $50,0 \mathrm{~mL}$ de acetonitrila.

- Solução de pireno (Nakalai Chemicals Ltd) (1,0×10-3 mol L-1): $10 \mathrm{mg}$ de pireno foram dissolvidos em $50,0 \mathrm{~mL}$ de acetonitrila.

- Solução de fenantreno (Nakalai Chemicals Ltd) $(1,0 \times 10-3 \mathrm{~mol} \mathrm{L-1}$ ): $9 \mathrm{mg}$ de fenantreno foram dissolvidos em $50,0 \mathrm{~mL}$ de acetonitrila.

- Solução de fluoranteno (Tokyo Kasei Kogyo) (1,0×10-3 mol L-1): $10 \mathrm{mg}$ de fluoranteno foram dissolvidos em $50,0 \mathrm{~mL}$ de acetonitrila.

- Solução de 9-nitroantraceno (Tokyo Kasei Kogyo) (1,0×10-3 mol L-1): 11 mg de 9-nitroantraceno foram dissolvidos em $50,0 \mathrm{~mL}$ de acetonitrila.

- Solução de 2-aminoantraceno (Nakalai Chemicals Ltd) (1,0×10-3 mol L-1): 9 mg de DFA foram dissolvidos em 50,0 mL de acetonitrila.

- Solução de antraquinona (Tokyo Kasei Kogyo) (1,0×10-3 mol L-1): 10 mg de antraquinona foram dissolvidos em $50,0 \mathrm{~mL}$ de acetonitrila.

- Solução de $\mathrm{NaClO}(1,0 \times 10-2 \mathrm{~mol} \mathrm{L-1):} 48 \mu \mathrm{L}$ de solução de $\mathrm{NaClO} 8-13 \%$ (Nakarai Teske) foram dissolvidos em balão de $25,0 \mathrm{~mL}$ com água desionizada. Imediatamente antes da análise, a partir da solução estoque 1,0×10-2 mol L-1 foram preparadas as soluções diluídas de hipoclorito. $O$ acerto da acidez da solução diluida de hipoclorito a $\mathrm{pH}=6,0-7,0$ foi feito com a adição de $\mathrm{HCl}$ 1,0 mol $\mathrm{L}^{-1}$ (Nakalai Teske). As soluções diluídas de hipoclorito foram utilizadas por no máximo 3 horas após a preparação. A solução estoque de hipoclorito foi padronizada pelo método iodométrico ${ }^{123}$. 
- Solução de $\mathrm{NH}_{4} \mathrm{Cl}$ (Kanto Chemical Co) 1,0×10-2 mol L-1: $27 \mathrm{mg}$ de cloreto de amônio foram dissolvidos em balão de 50,0 mL com água desionizada. Solução diluída foi preparada a partir da solução estoque de $\mathrm{NH}_{4} \mathrm{Cl} 1,0 \times 10^{-2}$ mol L-1.

As soluções estoque $\left(1,0 \times 10^{-3} \mathrm{~mol} \mathrm{~L}^{-1}\right)$ dos íons metálicos foram preparadas em solução acidificada com $\mathrm{HCl}$ para evitar a hidrólise. Nos balões volumétricos de $50,0 \mathrm{~mL}$ foram adicionados $5 \mu \mathrm{L}$ de $\mathrm{HCl}$ concentrado, a massa do sal foi adicionada e o volume foi acertado com água desionizada.

- Solução de $\mathrm{CoCl}_{2}$ (Kanto Chemicals Co) $\left(1,0 \times 10^{-3}\right.$ mol L-1): $12 \mathrm{mg}$ de $\mathrm{CoCl}_{2} \cdot 6 \mathrm{H}_{2} \mathrm{O}$ foram dissolvidos com água em balão de $50,0 \mathrm{~mL}$.

- Solução de $\mathrm{CuSO}_{4}$ (Kanto Chemicals Co) $\left(1,0 \times 10^{-3} \mathrm{~mol} \mathrm{~L}-1\right)$ : $14 \mathrm{mg}$ de $\mathrm{CuSO}_{4} .7 \mathrm{H}_{2} \mathrm{O}$ foram dissolvidos com água em balão de $50,0 \mathrm{~mL}$.

- Solução de $\mathrm{Fe}_{2}\left(\mathrm{SO}_{4}\right)_{3}$ (Kanto Chemicals $\left.\mathrm{Co}\right)\left(1,0 \times 10^{-3} \mathrm{~mol} \mathrm{~L}-1\right)$ : $29 \mathrm{mg}$ de $\mathrm{Fe}_{2}\left(\mathrm{SO}_{4}\right)_{3} \cdot \mathrm{n} \mathrm{H}_{2} \mathrm{O}$ foram dissolvidos com água em balão de $50,0 \mathrm{~mL}$.

- Solução de $\mathrm{MnSO}_{4}$ (Kanto Chemicals Co) $\left(1,0 \times 10^{-3} \mathrm{~mol} \mathrm{~L}-1\right)$ : $8 \mathrm{mg}$ de $\mathrm{MnSO}_{4} .4 \sim 5 \mathrm{H}_{2} \mathrm{O}$ foram dissolvidos com água em balão de $50,0 \mathrm{~mL}$.

As soluções diluídas $\left(1,0 \times 10^{-6}-1,0 \times 10^{-4} \mathrm{~mol} \mathrm{~L}^{-1}\right)$ dos ions metálicos de $\mathrm{Co}(\mathrm{II}), \mathrm{Cu}(\mathrm{II}), \mathrm{Fe}(\mathrm{III})$ e $\mathrm{Mn}(\mathrm{II})$ foram preparadas imediatamente antes de efetuar a análise. 
- Soluções $\mathrm{NaNO}_{3}$ (Nakalai Tesque) $\left(1,0 \times 10^{-3} \mathrm{~mol} \mathrm{~L}^{-1}\right): 8 \mathrm{mg}$ do sal de nitrato de sódio foram dissolvidos com água desionizada em balão de 50,0 mL.

- Soluções $\mathrm{NaSO}_{4}$ (Kanto Chemicals Co) $\left(1,0 \times 10^{-3} \mathrm{~mol} \mathrm{~L}-1\right): 14 \mathrm{mg}$ do sal de sulfato de sódio foram dissolvidos com água em balão de 50,0 mL.

- Soluções $\mathrm{NaCl}$ (Kanto Chemicals Co) $\left(1,0 \times 10^{-3} \mathrm{~mol} \mathrm{~L}^{-1}\right): 6 \mathrm{mg}$ do sal de cloreto de sódio foram dissolvidos com água em balão de $50,0 \mathrm{~mL}$.

- Soluções $\mathrm{NaHCO}_{3}$ (Kanto Chemicals Co) $\left(1,0 \times 10^{-3} \mathrm{~mol} \mathrm{~L}^{-1}\right): 11 \mathrm{mg}$ do sal de bicarbonato de sódio foram dissolvidos com água em balão de 50,0 mL.

- Soluções $\mathrm{Na}_{2} \mathrm{HPO}_{4}$ (Kanto Chemicals Co) $\left(1,0 \times 10^{-3} \mathrm{~mol} \mathrm{~L}-1\right)$ : $14 \mathrm{mg}$ do sal de hidrogeno fosfato de sódio foram dissolvidos com água em balão de 50,0 $\mathrm{mL}$.

- Solução de $\mathrm{NaClO}_{2}$ (Nakalai Teske) 1,0×10-2 mol L-1: $56 \mathrm{mg}$ de clorito de sódio $80 \%$ foram dissolvidos com água em balão de $50,0 \mathrm{~mL}$. As soluções diluidas tiveram o pH reduzido a 6,5 com a adição de $\mathrm{HCl}$ 1,0 mol L-1.

- Solução de $\mathrm{NaClO}_{3}$ (Nakalai Teske) $1,0 \times 10^{-3} \mathrm{~mol} \mathrm{~L}^{-1}$ (Nakalai Teske): $53 \mathrm{mg}$ de clorato de sódio foram dissolvidos com água em balão de 50,0 mL.

- Solução de $\mathrm{NaClO}_{4}$ (Nakalai Teske) $1,0 \times 10^{-3}$ mol L-1 (Nakalai Teske): $7 \mathrm{mg}$ de perclorato de sódio foram dissolvidos com água em balão de 50,0 mL.

Foi utilizado um pHmetro Methrohm model 713 equipado com eletrodo combinado de vidro (contendo solução saturada de $\mathrm{NaCl}$ ) para medições de pH. 


\section{III.5.1.a.2 - Padronizacão da solucão estoque de hipoclorito de sódio 124}

$15 \mathrm{~mL}$ da solução de hipociorito de sódio $8-13 \%$ foram diluídos com água desionizada em balão volumétrico de $100,0 \mathrm{~mL}$.

Em um erlenmeyer de $125 \mathrm{~mL}$, foi adicionada uma alíquota de $5,0 \mathrm{~mL}$ da solução de hipociorito de sódio, $2,0 \mathrm{~g}$ de $\mathrm{KI}$ sólido, $10 \mathrm{~mL}$ de ácido acético glacial e $25 \mathrm{~mL}$ de água desionizada.

A amostra foi titulada com solução de $\mathrm{S}_{2} \mathrm{O}_{3}{ }^{2-} 0,1060$ mol L-1 previamente padronizada com $\mathrm{KlO}_{3}$ (método iodométrico). Próximo à viragem, foram adicionados 2,0 mL de solução indicadora de amido. A titulação foi feita em duplicata e o volume médio gasto foi de $14,80 \mathrm{~mL}$ de $\mathrm{S}_{2} \mathrm{O}_{3}{ }^{2-}$.

Com base nas equações 22 e 23, a concentração calculada para a solução estoque de hipoclorito de sódio foi de 1,002 $\mathrm{mol} \mathrm{L}^{-1}$.

$$
\begin{aligned}
& \mathrm{ClO}^{-}+2 \mathrm{I}^{-}+2 \mathrm{H}^{+} \rightleftharpoons \mathrm{Cl}^{-}+\mathrm{I}_{2}+\mathrm{H}_{2} \mathrm{O} \\
& 2 \mathrm{~S}_{2} \mathrm{O}_{3}{ }^{2-}+\mathrm{I}_{2} \rightleftharpoons \mathrm{S}_{4} \mathrm{O}_{6}{ }^{2-}+2 \mathrm{I}^{-}
\end{aligned}
$$

III.5.1.a.3 - Determinação de cloro em amostra de áqua de torneira, através de método titrimétrico com DPD 88 
- Solução de $\mathrm{Fe}^{2+}\left(2,82 \times 10^{-3} \mathrm{~mol} \mathrm{~L}^{-1}\right): 0,2773 \mathrm{~g}$ de sulfato de ferro amoniacal $\left(\mathrm{Fe}\left(\mathrm{NH}_{4}\right)_{2}\left(\mathrm{SO}_{4}\right)_{2} \cdot 6 \mathrm{H}_{2} \mathrm{O}\right)$ foram dissolvidos com água em balão de $250,0 \mathrm{~mL}$ contendo $0,6 \mathrm{~mL}$ de ácido sulfúrico concentrado. $\mathrm{O}$ pH da solução final foi de 1,4 .

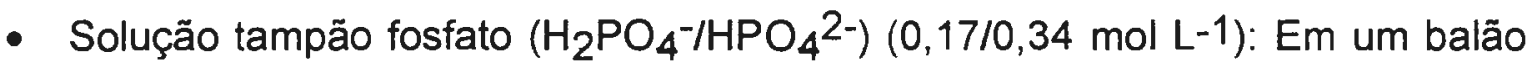
de $250,0 \mathrm{~mL}$, foram adicionados $11,5 \mathrm{~g}$ de $\mathrm{KH}_{2} \mathrm{PO}_{4}$ e $15,0 \mathrm{~g}$ de $\mathrm{Na}_{2} \mathrm{HPO}_{4}$ (Kanto Chemical Co) e o volume do balão foi acertado com água. As concentrações no tampão foram: $\left[\mathrm{H}_{2} \mathrm{PO}_{4}^{-}\right]=0,17 \mathrm{~mol} \mathrm{L-1}$ e $\left[\mathrm{HPO}_{4}{ }^{2-}\right]=0,34$ mol L-1.

- Solução indicadora DPD: $0,11 \mathrm{~g}$ de $N, N$-dietil-p-fenilenediamina, $0,02 \mathrm{~g}$ do sal dissódico de EDTA dihidratado e $0,8 \mathrm{~mL}$ de ácido sulfúrico concentrado foram adicionados a balão de $100,0 \mathrm{~mL}$ e o volume foi acertado com água desionizada.

Em um erlenmeyer de $500 \mathrm{~mL}$ foram adicionados $5,0 \mathrm{~mL}$ de solução tampão fosfato, $5,0 \mathrm{~mL}$ da solução indicadora de DPD e uma alíquota de $100,0 \mathrm{~mL}$ da solução de hipociorito de sódio $1,0 \times 10^{-4} \mathrm{~mol} \mathrm{~L}^{-1}$.

Uma amostra de água de torneira foi titulada com a solução de $\mathrm{Fe}^{2+}$ $\left(2,82 \times 10^{-3} \mathrm{~mol} \mathrm{~L}^{-1}\right)$ até o aparecimento de coloração avermelhada. A titulação foi feita em duplicata e o volume médio gasto da solução de $\mathrm{Fe}$ (II) foi de $7,09 \mathrm{~mL}$.

Com base na equação 24 , a concentração de hipociorito na amostra de água de torneira foi de $1,80 \times 10^{-5} \mathrm{~mol} \mathrm{~L}^{-1}$.

$$
2 \mathrm{Fe}^{2+}+\mathrm{Cl}_{2} \rightleftharpoons 2 \mathrm{Cl}^{-}+2 \mathrm{Fe}^{3+}
$$




\section{III.5.1.b - Procedimento experimental}

\section{Ill.5.1.b.1 - Experimentos no modo estático ("batch")}

Os experimentos no modo estático foram realizados empregando-se o luminômetro Lumicounter 1000 (Microtec NITI-ON, Japão), com o qual não é possivel discriminar o comprimento de onda de radiação emitida.

Um tubo de vidro de $10 \mathrm{~mL}$ foi colocado em um compartimento, posicionado em frente à FMT. $200 \mu \mathrm{L}$ de cada solução de TCPO, DFA e cloro livre foram injetados com uma seringa, no interior do tubo mantido sob agitação. A intensidade de emissão vs tempo foi registrada com um registrador U-135 (Shimadzu, Kioto). As concentrações das soluções, depois da mistura dos reagentes, estão representadas nas legendas das figuras.

\section{III.5.1.b.2 - Experimentos com injecão de amostra em fluxo}

O sistema em fluxo empregado nas análises está representado na figura 13. Este sistema consiste de 2 bombas peristálticas (P1: SJ-1215 e P2: SJ-1211, Atto, Tóquio), uma válvula de injeção de 6 vias com um tubo em espiral ("loop") de teflon, localizada nas proximidades da célula de vidro em espiral, e o detector de radiação 


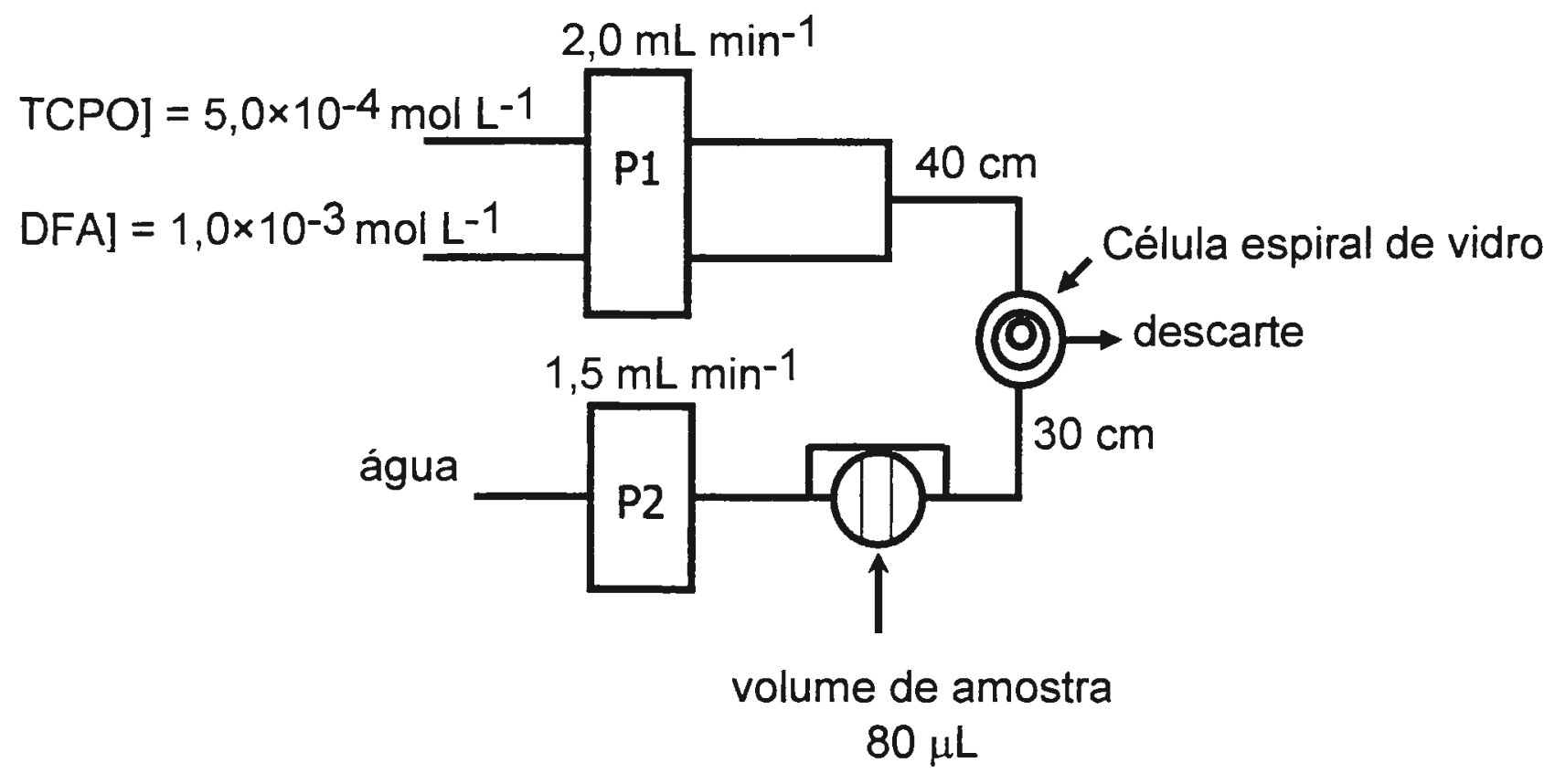

Figura 13 - Esquema do sistema FIA utilizado para determinação de cloro. As condições experimentais ótimas estão indicadas na figura. TCPO e DFA foram dissolvidos em acetonitrila $100 \%$ e o pH da amostra aquosa foi ajustado em 7,0. 
(Lumicounter 1000, Microtec NITI-ON, Japão). Foram usados tubos de propulsão de silicone, de $2,0 \mathrm{~mm}$ de diâmetro interno, para conduzir os reagentes na bomba peristáltica e tubos de extensão de teflon, de $1,0 \mathrm{~mm}$ de diâmetro interno, para transportar os reagentes pelas linhas de fluxo e formar a alça de amostragem. $80 \mu \mathrm{L}$ da solução de cloro foram injetados na solução transportadora a uma vazão de 1,5 $\mathrm{mL} \min ^{-1}$ de água e misturados com a solução de TCPO/fluoróforo (2,0 $\mathrm{mL} \mathrm{min}^{-1}$ ) em uma célula de vidro em espiral, posicionada em frente à FMT, na qual foi aplicada baixa voltagem.

Variações nas condições ótimas de volume de amostra e $\circ$ fluxo dos reagentes estão indicados nas legendas das figuras e tabelas.

\section{III.5.2 - Resultados e discussão}

A figura 14 representa a variação da intensidade de emissão em função do tempo, em experimentos realizados no modo estático ("batch") após a adição de solução de cloro livre a uma mistura contendo TCPO e DFA. A intensidade de radiação e o tempo de emissão aumentaram com a concentração de cloro livre. Como a reação é muito rápida, isto é, Imax (intensidade máxima de radiação) ocorre nos primeiros 5 segundos, foi proposto um método analítico alternativo para a determinação de cloro livre, utilizando um sistema de injeção da amostra em fluxo. 


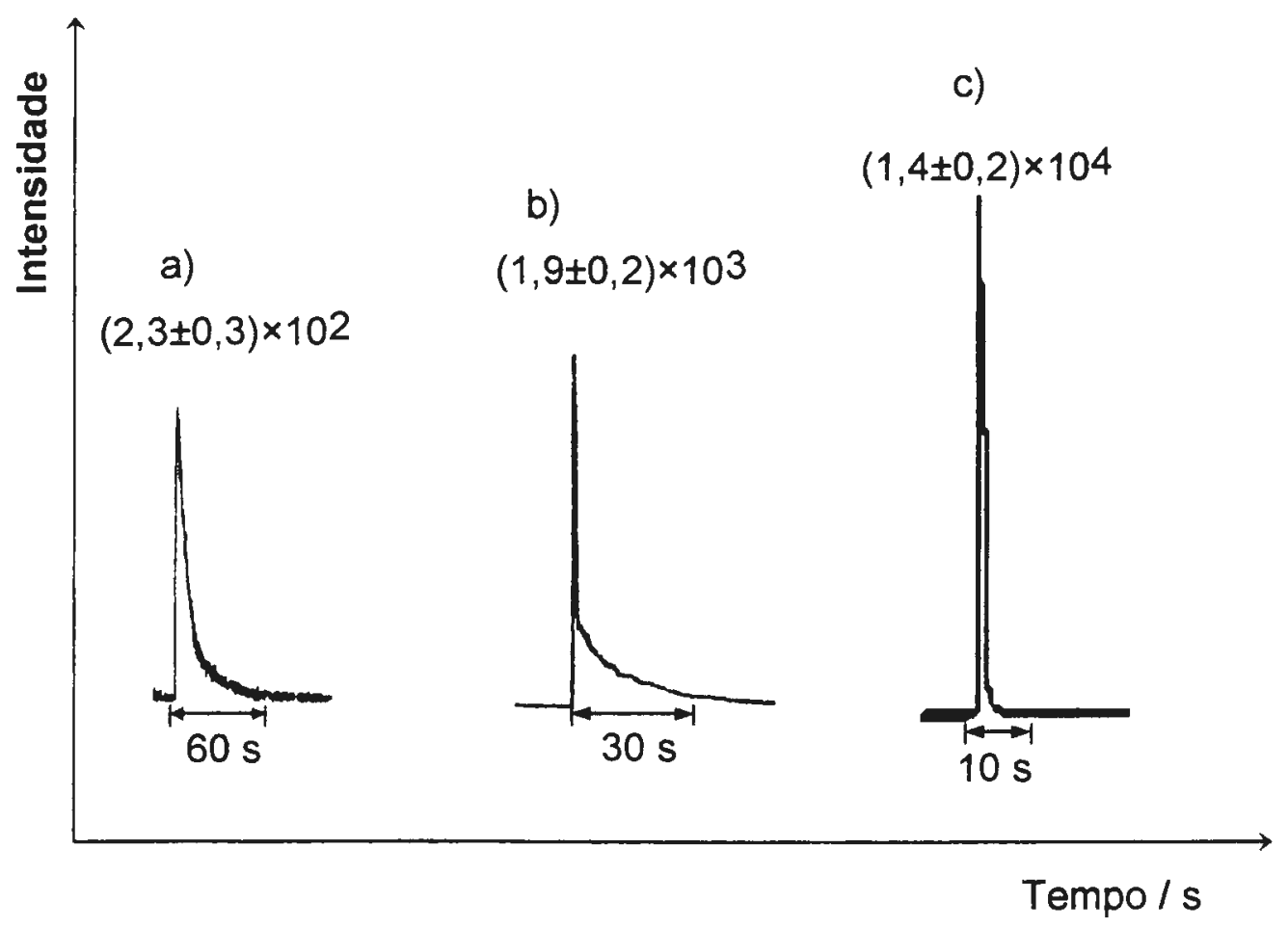

Figura 14 - Intensidade de emissão QL com a adição de amostra de cloro a uma mistura das soluções de TCPO e DFA.

$[\mathrm{TCPO}]=1,7 \times 10^{-4} \mathrm{~mol} \mathrm{~L}^{-1},[\mathrm{DFA}]=3,3 \times 10^{-4} \mathrm{~mol} \mathrm{~L}^{-1}$ e [cloro]:

a) $8,3 \times 10^{-6}$, b) $3,3 \times 10^{-5}$ e c) $3,3 \times 10^{-4} \mathrm{~mol} \mathrm{~L}^{-1}$ a pH $=7,2$. 


\section{ll.5.2.1 - Estudos empregando um sistema de injecão em fluxo}

A figura 15 representa 0 fiagrama obtido quando TCPO e DFA foram misturados e água foi injetada como amostra. Observou-se uma emissão de fundo (ruido). Alguns autores atribuem o sinal de fundo e a instabilidade da linha de base às impurezas presentes nos reagentes e solventes ${ }^{125}$, aos problemas de mistura de reagentes, à influência do frasco utilizado para estocagem das soluções reagentes ${ }^{126}$ e também aos problemas de pulsação de bombas peristálticas, utilizadas para impulsionar os reagentes em sistemas de cromatografia líquida, que criam flutuações nas concentrações dos reagentes e geram o ruído 127.

O rápido decaimento da emissão de luz (o que pode ser observado na figura 14) requer um dispositivo tendo baixo volume interno, que realize mistura efetiva dos reagentes. Uma mistura eficiente dos reagentes e amostra é essencial para obter resultados reprodutíveis e sensibilidade elevada. No sistema em fluxo (figura 13) empregado, a mistura dos reagentes em fluxo foi feita na célula de vidro em espiral, posicionada nas proximidades do detector, permitindo que o máximo de emissão de luz ocorra ao alcance do detector.

No presente trabalho, o sinal analítico, ou simplesmente sinal, está representado como uma relação entre a intensidade máxima de emissão QL (altura de pico) e o ruído $-\mathbf{S} / \mathbf{R}$.

Como os experimentos foram realizados em condições diferentes de sensibilidade do equipamento, considerar os números indicados nos gráficos como intensidade relativa. 


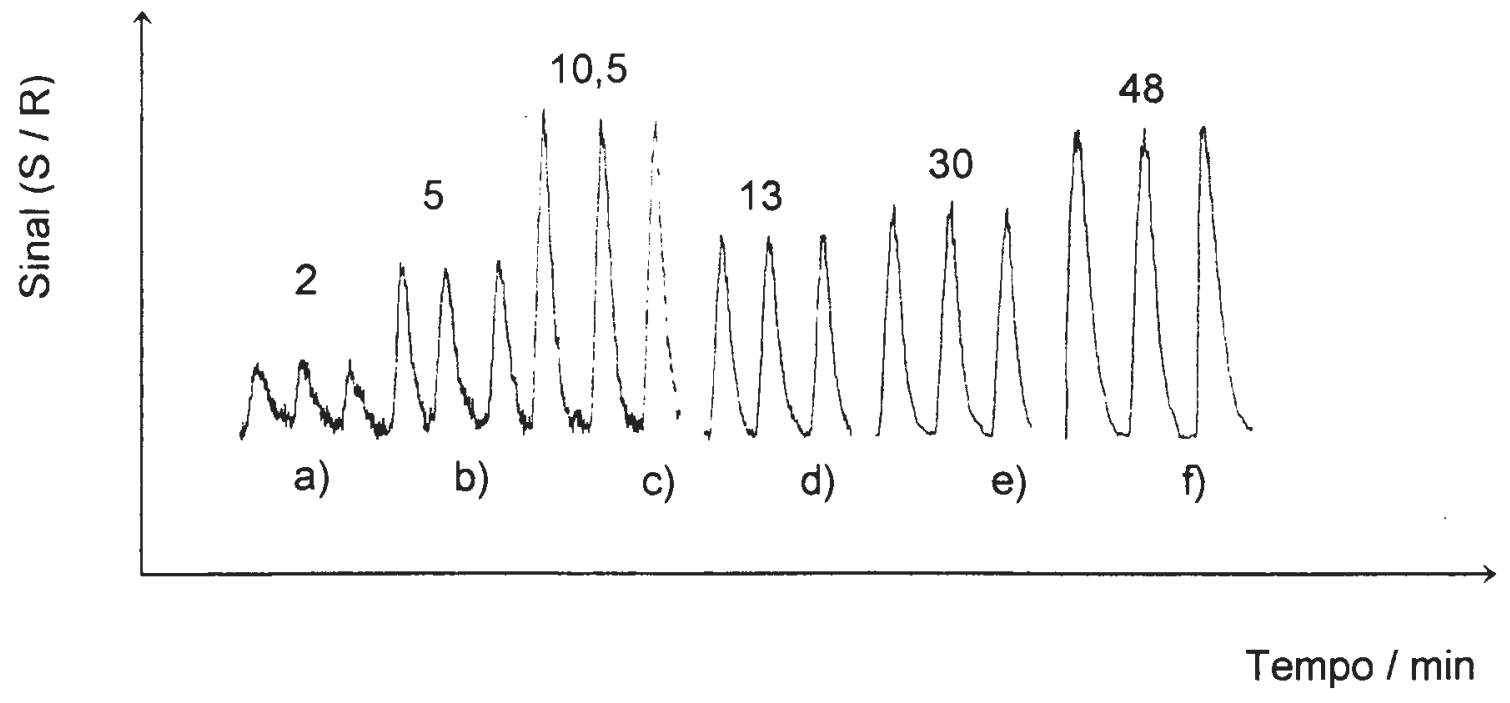

Figura 15 - Determinação de cloro por FIA através da reação QL entre TCPO e cloro. $[T C P O]=5,0 \times 10^{-4} \mathrm{~mol} \mathrm{~L}^{-1}$ e $[D F A]=1,0 \times 10^{-3} \mathrm{~mol} \mathrm{~L}^{-1}$ a $1,0 \mathrm{~mL} \mathrm{~min}^{-1}$, fluxo da água a $1,5 \mathrm{~mL} \mathrm{~min}^{-1}$. Amostra de cloro $(80 \mu \mathrm{l}) \mathrm{em} \mathrm{pH}=7,0$ :

a) $2,0 \times 10^{-6}$, b) $5,0 \times 10^{-6}$, c) $8,0 \times 10^{-6}$, d) $1,0 \times 10^{-5}$, e) $2,0 \times 10^{-5}$ e f) $4,0 \times 10^{-5}$

OBS.: Os experimentos foram realizados em condições diferentes de sensibilidade do equipamento 
A figura 16 representa a intensidade de emissão quando água (branco) foi injetada. $\mathrm{O} \mathrm{pH}$ da água foi ajustado com soluções de $\mathrm{HCl}$ ou $\mathrm{NaOH}$. $\mathrm{O}$ sinal aumentou drasticamente em meio de $\mathrm{pH}>9,0$. Assim, em todos os experimentos a acidez da amostra foi mantida em torno de $\mathrm{pH}=6,5$ para evitar um ruído muito alto. $\mathrm{Em} \mathrm{pH}=6,5$ o ruido foi três vezes menor que o sinal medido quando uma amostra de [cloro] $=2,0 \times 10^{-6} \mathrm{~mol} \mathrm{~L}^{-1}$ (limite de detecção) foi injetada.

A origem dessa radiação de fundo é desconhecida, e parece ser diferente daquela observada quando peróxido de hidrogênio é usado no lugar de cloro livre. Na literatura, alguns estudos 128,129 verificaram uma emissão resultante da reação de TCPO com peróxido de hidrogênio na ausência de um fluoróforo, em meio tamponado $(\mathrm{pH}=6,0$ a 12,0) em mistura de solvente contendo tetrahidrofurano/acetonitrila. N.W. Barnett e colaboradores atribuíram os aumentos de até $750 \%$ na intensidade de emissão de fundo à presença do ânion 2,4,6-triclorofenolato, que sofre oxidação por peróxido de hidrogênio levando a formação do radical fenoxila. Nesse caso também foi observado que a emissão de fundo diminuiu drasticamente em $\mathrm{pH}<8,5$.

\section{III.5.2.1.a - Efeito do solvente da solução de TCPO}

O solvente no qual ocorre a reação QL deve ser selecionado de maneira a obter uma cinética apropriada da reação com o maior rendimento QL ( $\left.\Phi_{Q L}\right)$. 


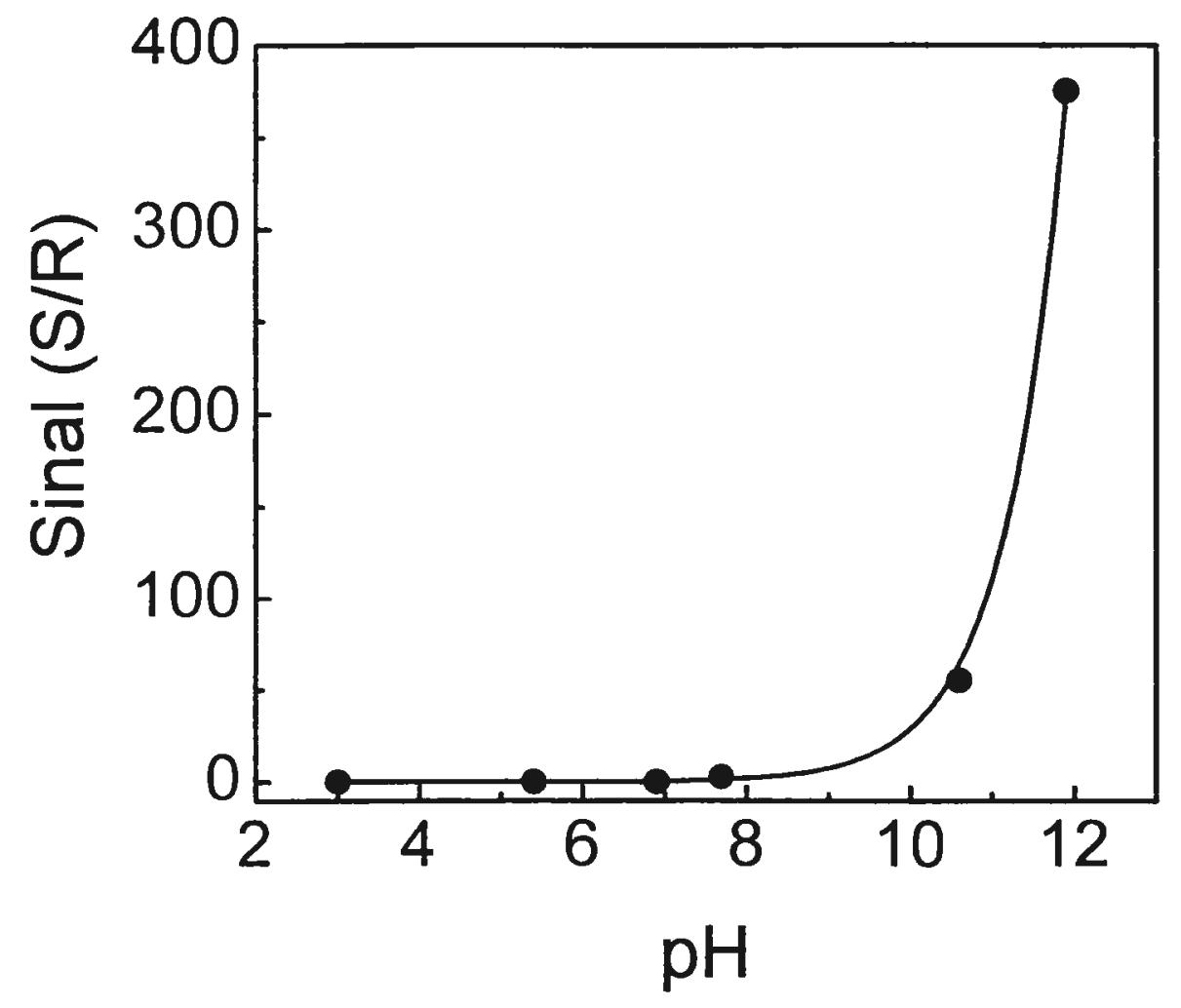

Figura 16 - Efeito da acidez da amostra na intensidade de emissão QL, na ausência de cloro (emissão do "branco"):

$[\mathrm{TCPO}]=5,0 \times 10^{-4} \mathrm{~mol} \mathrm{~L}^{-1},[\mathrm{DFA}]=1,0 \times 10^{-3} \mathrm{~mol} \mathrm{~L}^{-1}(\mathrm{em}$ acetonitrila $)$. TCPO e DFA a 1,0 mL min-1, fluxo da água a $1,5 \mathrm{~mL} \mathrm{~min}^{-1}$ e volume da amostra $=150 \mu \mathrm{L}$. 
Em um método analítico em que a introdução da amostra é feita por injeção em fluxo, é desejável que a reação seja relativamente rápida e que a intensidade máxima seja medida em um tempo relativamente pequeno, dentro de um processo de mistura reprodutivel.

É conhecido que a presença de água na solução de TCPO é desfavorável devido à sua baixa solubilidade neste solvente e também devido à possibilidade de hidrólise do oxalato ${ }^{130-132}$ (equações 25 e 26). Entretanto, como a amostra de cloro livre é aquosa, e sendo desejável que a solução de TCPO/fluoróforo seja o máximo solúvel em água, o efeito do conteúdo de água em acetonitrila na solução de TCPO foi explorado.<smiles>[Y14]C1C(O)C1Oc1cc(Cl)c(OC(=O)C(=O)O[CH2+])c(Cl)c1</smiles><smiles>O=C(O[18OH])C(=O)Oc1c(Cl)cc(Cl)cc1Cl</smiles><smiles>O=C(O)C(=O)[OH2+]</smiles>

O efeito do teor de água e de alguns solventes orgânicos na solução de TCPO, inicialmente dissolvida em acetonitrila, está representado na tabela 7.

Quando uma solução de TCPO contendo 10/90\% (v/v) de água/acetonitrila foi testada, a emissão de fundo (ruido) aumentou e o sinal de emissão correspondente a uma solução de $1,0 \times 10^{-4} \mathrm{~mol} \mathrm{~L}^{-1}$ de cloro foi completamente suprimido (tabela 7 ). 
Tabela 7 - Efeito do solvente utilizado na solubilização de TCPO.

$[T C P O]=5,0 \times 10^{-4} \mathrm{~mol} \mathrm{~L}^{-1},[\mathrm{DFA}]=1,0 \times 10^{-3} \mathrm{~mol} \mathrm{~L}^{-1}(\mathrm{em}$ acetonitrila). TCPO e DFA a $1,0 \mathrm{~mL} \mathrm{~min}-1$, fluxo da água a $1,5 \mathrm{~mL} \mathrm{~min}{ }^{-1}$. Amostra de [cloro] $(150 \mu \mathrm{L})$ ] $=$ $1,0 \times 10^{-4} \mathrm{~mol} \mathrm{~L}^{-1}$, a pH $=7,0$. N.D.: não detectado.

\begin{tabular}{lcc}
\hline & \multicolumn{2}{c}{ Sinal / (S/R) } \\
\cline { 2 - 3 } Solvente & \multicolumn{2}{c}{ [cloro] / mol L-1 } \\
(v/v)\% em águal acetonitrila & $1,0 \times 10^{-5}$ & $1,0 \times 10^{-4}$ \\
\hline $100 \%$ acetonitrila & 19 & 80 \\
$10 \%$ água & N.D. & N.D. \\
$20 \%$ 1-propanol & 15 & 45 \\
$20 \%$ 2-propanol & 1,8 & 12 \\
$20 \%$ metanol & 17 & 88 \\
$20 \%$ tetrahidrofurano & 6,3 & 20 \\
\hline
\end{tabular}


Misturas de acetonitrila com outros solventes orgânicos foram testadas. O uso de $20 / 80 \%(\mathrm{v} / \mathrm{v})$ de metanol/acetonitrila e $100 \%$ de acetonitrila produziram a melhor relação sinal/ruído. A emissão foi suprimida com o uso de $100 \%$ propanol ou metanol (dados não representados na tabela). O uso de acetato de etila ou tetrahidrofurano não foi conveniente devido ao dano causado aos tubos de silicone utilizados para como tubos de propulsão, na bomba peristáltica.

Williams e colaboradores ${ }^{133}$ observaram que a utilização de solventes como dimetoxietano ou dioxano, que possuem tendência a formar peróxidos, produziram alto nivel de emissão de radiação de fundo. A utilização de acetato de etila como solvente produziu ruído elevado e o sinal tornou-se irreprodutível. Os autores atribuíram o resultado à imiscibilidade do acetato de etila com amostras aquosas.

R. Weinberger ${ }^{134}$ explicou o efeito do solvente (acetonitrila, isopropanol e metanol) na emissão QL em termos de algumas constantes físicas, tais como: constante dielétrica, momento de dipolo, viscosidade e tamanho das moléculas. (tabela 8). A solvatação da molécula de TCPO pela acetonitrila, que possui maior momento dipolo, dificulta a hidrólise do TCPO, enquanto a presença de água na acetonitrila resulta em uma diminuição na eficiência da emissão. A alta viscosidade e o tamanho da molécula de isopropanol protegem a molécula de TCPO do ataque do oxidante, reduzindo a intensidade de emissão QL. O tamanho da molécula de metanol é próximo ao da acetonitrila, mas a distribuição de carga na acetonitrila é maior (momento de dipolo 3,92D), resultando em reação com tempo de emissão maior e conseqüentemente rendimento quântico maior. Além disso, a adição de água a acetonitrila pode influenciar também não somente a velocidade de reação, mas também a basicidade dos reagentes, alterando o valor de pK. 
Tabela 8 - Constantes físicas de alguns solventes

\begin{tabular}{|c|c|c|c|c|}
\hline Solvente & $\begin{array}{l}\text { Constante } \\
\text { dielétrica }\end{array}$ & $\begin{array}{c}\text { Viscosidade } \\
\text { (cP) }\end{array}$ & $\begin{array}{l}\text { Dipolo } \\
\text { (D) }\end{array}$ & $\begin{array}{c}\text { Tamanho } \\
(\AA)\end{array}$ \\
\hline Acetonitrila & 37,5 & 0,34 & 3,92 & 3,7 \\
\hline Acetato de etila & 6,0 & - & 1,78 & - \\
\hline Água & 80,2 & 1,00 & 1,85 & - \\
\hline Isopropanol & 20,3 & 1,9 & 1,66 & 5,3 \\
\hline Metanol & 32,7 & 0,54 & 1,70 & 3,5 \\
\hline THF & 7,4 & - & 1,63 & - \\
\hline
\end{tabular}




\section{III.5.2.1.b - Efeito da acidez da amostra}

O efeito da concentração hidrogeniônica da amostra na intensidade de quimiluminescência está representado na figura 17. O sinal parece depender também da hidrólise do TCPO.

Experimentos em amostras de $\mathrm{pH}>8,0$ não são convenientes devido à elevada relação sinal/ruído (vide figura 16).

Um possível tampão que poderia ser usado na amostra no intervalo de $\mathrm{pH}=$ 6,0-7,0 seria $\mathrm{H}_{2} \mathrm{PO}_{4}^{-/} / \mathrm{HPO}_{4}^{2-}$. Entretanto, o efeito de $\mathrm{HPO}_{4}{ }^{2-}$ pode ser observado na tabela 11 (página 110) (em concentrações elevadas, diminui o sinal QL).

A literatura também reporta o efeito da fôrça iônica, acidez, cloreto, fosfato, carbonato, borato e acetato 93 na reação de decomposição de hipoclorito. Por esta razão, o pH da solução estoque de hipoclorito de sódio $5,0 \times 10^{-2} \mathrm{~mol} \mathrm{~L}^{-1}$, usada para o preparo das soluções mais diluídas, foi ajustado em $\mathrm{pH}=7,0 \mathrm{com} \mathrm{HCl} 1,0 \mathrm{~mol} \mathrm{~L}^{-1}$.

HTRIS $^{+}$TRRIS, um outro tampão que poderia ser sugerido, não é adequado, pois TRIS atua como catalisador da reação de sistemas PO-QL e altera a velocidade da reação 135,136 .

Assim sendo optou-se por conduzir os estudos do presente trabalho em meio não tamponado, tomando o cuidado de verificar a acidez da amostra injetada. 


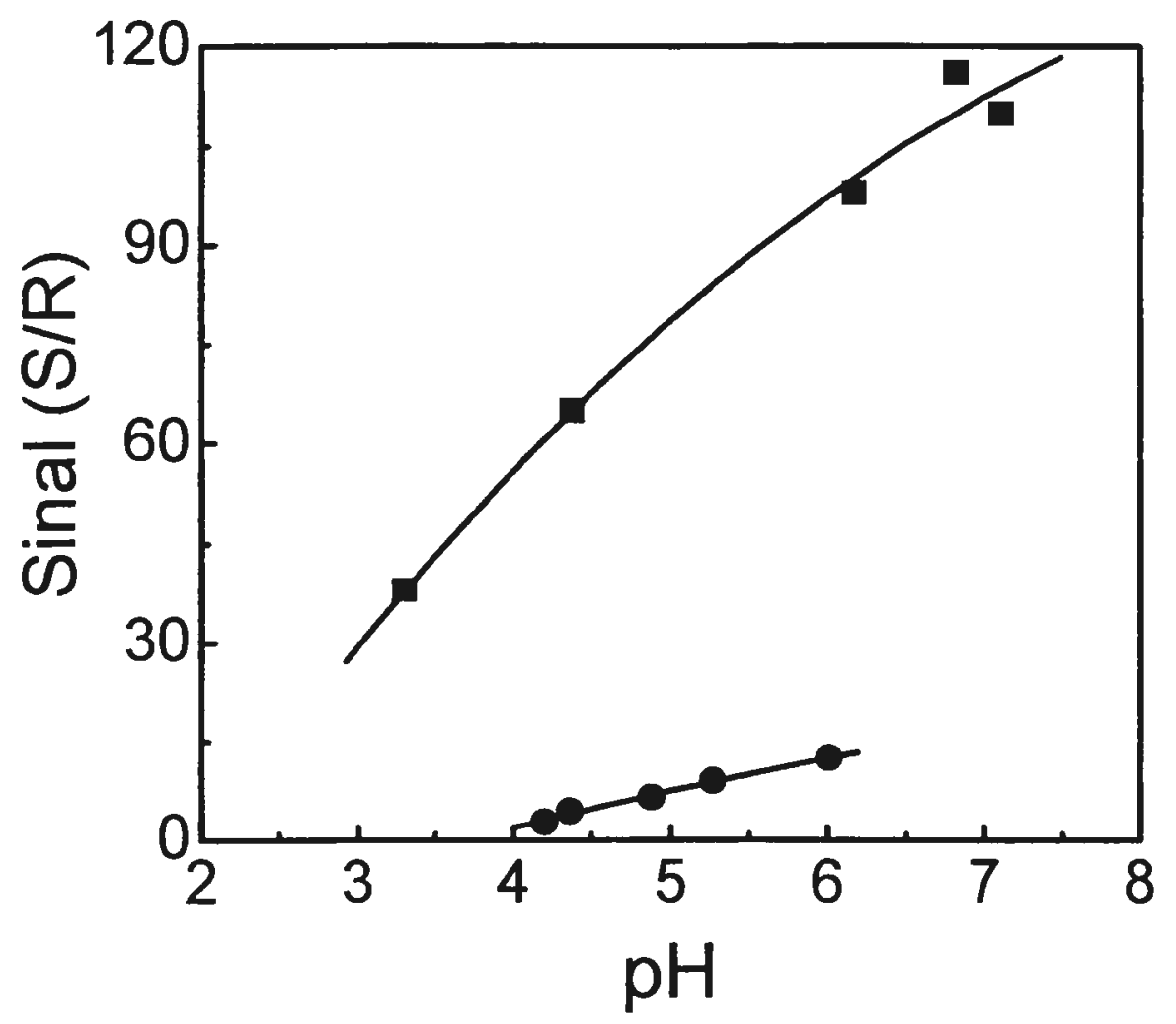

Figura 17 - Efeito da acidez da amostra na intensidade de emissão QL produzida pela reação de TCPO e cloro.

$[\mathrm{TCPO}]=5,0 \times 10^{-4} \mathrm{~mol} \mathrm{~L}^{-1}$ e $[\mathrm{DFA}]=1,0 \times 10^{-3} \mathrm{~mol} \mathrm{~L}^{-1}(\mathrm{em}$ acetonitrila). TCPO e DFA a $1,0 \mathrm{~mL} \mathrm{~min}-1$, fluxo da água a $1,5 \mathrm{~mL} \mathrm{~min}^{-1}$.

Amostra de cloro: $-1,0 \times 10^{-4}(150 \mu \mathrm{L}), \cdot 2,5 \times 10^{-5}(80 \mu \mathrm{L}) \mathrm{mol} \mathrm{L}^{-1}$ 


\section{III.5.2.1.c - Efeito do fluoróforo}

Sensibilidades diferentes foram obtidas empregando-se vários fluoróforos (tabela 9). Com o uso de DFA (9,10-difenilantraceno) dissolvido em acetonitrila, observou-se maior sensibilidade e menor emissão de fundo (ruído), enquanto que antraceno, pireno, fenantreno, fluoranteno e antraquinona produziram sinais menores; com o uso de 2-aminoantraceno não houve aumento significativo. $O$ uso de compostos derivados de antraceno, tais como: 9,10-dinitroantraceno e 9,10-dicianoantraceno (dados não representados na tabela) não produziram emissão QL; esses fluoróforos são pouco solúveis em água.

Os experimentos realizados no modo estático ("batch"), representados na figura 18, mostram que as intensidades de emissão $Q L$ seguem a seguinte ordem:

DFA $\left(E_{O X}=1,1 \mathrm{~V}\right)>$ antraceno $\left(E_{O X}=1,2 \mathrm{~V}\right)>$ fluoranteno $\left(E_{O X}=1,4 \mathrm{~V}\right)$ e fenantreno $\left(E_{o x}=1,5 \mathrm{~V}\right)$.

Existe uma correlação entre o potencial de oxidação ( $\left.E_{0 x}\right)$ (dados representados com relação ao eletrodo de calomelano) e a intensidade de emissão QL, sendo esta uma evidência de um mecanismo de transferência de elétrons, conforme observado por alguns autores $48-50$, na qual fluoróforos com menor potencial de oxidação levam a uma maior intensidade de emissão QL (mecanismo CIELL ou "chemically initiated electron exchange luminescence" (esquema 5)). No mecanismo CIELL, a energia necessária para promover o fluoróforo para o estado excitado provém da aniquilação de ions radicais gerados da ruptura de ligações do intermediário formado na reação peróxi-oxalato 
Tabela 9 - Efeito da natureza do fluoróforo na reação QL de TCPO com cloro.

$[\mathrm{TCPO}]=5,0 \times 10^{-4} \mathrm{~mol} \mathrm{~L}^{-1}$, [fluoróforo $]=1,0 \times 10^{-3} \mathrm{~mol} \mathrm{~L}^{-1}(\mathrm{em}$ acetonitrila). TCPO e DFA a $1,0 \mathrm{~mL} \mathrm{~min}-1$, fluxo da água a $1,5 \mathrm{~mL} \mathrm{~min}^{-1}$. Amostra $(150 \mu \mathrm{L})$ a $\mathrm{pH}=7,0$. N.D.: não detectado.

\begin{tabular}{lcc}
\hline \multirow{2}{*}{ Fluoróforo } & \multicolumn{2}{c}{ Sinal / (S/R) } \\
\cline { 2 - 3 } & \multicolumn{2}{c}{ [cloro] / mol L-1 } \\
\cline { 2 - 3 } & $1,0 \times 10^{-5}$ & $1,0 \times 10^{-4}$ \\
\hline 9,10-difenilantraceno & 8,7 & \\
Antraceno & 3,0 & 27 \\
Pireno & N.D. & 6,0 \\
Fenantreno, fluoranteno, antraquinona & N.D. & 4,0 \\
2-aminoantraceno & N.D. & 1,5 \\
9-nitroantraceno & N.D. & N.D. \\
\hline
\end{tabular}




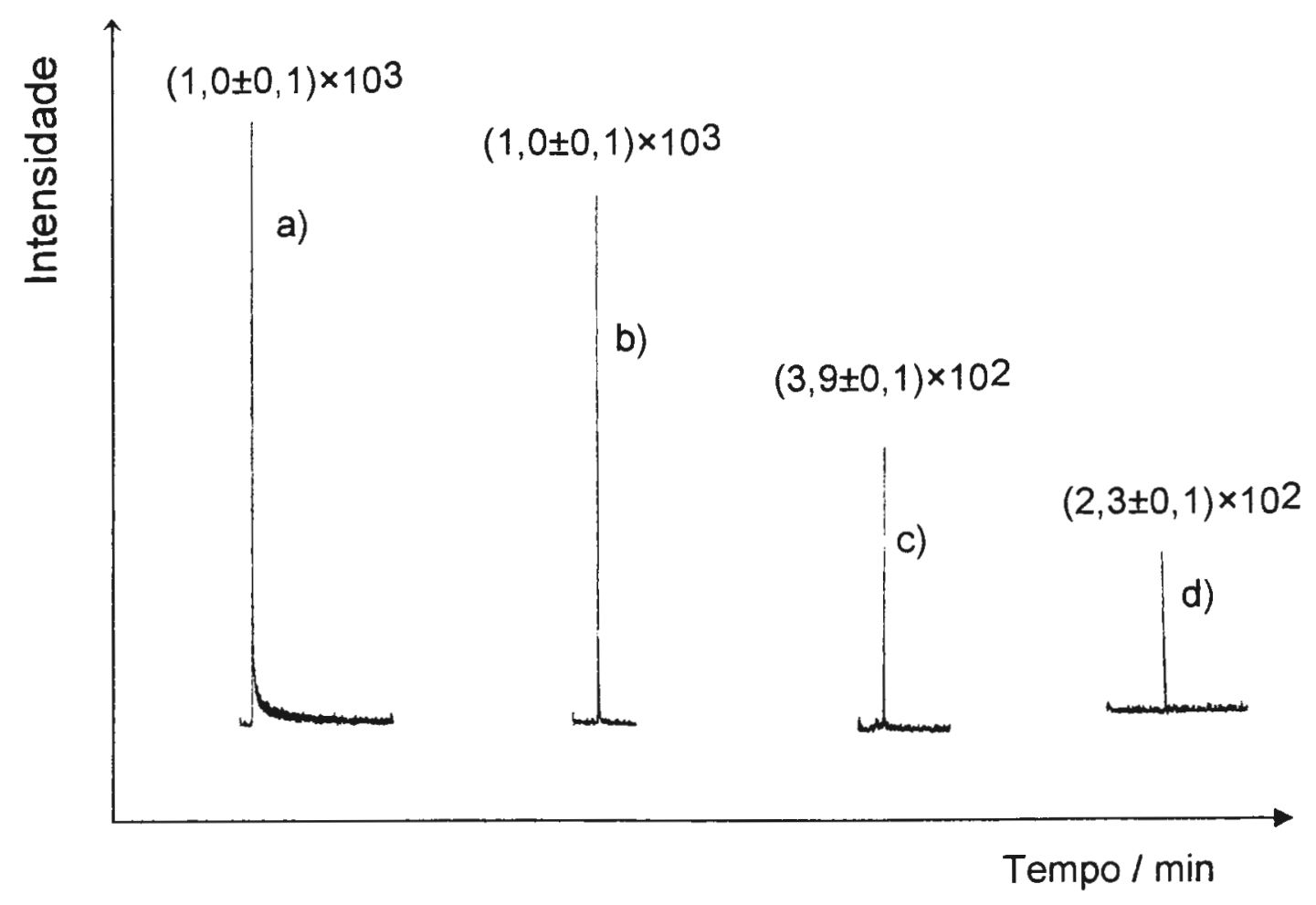

Figura 18 - Intensidade de emissão QL da reação de TCPO e cloro com diferentes fluoróforos. O início da emissão de radiação inicia com a adição de cloro a uma mistura das soluções de TCPO e fluoróforo.

$[T C P O]=1,7 \times 10^{-4} \mathrm{~mol} \mathrm{~L}^{-1},[$ fluoróforo $]=3,3 \times 10^{-4} \mathrm{~mol} \mathrm{~L}^{-1}$ (em acetonitrila) e [cloro] $=1,6 \times 10^{-2} \mathrm{~mol} \mathrm{~L}^{-1} \mathrm{a} \mathrm{pH}=7,2$.

Fluoróforo: a) DFA, b) antraceno, c) fluoranteno e d) fenantreno.

O tempo de reação nessas condições foi menor do que 5 segundos. 


\section{III.5.2.1.d - Efeito das concentrações de TCPO e DFA}

A tabela 10 mostra que o sinal aumentou com as concentrações de TCPO e DFA.

As concentrações selecionadas no desenvolvimento do método analítico foram: $[\mathrm{TCPO}]=5,0 \times 10^{-4} \mathrm{~mol} \mathrm{~L}^{-1}$ e $[D F A]=1,0 \times 10^{-3} \mathrm{~mol} \mathrm{~L}-1$ dissolvidos em acetonitrila. Essas escolhas foram limitadas pela solubilidade de TCPO em acetonitrila e também para evitar um consumo maior de solução de DFA.

A concentração típica do TCPO é de 0,1 a $10 \mathrm{mmol} \mathrm{L}^{-1}$ (51). Somente alguns oxalatos, como TDPO, oxalato de bis[2-(3,6,9-(trioxadeciloxicarbonila)-4-nitrofenila, que foi especialmente sintetizado para ser utlizado em cromatografia líquida de alta eficiência, apresenta solubilidade de até $1 \mathrm{~mol} \mathrm{~L}^{-1} \mathrm{em}$ acetonitrila(51).

\section{III.5.2.1.e - Efeito do volume de amostra}

A figura 19 mostra que quando volumes maiores que $80 \mu \mathrm{L}$ foram injetados, não ocorreu um aumento significativo do sinal de emissão QL. Assim considerou-se como volume ótimo $80,0 \mu \mathrm{L}$. 
Tabela 10 - Efeito das concentrações de TCPO e DFA na intensidade de emissão QL.

(a) $[D F A]=1,0 \times 10^{-3} \mathrm{~mol} \mathrm{~L}^{-1}$, (b) $[$ TCPO $]=5,0 \times 10^{-4} \mathrm{~mol} \mathrm{~L}^{-1}$, TCPO e DFA a 1,0 $\mathrm{mL} \min ^{-1}$, fluxo da água a $1,5 \mathrm{~mL} \mathrm{~min}-1$. Amostra: [cloro] $(150 \mu \mathrm{L})=1,0 \times 10^{-4}$ mol L-1, a $\mathrm{pH}=7,0$.

\begin{tabular}{lccc}
\hline TCPO / 10-5 mol L-1(a) & 5,0 & 10 & 50 \\
Sinal / (S/R) & 4,2 & 37 & 87 \\
\hline DFA / 10-5 mol L-1 (b) & 5,0 & 10 & 100 \\
Sinal / (S/R) & 6,4 & 16,0 & 84 \\
\hline
\end{tabular}




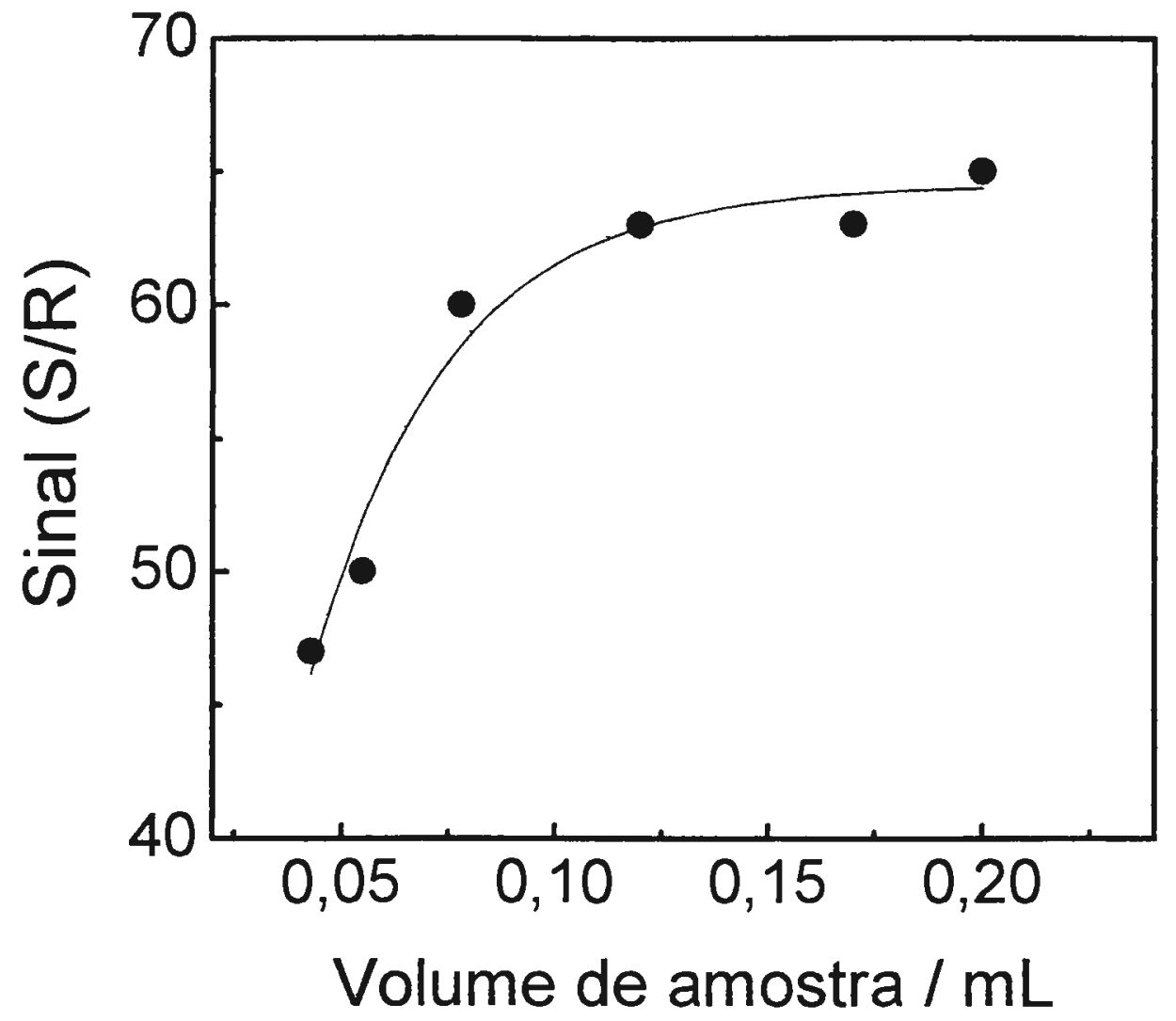

Figura 19 - Efeito do volume da amostra injetada $[T C P O]=5,0 \times 10^{-4} \mathrm{~mol} \mathrm{~L}^{-1},[D F A]=1,0 \times 10^{-3} \mathrm{~mol} \mathrm{~L}^{-1}, \mathrm{TCPO}$ e DFA a $1,0 \mathrm{~mL} \mathrm{~min}{ }^{-1}$, fluxo da água a $1,5 \mathrm{~mL} \mathrm{~min}^{-1}$, amostra de [cloro] $=1,0 \times 10^{-5} \mathrm{~mol} \mathrm{~L}^{-1}$, em meio de $\mathrm{pH}=7,0$. 


\section{III.5.2.1.f - Efeito da vazão das solucões de TCPO e DFA}

Os aumentos das vazões das soluções de TCPO e de fluoróforo aumentaram marcadamente a intensidade de emissão, enquanto a vazão da solução transportadora apresentou um efeito menor na intensidade de emissão (figura 20).

$\mathrm{Na}$ análise da amostra e construção da curva analítica para cloro utilizou-se a vazão em 2,0 mL min-1 para as soluções de TCPO e do fluoróforo, para evitar um consumo excessivo de reagentes e vazão da água em $1,5 \mathrm{~mL} \mathrm{~min}^{-1}$, para evitar o alargamento do pico. Nos experimentos de estudo dos parâmetros que afetam o sinal analítico de cloro, as variações nas condições da vazão dos reagentes estão descritas nas figuras e tabelas.

\section{III.5.2.1.g - Estudo de interferentes}

O efeito de alguns interferentes na determinação de cloro foi investigado e está representado na tabela 11. A intensidade de emissão QL foi normalizada $(=100)$ com relação ao sinal produzido por [cloro] $=2,0 \times 10^{-5} \mathrm{~mol} \mathrm{~L}^{-1}$, na ausência de interferente.

Soluções de íons metálicos foram preparadas imediatamente antes da utilização. As soluções dos íons metálicos foram adicionadas como sais de sulfato, na faixa de $1,0 \times 10^{-6}-1,0 \times 10^{-4} \mathrm{~mol} \mathrm{~L}^{-1}$, em solução de [cloro] $=2,0 \times 10^{-5} \mathrm{~mol} \mathrm{~L}^{-1}$. 


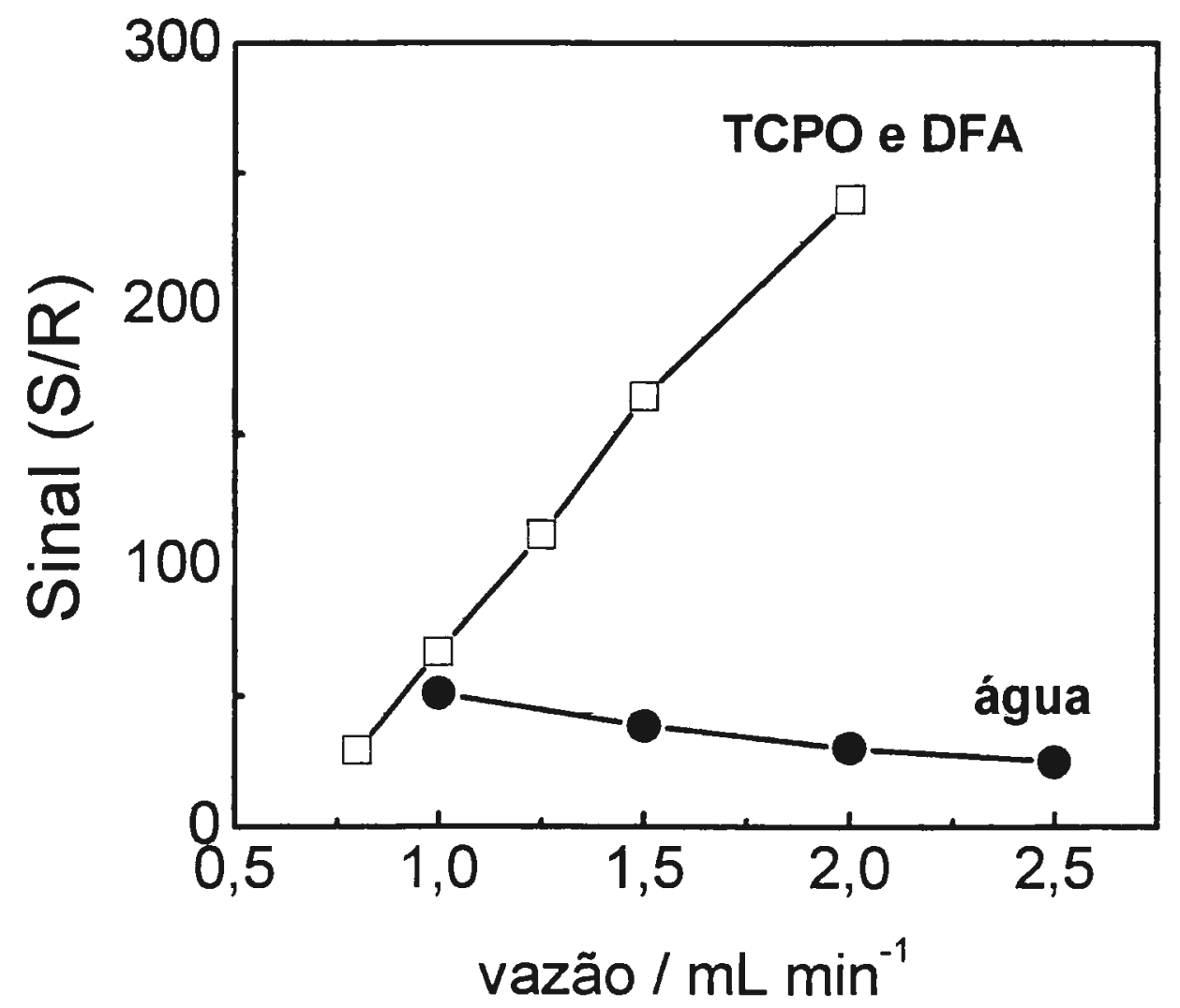

Figura 20 - Efeito da vazão dos reagentes na intensidade de emissão.

$[T C P O]=5,0 \times 10^{-4} \mathrm{~mol} \mathrm{~L}^{-1},[\mathrm{DFA}]=1,0 \times 10^{-3} \mathrm{~mol} \mathrm{~L}^{-1}$, amostra de $[$ cloro $]=1,0 \times 10^{-5}$ mol L-1 $(80(\mu \mathrm{L})$, em meio de $\mathrm{pH}=7,0$.

- água (vazão de TCPO e DFA = 1,5 mL min-1)

$\square$ TCPO e DFA (vazão de água $=1,0 \mathrm{~mL} \mathrm{~min}-1$ ) 
Tabela 11 - Efeito de interferentes na determinação de cloro através da reação QL de $\mathrm{TCPO}$ e cloro. $[\mathrm{TCPO}]=5,0 \times 10^{-4}$ e $[\mathrm{DFA}]=1,0 \times 10^{-3} \mathrm{~mol} \mathrm{~L}^{-1} \mathrm{em}$ acetonitrila. TCPO e DFA a 1,0 mL min-1, vazão da água a 1,5 mL min-1. Amostra de [cloro] = $2,0 \times 10^{-5} \mathrm{~mol} \mathrm{~L}^{-1}(80 \mu \mathrm{L}), \mathrm{a} \mathrm{pH}=7,0 .{ }^{*} \mathrm{pH}=3,5$. N.D.: não detectado.

\begin{tabular}{lccc}
\hline & \multicolumn{3}{c}{ Sinal / (S/R) } \\
\cline { 2 - 4 } Interferente & \multicolumn{3}{c}{$\left[\right.$ Interferente] $/ \mathrm{mol} \mathrm{L}^{-1}$} \\
& $1,0 \times 10^{-6}$ & $1,0 \times 10^{-5}$ & $1,0 \times 10^{-4}$ \\
\hline Nenhum & 100 & 100 & 100 \\
$\mathrm{Co}^{2+}$ & 91 & 94 & - \\
$\mathrm{Mn}^{2+}$ & 91 & 79 & - \\
$\mathrm{Cu}^{2+}$ & 70 & 70 & - \\
$\mathrm{Fe}^{3+*}$ & $\mathrm{~N} . \mathrm{D}$. & $\mathrm{N} . \mathrm{D}$. & - \\
$\mathrm{NH}_{4} \mathrm{Cl}^{+}$ & - & 500 & - \\
$\mathrm{SO}_{4}{ }^{2-}, \mathrm{HCO}_{3}{ }^{-}$ & 100 & 100 & 95 \\
$\mathrm{HPO}_{4}{ }^{2-}, \mathrm{NO}_{3}{ }^{-}$ & 100 & 100 & 87 \\
\hline
\end{tabular}


Os íns metálicos manganês(II) e cobre(II) apresentaram um efeito marcante. A influência de $\mathrm{Fe}$ (III) não pôde ser verificada, uma vez que a reação QL não é favorável em meio tão ácido, pois o pH da solução contendo Fe(III) precisou ser ajustado em $\mathrm{pH}=3,5$ para evitar a hidrólise deste íon (figura 17).

A presença de íons sulfato e hidrogenocarbonato $\left(1,0 \times 10^{-4} \mathrm{~mol} \mathrm{~L}-1\right)$ não influenciou o sinal de uma amostra de $\left[\right.$ cloro] $=2,0 \times 10^{-5} \mathrm{~mol} \mathrm{~L}^{-1}$; entretanto, ions $\mathrm{HPO}_{4}{ }^{2-}$ e NO 3 - diminuíram o sinal de $13 \%$ (tabela 4).

\section{Ill.5.2.1.h - Efeito da formação de cloramina}

O sinal de emissão QL aumentou na presença de $\mathrm{NH}_{4} \mathrm{Cl}$ (tabela 11). Sabe-se que o cloro reage com a amônia (equações 11 a 13) e forma mono-, di- e tricloramina.

A influência da cloroamina foi melhor avaliada analisando-se duas amostras diferentes: uma solução continha apenas cloro $\left([\mathrm{ClO}-]=2,0 \times 10^{-5} \mathrm{~mol} \mathrm{~L}^{-1}\right.$ e outra solução foi preparada pela mistura de $\mathrm{NH}_{4} \mathrm{Cl}$ e $\mathrm{ClO}^{-}$, de modo que as concentrações iniciais das soluções foram: $\left[\mathrm{NH}_{4} \mathrm{Cl}\right]=1,0 \times 10^{-5} \mathrm{~mol} \mathrm{~L}^{-1}$ e $[\mathrm{ClO}]=2,0 \times 10^{-5} \mathrm{~mol} \mathrm{~L}^{-1}$. Supondo a formação de $\mathrm{NH}_{2} \mathrm{Cl}$ (monocloramina, segundo equação 11), tem-se uma mistura de soluções $\left[\mathrm{NH}_{2} \mathrm{Cl}\right]=1,0 \times 10^{-5} \mathrm{~mol} \mathrm{~L}^{-1}$ e $[\mathrm{ClO}]=1,0 \times 10^{-5} \mathrm{~mol} \mathrm{~L}^{-1}$. 
A figura 21 mostra que o sinal obtido com a solução contendo $\left[\mathrm{NH}_{2} \mathrm{Cl}\right]=1,0 \times 10^{-5} \mathrm{~mol} \mathrm{~L}^{-1}$ e $[\mathrm{ClO}]=1,0 \times 10^{-5} \mathrm{~mol} \mathrm{~L}^{-1}$ aumentou e atingiu um valor máximo após 30 minutos de preparo da solução. Após 120 minutos, a solução contendo a mistura inicial de $\mathrm{NH}_{4} \mathrm{Cl}$ e $\mathrm{ClO}^{-}$e a solução contendo apenas $\mathrm{ClO}^{-}$ apresentaram emissão $Q L$ referente a $\left[\mathrm{ClO}^{-}\right]=1,0 \times 10^{-5} \mathrm{~mol} \mathrm{~L}^{-1}$ e $2,0 \times 10^{-5} \mathrm{~mol} \mathrm{~L}^{-1}$, respectivamente.

Durante a análise (60 minutos), a acidez da solução contendo $\mathrm{ClO}^{-}$mudou de 6,4 para 6,0 enquando a acidez da solução contendo a mistura de $\mathrm{NH}_{4} \mathrm{Cl}$ e ClOmudou de e 5,9 para 5,2. Como o sinal é fortemente influenciado pela acidez do meio (figura 17) e as variações de $\mathrm{pH}$ observadas neste experimento foram relativamente pequenas, 0 aumento da intensidade de emissão pode ser um indicativo da influência da formação de cloroamina na reação QL.

\section{III.5.2.1.i - Efeito de $\mathrm{ClO}_{2}^{-}, \mathrm{ClO}_{3}^{-}-$e $\mathrm{ClO}_{4}=$}

A tabela 12 mostra o efeito de $\mathrm{ClO}_{2}^{-}, \mathrm{ClO}_{3}^{-}$e $\mathrm{ClO}_{4}^{-}$na intensidade QL. As amostras de $\mathrm{ClO}_{2}^{-}, \mathrm{ClO}_{3}^{-}$e $\mathrm{ClO}_{4}^{-}$foram injetadas no sistema de análise em fluxo, na ausência de hipoclorito, para avaliar o efeito dos ânions individualmente. 


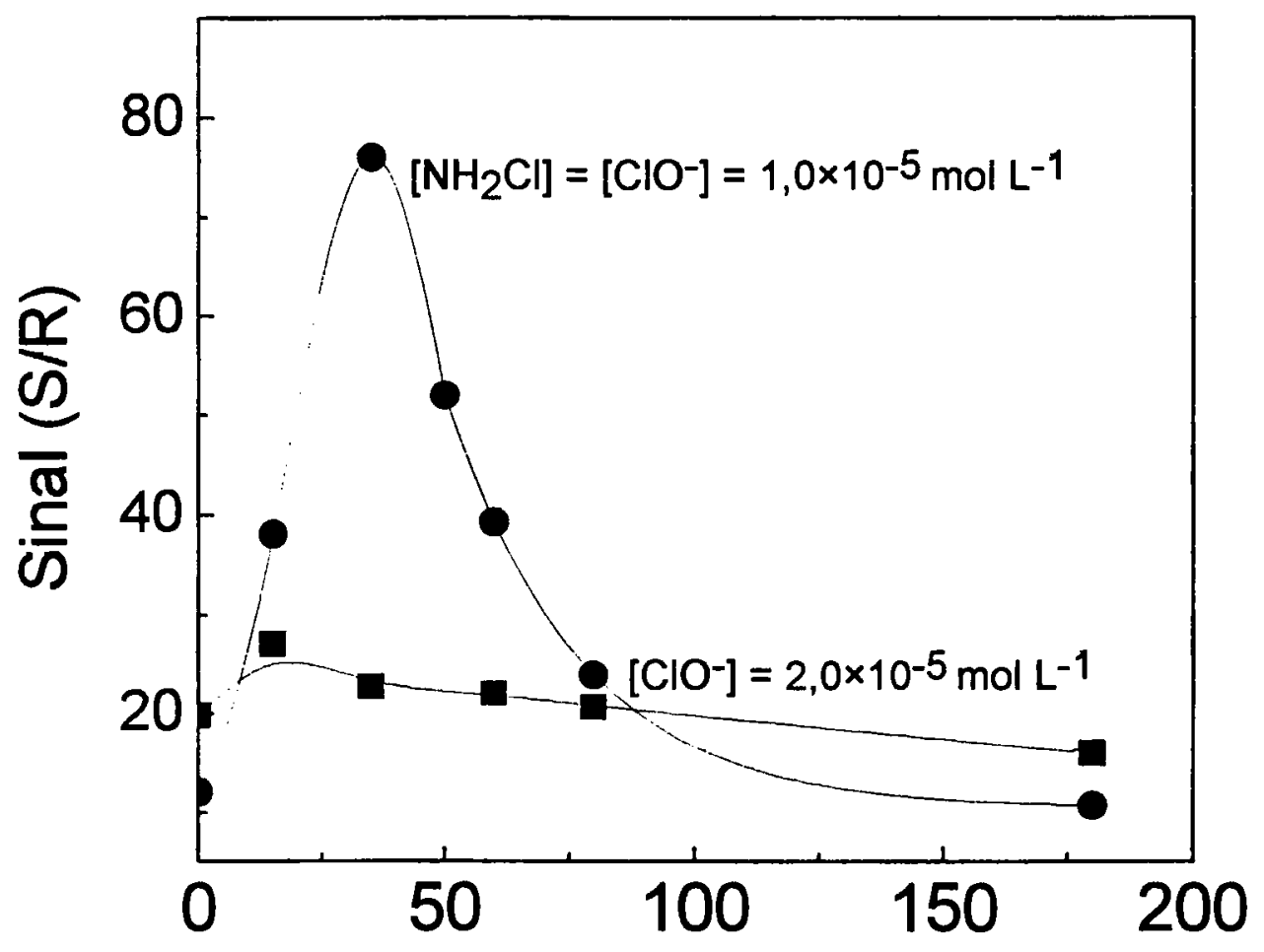

Tempo após a preparação da amostra/min

Figura 21 - Influência da formação da cloramina na intensidade de emissão QL da reação de TCPO e cloro.

$[T C P O]=5,0 \times 10^{-4} \mathrm{~mol} \mathrm{~L}^{-1}$ e $[D F A]=1,0 \times 10^{-3} \mathrm{~mol} \mathrm{~L}^{-1}$ dissolvidos em acetonitrila. TCPO e DFA a 1,0 mL min-1, vazão da água a 1,5 mL min-1. Amostra injetada (80 $\mu \mathrm{L})$ :

- [cloro]: $2,0 \times 10^{-5} \mathrm{~mol} \mathrm{~L}^{-1}$,

- mistura de $[$ cloro $]=2,0 \times 10^{-5}$ e $\left[\mathrm{NH}_{4} \mathrm{Cl}\right]=1,0 \times 10^{-5} \mathrm{~mol} \mathrm{~L}^{-1}$. 
Tabela 12 - Intensidade de emissão QL através da reação de TCPO com espécies contendo cloro.

$[T C P O]=5,0 \times 10^{-4} \mathrm{~mol} \mathrm{~L}^{-1},[D F A]=1,0 \times 10^{-3} \mathrm{~mol} \mathrm{~L}^{-1}(\mathrm{em}$ acetonitrila $)$. TCPO e DFA a $1,0 \mathrm{~mL} \min ^{-1}$, vazão da água a $1,5 \mathrm{~mL} \min ^{-1}$. Volume da amostra $=80 \mu \mathrm{L}$. N.D.: não detectado.

\begin{tabular}{lcc}
\hline \multirow{2}{*}{ Espécie } & \multicolumn{2}{c}{ Sinal (S/R) } \\
\cline { 2 - 3 } & $2,0 \times 10^{-5}$ & $1,0 \times 10^{-4}$ \\
\hline Cloro & 51 & - \\
$\mathrm{ClO}_{2}^{-}$ & & 700 \\
$\mathrm{ClO}_{3}^{-}, \mathrm{ClO}_{4}^{-}$ & 100 & N.D. \\
& & \\
\hline
\end{tabular}


Adam e colaboradores ${ }^{95}$ verificaram que na decomposição de uma solução de cloro ocorre a formação de clorato $\left(\mathrm{ClO}_{3}^{-}\right)$com diminuição da acidez do meio

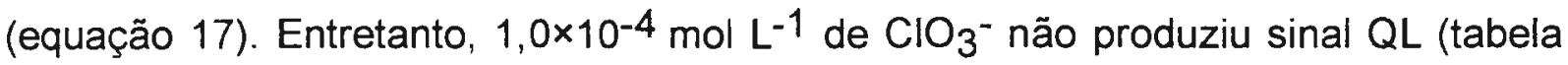
12).

A análise do efeito de clorito $\left(\mathrm{ClO}_{2}^{-}\right)$é interessante, pois ele pode ser formado pela decomposição de hipoclorito (ClO-) (equação 19$)^{89}$ ou ser produzido quando dióxido de cloro $\left(\mathrm{ClO}_{2}\right)$ é usado como um reagente alternativo no tratamento de água potável. $\mathrm{ClO}_{2}$ é gerado pela mistura de solução aquosa de cloro e clorito de sódio. O desproporcionamento de cloro leva à formação do ácido hipocloroso (equação 15), que reage com clorito, formando dióxido de cloro (equação 27) e clorato (equação 28) 91 :

$$
\begin{aligned}
& \mathrm{HClO}+2 \mathrm{ClO}_{2}^{-}+\mathrm{H}^{+} \rightarrow 2 \mathrm{ClO}_{2}+\mathrm{Cl}^{-}+\mathrm{H}_{2} \mathrm{O} \\
& \mathrm{HClO}+\mathrm{ClO}_{2}^{-} \rightarrow \mathrm{ClO}_{3}^{-}+\mathrm{Cl}^{-}+\mathrm{H}^{+}
\end{aligned}
$$

No presente trabalho, a dissolução de $\mathrm{ClO}_{2}^{-}$em água resultou em solução de $\mathrm{pH}$ aproximadamente 10,0 . Para acertar $\mathrm{opH}=6,0$ da solução estoque de cloro $1,0 \times 10^{-2} \mathrm{~mol} \mathrm{~L}^{-1}$, foi necessário adicionar $\mathrm{HCl} 1,0 \mathrm{~mol} \mathrm{~L}^{-1}$. Na tabela 12 verificou-se que $\left[\mathrm{ClO}_{2}^{-}\right]=1,0 \times 10^{-4} \mathrm{~mol} \mathrm{~L}-1$ produziu intensidade de emissão elevada.

Assim, no presente método, as espécies que podem reagir com TCPO na presença de DFA são as seguintes: cloro, cloroamina e clorito. 
III.5.2.1.j - Curva analitica para determinacão de cloro em água de torneira

Para o sistema de análise por injeção em fluxo (conforme esquema representado na figura 13) e condições otimizadas descritas na tabela 13, foi obtida uma curva analítica (figura 22 e tabela 13).

Tabela 13 - Condições ótimas para determinação de cloro pelo presente método FIA.

\begin{tabular}{lc}
\hline Parâmetros & Condições ótimas \\
\hline [TCPO] & $5,0 \times 10^{-4} \mathrm{~mol} \mathrm{~L}^{-1}$ \\
[DFA] & $1,0 \times 10^{-3} \mathrm{~mol} \mathrm{~L}^{-1}$ \\
Vazão de TCPO e DFA & $2,0 \mathrm{~mL} \mathrm{~min}{ }^{-1}$ \\
Vazão da água & $1,5 \mathrm{~mL} \mathrm{~min}^{-1}$ \\
Volume de amostra & $80 \mu \mathrm{L}$ \\
pH da amostra & 7,0 \\
\hline
\end{tabular}




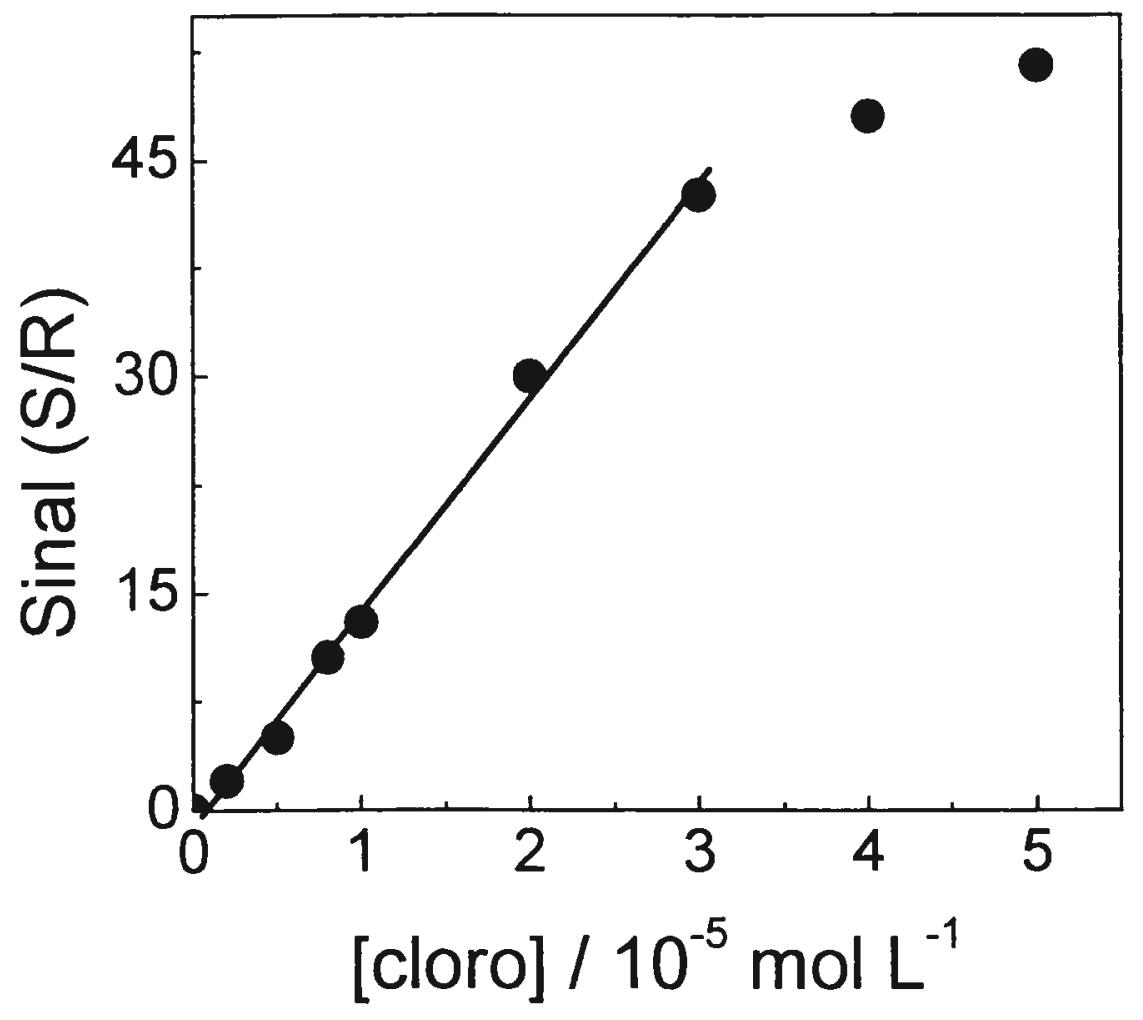

Figura 22 - Curva analítica para determinação de cloro por QL 
A análise de uma amostra de água da torneira (dentre várias analisadas), pelo presente método e o método envolvendo o procedimento titrimétrico (recomendado oficialmente) usando DPD (vide página 87 ) levou a concentrações $2,0 \times 10^{-5} \mathrm{~mol} \mathrm{~L}^{-1}$ e $1,8 \times 10^{-5} \mathrm{~mol} \mathrm{~L}^{-1}$, respectivamente.

As características do sistema FIA desenvolvidas no presente método estão descritas na tabela 14 .

Tabela 14 - Caracteristicas do presente sistema QL

Cloro

\begin{tabular}{ll}
\hline Linearidade & $2,0 \times 10^{-6}-3,0 \times 10^{-5} \mathrm{~mol} \mathrm{~L}^{-1}$ \\
Equação da reta & $-0,6+1,5 \times 10^{6} \times$ [cloro livre] \\
Limite de detecção & $2,0 \times 10^{-6} \mathrm{~mol} \mathrm{~L}^{-1}$ \\
$\mathrm{R}$ & $0,998(\mathrm{~N}=7)$ \\
Reprodutibilidade & $97 \%\left(\mathrm{n}=10\right.$, amostra de $\left.2,0 \times 10^{-5} \mathrm{~mol} \mathrm{~L}^{-1}\right)$ \\
\hline
\end{tabular}




\section{III.6.2 - Estudos espectrofotométricos para verificacão da hidrólise do TCPO}

A cinética da reação QL de TCPO com cloro livre, na presença de DFA é bastante complexa. Além disso, como a amostra está em meio aquoso, a hidrólise do TCPO (equações 25 e 26) deve ser considerada.

A intensidade de emissão de sistemas PO-QL é afetada pelas condições experimentais, incluindo natureza do solvente, teor de água, concentrações dos reagentes, acidez do meio e natureza do catalisador. Em meio composto por uma mistura de solvente orgânico e água, um dos parâmetros mais importantes parece ser a acidez do meio $51-54$.

Além disso, a detecção baseada em reações PO-QL está sujeita a emissão de fundo, um dos mais importantes fatores que limitam a sensibilidade dos métodos analiticos que utilizam estes sistemas QL.

Alguns estudos descritos na literatura atribuem a emissão de fundo à reação de TCPO com peróxido de hidrogênio, na ausência de um fluoróforo. Sigvardson e Birks ${ }^{137}$ registraram o espectro da emissão de fundo de uma mistura de TCPO e peróxido de hidrogênio, cujos máximos de emissão foram observados em 440 e 550 nm. 2,4,6-triclorofenol, o principal produto da reação PO-QL, foi considerado o responsável pela fraca emissão observada em $440 \mathrm{~nm}$.

Mann e Grayeski138 tentaram determinar a natureza das espécies responsáveis pela emissão de fundo. Observaram que a intensidade de emissão era dependente da natureza do oxalato de diarila, do fenol formado e também do $\mathrm{pH}$ da reação, sendo a intensidade de emissão menor em meio de maior concentração 
hidrogeniônica. Os autores sugeriram que a degradação do intermediário 1,2-dioxetanodiona produz duas moléculas de dióxido de carbono, uma delas no estado excitado, e que a emissão de fundo em $440 \mathrm{~nm}$ é causada pela fosforescência do dióxido de carbono excitado.

Hanaoka e colaboradores 139 observaram que a intensidade de emissão de fundo diminuía com a diminuição do $\mathrm{pH}$ do meio, sendo esta dependente da temperatura, teor de água e concentração do catalisador.

Os estudos de Barnett e colaboradores 128,129 sugeriram que a oxidação de fenol ao radical fenoxila, em meio alcalino poderia ser responsável pela emissão de fundo.

Tripathi e Schuler ${ }^{140}$ utilizaram espectroscopia Raman para sugerir que a emissão de fundo da reação QL de PO-QL pode ser devido a radicais fenoxila quimicamente excitados.

No presente trabalho, a hidrólise do TCPO, com formação do ácido oxálico e 2,4,6-triclorofenol (TCP) foi estudada pelo método espectrofotométrico.

Estudos complementares foram realizados, pois no método analítico desenvolvido, a amostra contendo cloro é aquosa, de modo que no sistema de análise em fluxo (figura 13, página 89), a solução contida na célula após a mistura contém: TCPO, DFA, cloro em 50/50\% (v/v) água/acetonitrila. Além do mais, a tabela 7 (página 97) mostra que quando uma solução de TCPO foi preparada em solvente contendo 10/90\% (v/v) água/acetonitrila, não foi observado sinal QL. 


\section{II.6.1 - Parte Experimental}

\section{III.6.1a-Reagentes}

- Solução de oxalato de bis(2,4,6-triclorofenila) (TCPO) (Nakalai Chemicals Ltd) (5,0×10-4 mol L-1): $6 \mathrm{mg}$ de TCPO foram dissolvidos em 25,0 mL de acetonitrila. A solução foi mantida em banho de ultrassom, até completa solubilização. A solução foi preparada diariamente.

- Solução de 2,4,6-triclorofenol (TCP) (Merck) (5,0×10-4 mol L-1): 3 mg de TCP foram dissolvidos em $25,0 \mathrm{~mL}$ de acetonitrila.

- Solução de $\mathrm{NaClO}(1,0 \times 10-2 \mathrm{~mol} \mathrm{L-1}): 48 \mu \mathrm{L}$ de solução de $\mathrm{NaClO} 8-13 \%$ (Synth) foram dissolvidos em balão de $25,0 \mathrm{~mL}$ com água desionizada. Imediatamente antes da análise, a partir da solução estoque 1,0×10-2 mol L-1 foram preparadas as soluções diluídas de hipoclorito. O acerto da acidez da solução diluída de hipoclorito a $\mathrm{pH}=6,0-7,0$ foi feito com a adição de $\mathrm{HCl} 1,0$ mol L-1 (Merck), utilizando potenciômetro Metrohm 654 equipado com eletrodo de vidro combinado. As soluções diluídas de hipoclorito foram utilizadas por no máximo 3 horas após a preparação. A solução estoque de hipoclorito foi padronizada pelo método iodométrico ${ }^{123}$.

\section{III.6.1b-Procedimento experimental}


Nos estudos espectrofotométricos para verificação da reação de hidrólise de TCPO, os espectros UV-VIS foram registrados com o espectrofotômetro HP 8543 "diode array". Uma cela de quartzo (Tanden), de caminho óptico 1,0 cm, com dois compartimentos, foi empregada. A água foi utilizada como solução de referência (branco). A temperatura foi mantida constante em $25,0^{\circ} \mathrm{C}$. Os experimentos foram realizados misturando-se $1,0 \mathrm{~mL}$ de solução de [TCPO] ou [TCP] $=5,0 \times 10^{-4} \mathrm{~mol} \mathrm{~L}^{-1}$ e 1,0 mL de água, em diferentes pH. As concentrações finais das soluções após a mistura dos reagentes estão indicadas nas legendas

Para o acompanhamento de reações rápidas, foi utilizado o aparelho de "stopped flow" Pro-K 2000 Stopped Flow Mixing Accessory (Applyed Photophysics) acoplado a espectrofotômetro HP 8543 "diode-array".

O esquema do aparelho "stopped flow" empregado está representado na figura 23. Um dispositivo, que funciona sob pressão de ar comprimido (4 atm) empurra as soluções contidas nas seringas $A$ e $B$, fazendo com que elas se misturem rapidamente no compartimento de mistura para chegar instantaneamente à célula. Quando o fluxo é parado subitamente logo após a mistura, um "trigger" é acionado dando início à aquisição de dados de absorbância, em função do tempo, através de um computador acoplado em série.

Neste sistema, a seringa A foi preenchida com solução de $[\mathrm{TCPO}]=5,0 \times 10^{-4}$ mol L-1 (solubilizado em acetonitrila) e a seringa B com água ou solução aquosa de hipoclorito $\left[\mathrm{CIO}^{-}\right]=1,0 \times 10^{-3} \mathrm{~mol}$ L-1. Nos testes realizados para verificar a influência do teor de água, somente a solução de hipoclorito foi preparada em meios de diferente acidez, ou com teor de água variável. 


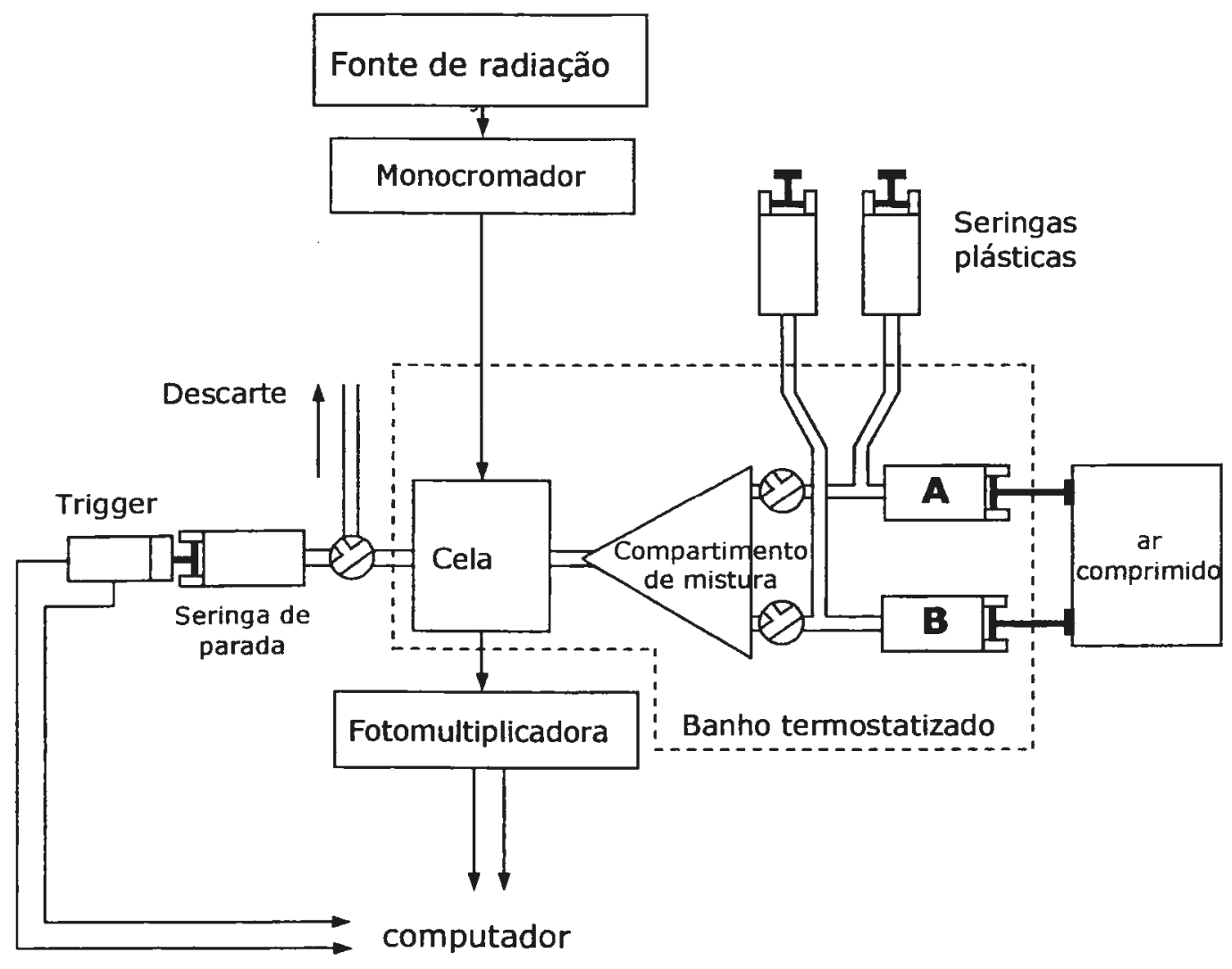

Figura 23 - Diagrama esquemático do aparelho "stopped flow" empregado. 


\section{III.6.2 - Resultados e discussão}

\section{III.6.2a - Estudo da hidrólise de TCPO, na ausência de hipoclorito}

Nos experimentos para verificar a hidrólise do TCPO, foram realizadas misturas de soluções de TCPO com água, acompanhando-se a variação dos espectros da solução resultante contendo TCPO e TCP (produto da hidrólise) (equações 25 e 26, página 96). Uma solução de oxalato $\left(2,0 \times 10^{-4} \mathrm{~mol} \mathrm{L-1}\right.$ ) praticamente não absorve em $\lambda<280 \mathrm{~nm}$.

Inicialmente foram preparadas soluções contendo apenas TCP $\left(\mathrm{pK}_{\mathrm{a}}=6,35\right.$ em meio aquoso e $\mathrm{pK}_{\mathrm{a}}=20,4$, em meio de acetonitrila ${ }^{141}$ ) em meio contendo $50 / 50 \%(v / v)$ acetonitrila/água em meios com diferentes $\mathrm{pH}$ (figura 24). Em pH = 1,0, predomina a espécie 2,4,6-triclorofenol $\left(\lambda_{\max }=286 \mathrm{~nm}\right)$ e em pH $=12,0$, a espécie $2,4,6$ triclorofenolato $\left(\lambda_{\max }=316 \mathrm{~nm}\right)$

A figura 25 mostra espectros comparativos de soluções de 2,4,6-triclorofenol em $\mathrm{pH}=1,0$ (fig. 25c) e pH = 12,0 (fig. 25d). Quando a solução de TCPO é preparada em $100 \%$ acetonitrila (fig. 25a), uma banda foi observada em $\lambda<300 \mathrm{~nm}$. A hidrólise de TCPO pôde ser observada em meio contendo $50 / 50 \%(v / v)$ água/acetonitrila ( $\mathrm{pH}=5,6$ ) (fig. $25 b$ ), no qual aparecem os máximos de absorção característicos de TCPO: $286 \mathrm{~nm}$ (correspondente ao 2,4,6-triclorofenol) e $320 \mathrm{~nm}$ (ânion 2,4,6-triclorofenolato). 


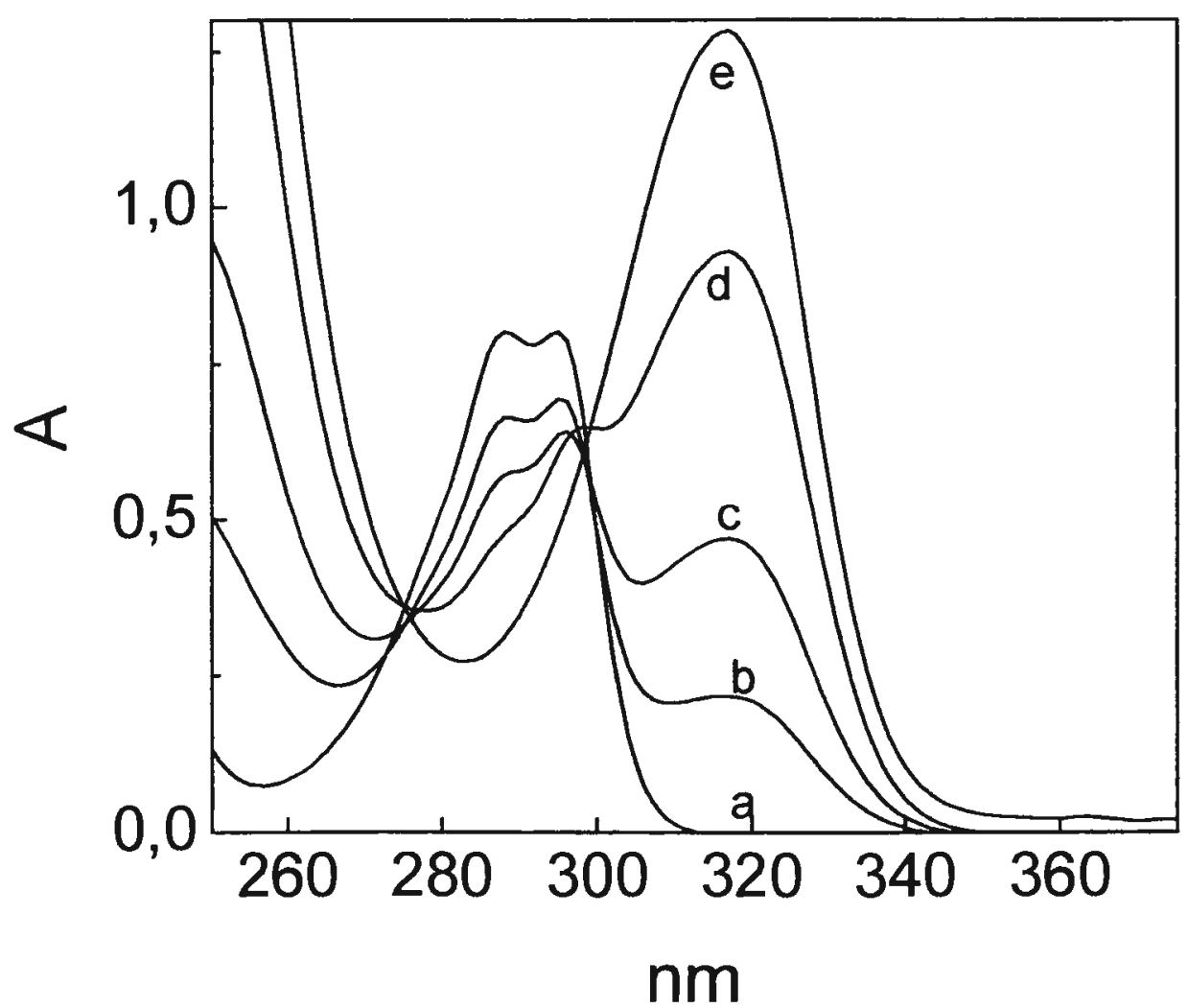

Figura 24 - Espectros UV-ViS de soluções de 2,4,6-triclorofenol $\left([T C P]=2,5 \times 10^{-4}\right.$ mol L-1) em diferentes $\mathrm{pH}$ : a) 1,0, b) 6,3, c) 6,8, d) 7,4 e e) 12,0 


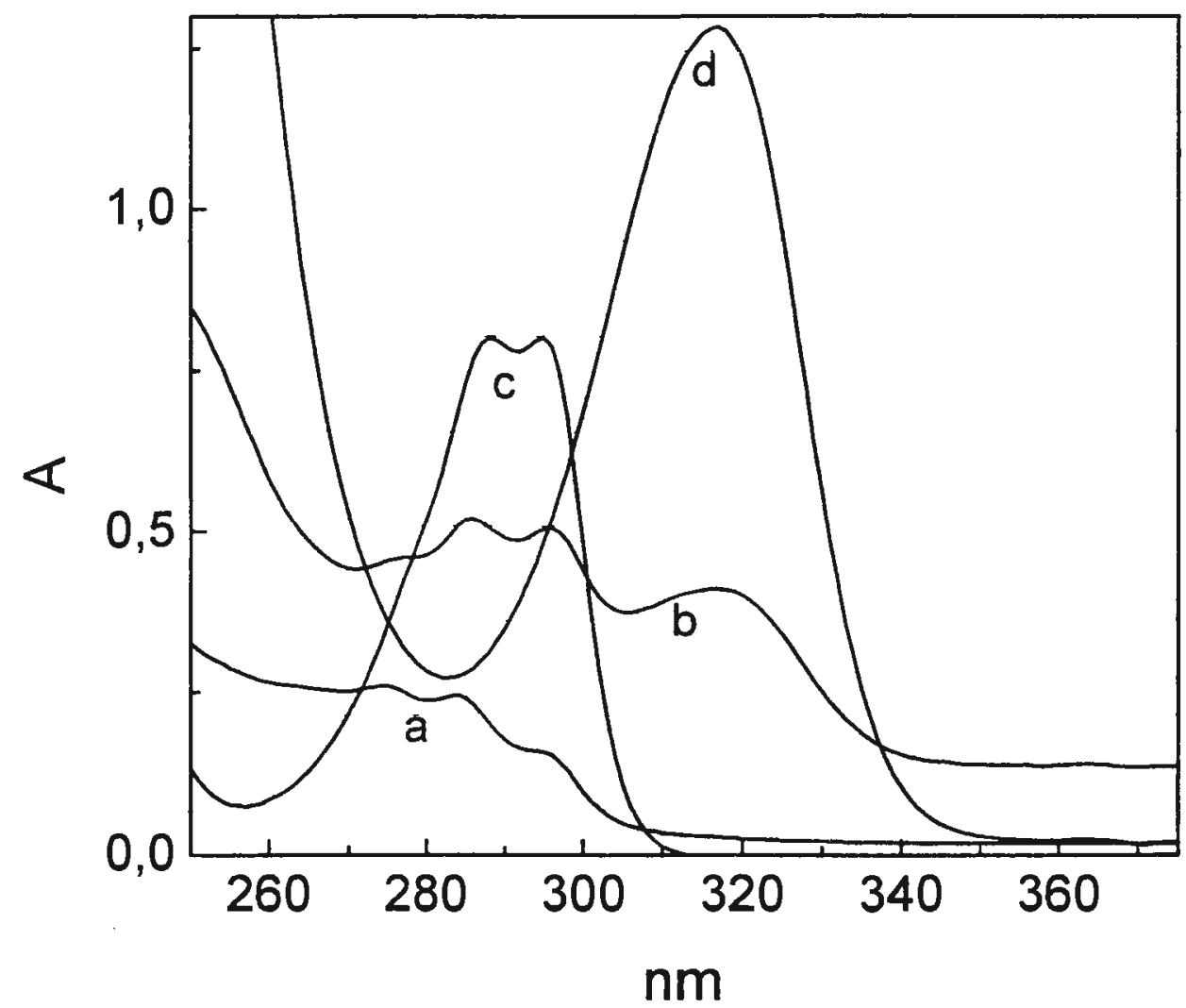

Figura 25 - Comparação dos espectros de: a) $[\mathrm{TCPO}]=2,5 \times 10^{4} \mathrm{~mol} \mathrm{~L}^{-1} \mathrm{em}$ acetonitrila, b) $[\mathrm{TCPO}]=2,5 \times 10^{-4} \mathrm{~mol} \mathrm{~L}^{-1}(\mathrm{pH}=5,6) \mathrm{em} 50 \%(\mathrm{v} / \mathrm{v})$ água/acetonitrila, c) $[2,4,6$-triclorofenol $]=2,5 \times 10^{-4} \mathrm{~mol} \mathrm{~L}^{-1}$ em $50 / 50 \%(\mathrm{v} / \mathrm{v})$ água/acetonitrila, $\mathrm{pH}=1,0$ e d) $[2,4,6$-triclorofenol $]=2,5 \times 10^{-4} \mathrm{~mol} \mathrm{~L}^{-1} \mathrm{em} 50 / 50 \%(\mathrm{v} / \mathrm{v})$ água/acetonitrila, $\mathrm{pH}=$ 12,0. Branco: água 
Acompanhando-se as variações de absorbância com o tempo em $286 \mathrm{~nm}$, foi possível concluir que, em meio contendo 50/50\% (v/v) água/acetonitrila, a reação de hidrólise de TCPO não foi completa nos primeiros 60 segundos (figura 26). Isso significa que no sistema de análise em fluxo (figura 13, página 89), descrito no presente trabalho, além da reação $Q \mathrm{~L}$, também ocorre a reação de hidrólise do TCPO, na célula em espiral (depois da mistura com a água), em pequena extensão.

Entretanto, uma solução $[\mathrm{TCPO}]=5,0 \times 10-4 \mathrm{~mol} \mathrm{L-1}$ preparada em meio água/acetonitrila, não pode ser usada no sistema em fluxo (tabela 7, página 97), uma vez que conforme o tempo de preparo da solução de TCPO aumenta, em meio parcialmente aquoso a hidrólise ocorre em extensão suficiente para o sinal QL não ser observado.

\section{IIl.6.2b - Estudos espectrofotométricos da reação de TCPO com hipoclorito}

Inicialmente foram registrados espectros de soluções de hipoclorito $(\mathrm{pKa}=$ 7,4, equação 20(89)) em meios com diferentes pH (figura 27). $\mathrm{Em} \mathrm{pH}=3,3$ e 6,3 predomina a espécie $\mathrm{HClO}\left(\lambda_{\max }=240 \mathrm{~nm}\right.$ e em pH $=8,5$ e 9,8, a espécie $\mathrm{ClO}^{-}$ $\left(\lambda_{\max }=292 \mathrm{~nm}\right)$

$\mathrm{Na}$ figura 28 estão representados os espectros sucessivos, a cada $0,6 \mathrm{~s}$, da mistura de solução de TCPO (em 100\% de acetonitrila) com solução de hipoclorito (em 10/90\%(v/v) água/acetonitrila). 


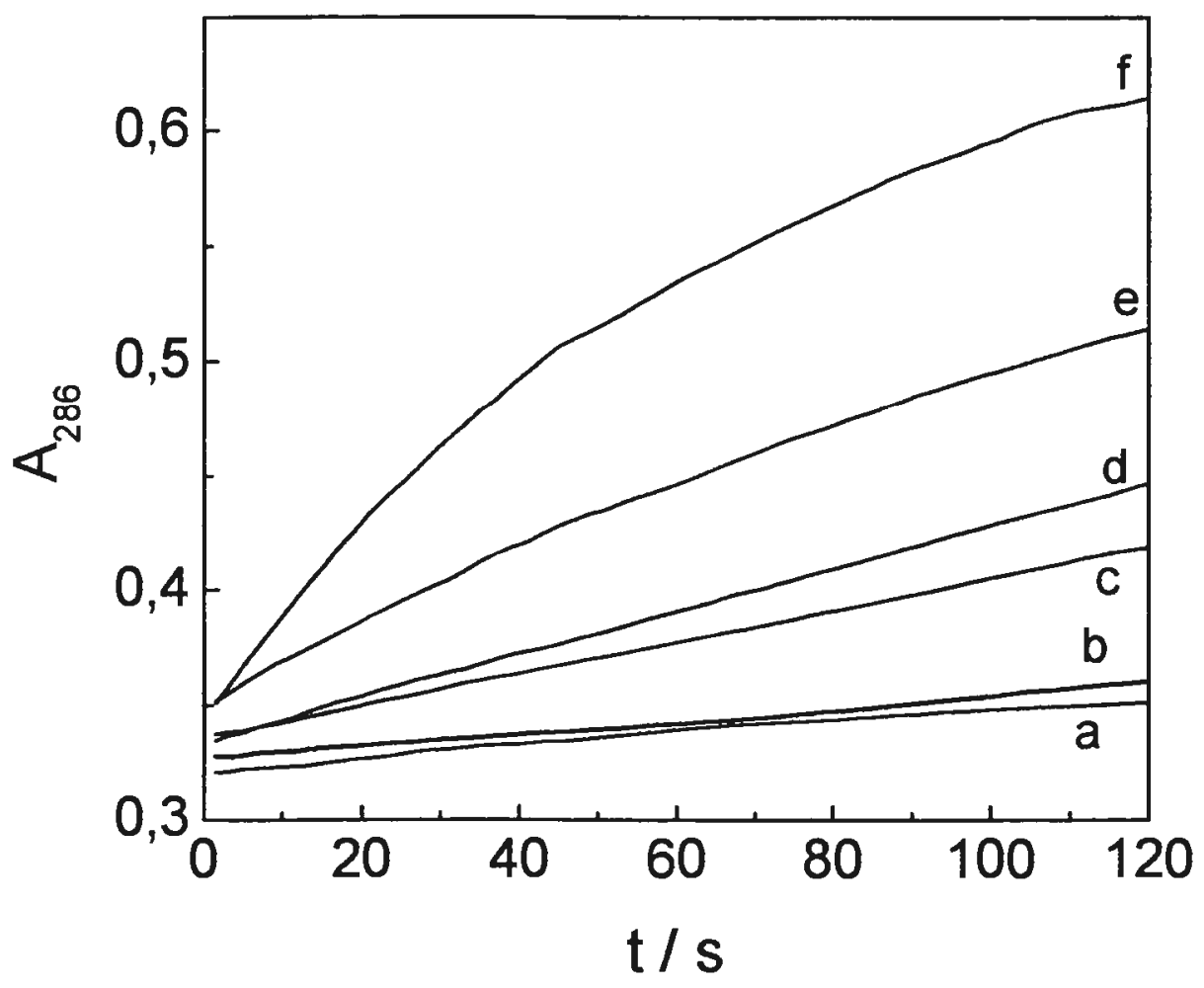

Figura 26 - Acompanhamento da reação de hidrólise de $[\mathrm{TCPO}]=2,5 \times 10^{4} \mathrm{~mol} \mathrm{~L}^{-1}$ em meio com diferentes teores de água $(\% \mathrm{v} / \mathrm{v})$, em relação à acetonitrila:

a) zero, b) 10 , c) 20 , d) 30 , e) 40 e f) 50 . 


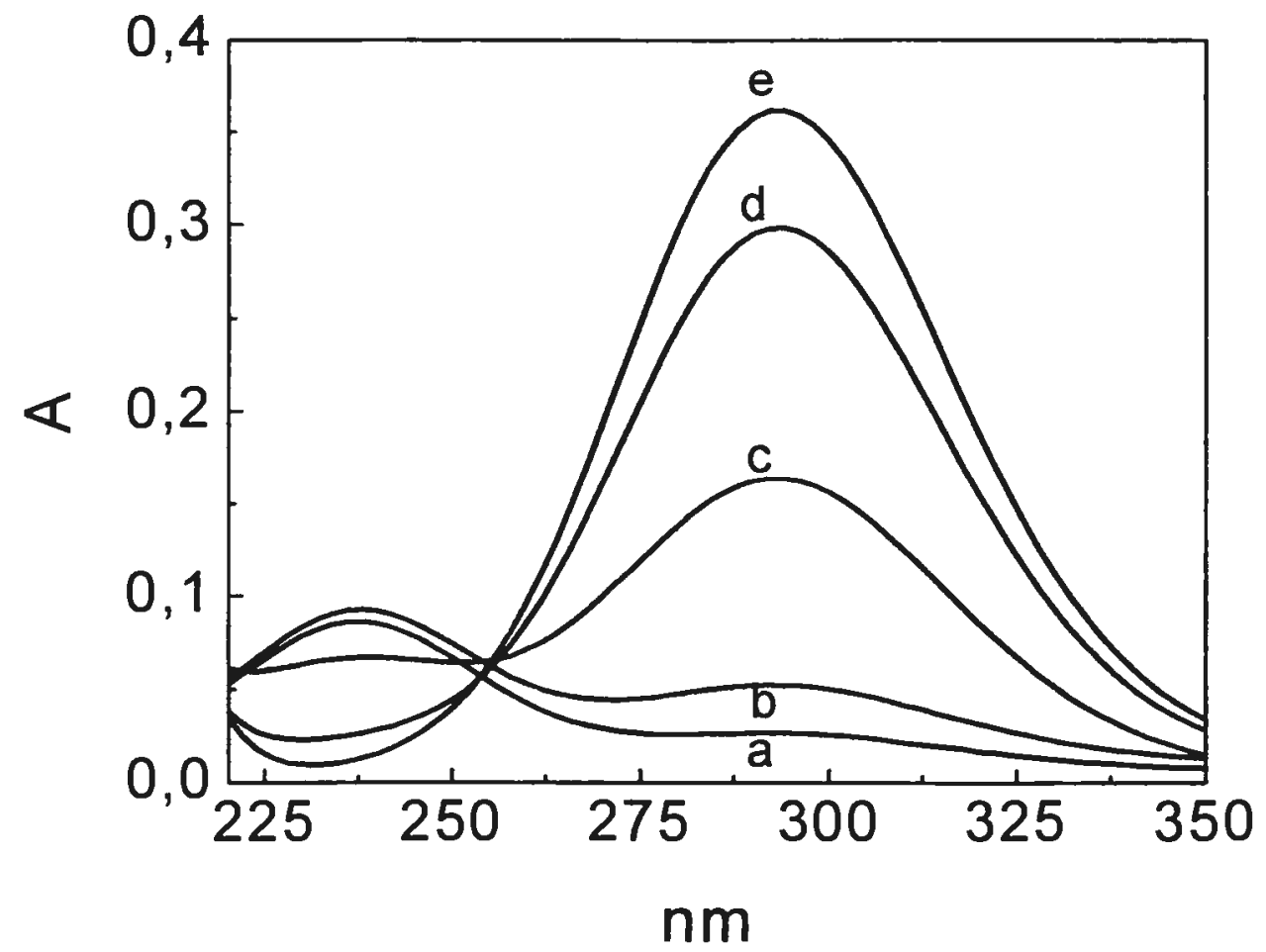

Figura 27 - Espectros UV-ViS de soluções de cloro $\left[\left(\mathrm{HClO}+\mathrm{ClO}^{-}\right)\right]=1,0 \times 10^{-3}$ $\mathrm{mol} \mathrm{L}^{-1} \mathrm{em} \mathrm{pH}$ a) 3,3, b) 6,3, c) 7,5 , d) 8,5 e e) 9,8 . 


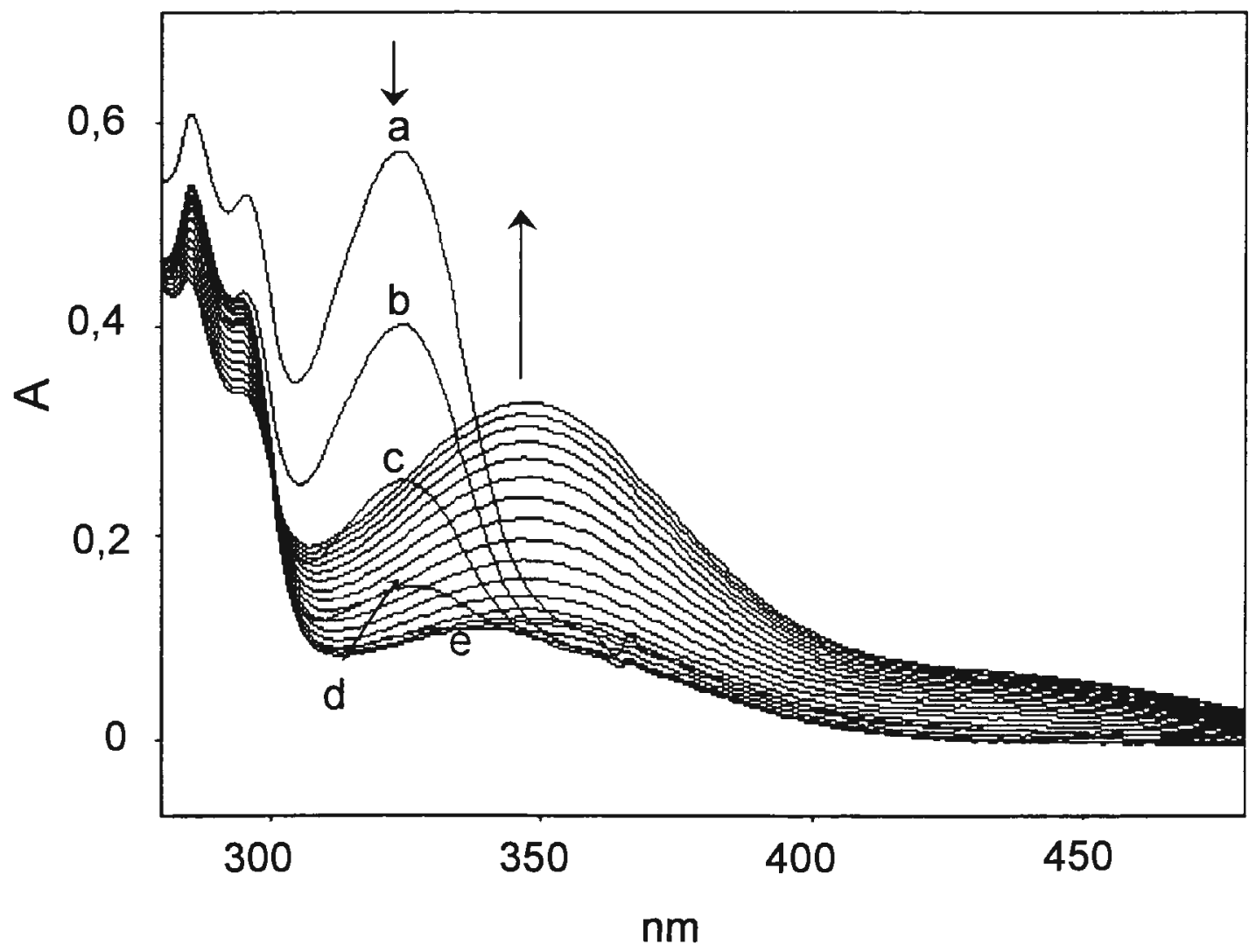

Figura 28 - Espectros sucessivos a cada 0,6 s após mistura de TCPO (em 100\% acetonitrila) com solução de cloro (em 10/90 (\%v/v) água/acetonitrila). As letras indicam a sequência dos cinco primeiros espectros após mistura das soluções de TCPO e cloro. Concentrações das soluções imediatamente após a mistura: [TCPO] $=2,5 \times 10^{-4}$ e $[$ cloro $]=5,0 \times 10^{-4} \mathrm{~mol} \mathrm{~L}^{-1}$ em meio contendo $10 / 90(\% \mathrm{v} / \mathrm{v})$ água/acetonitrila. 


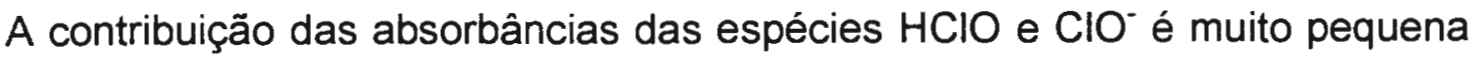
nesse nivel de concentração $\left(5,0 \times 10^{-4} \mathrm{~mol} \mathrm{~L}^{-1}\right)$, uma vez que as absortividades molares são : $\varepsilon=100 \mathrm{~mol}^{-1} \mathrm{~L} \mathrm{~cm}^{-1}(\mathrm{HClO}$, em $292 \mathrm{~nm})$ e $\varepsilon=351 \mathrm{~mol}^{-1} \mathrm{Lcm}^{-1}(\mathrm{ClO}$, em $292 \mathrm{~nm})^{89}$. Os espectros das soluções de TCPO e cloro, antes da mistura, estão representados na figura 25a. Na figura 28a está representado o espectro depois de $0,6 \mathrm{~s}$ após a mistura das soluções de TCPO e cloro, seguidos dos demais espectros (figuras $28 \mathrm{~b}-\mathrm{e}$ ). A reação QL ocorre nos primeiros segundos com formação de produtos (que absorvem em $320 \mathrm{~nm}$ ), seguida de suas decomposições em uma etapa mais lenta, mostrada pelo aumento da absorbância em $350 \mathrm{~nm}$.

Quando soluções de hipoclorito $\left(5,0 \times 10^{-4} \mathrm{~mol} \mathrm{~L}^{-1}\right)$ em diferentes concentrações hidrogeniônicas ( $\mathrm{pH}=6,0$ a 9,0) foram empregadas, observou-se que a absorbância em $320 \mathrm{~nm}$ aumenta com $\mathrm{opH}$ da solução. Um aumento da absorbância também ocorreu com o aumento do teor de água da solução resultante, nesse caso os expertimentos foram realizados com solução de hipoclorito $\left(5,0 \times 10^{-4}\right.$ mol $\mathrm{L}^{-1}$ ) e teor de água variável (de 5-50\%)

\section{$\underline{11.7-\text { Conclusões }}$}

No método ora proposto, o intervalo de linearidade dependerá também da intensidade de emissão vs tempo (figura 14). O tempo total da reação decresce com o aumento da concentração de cloro livre. Por exemplo, quando amostras de $\mathrm{ClO}^{-}$ 
tempo total de reação foi 10 e $2 \mathrm{~s}$, respectivamente. Em sistemas em fluxo somente uma parte da curva de intensidade vs tempo (figura 1) pode ser medida e o intervalo de tempo de medida é também afetado por parâmetros como: vazão do transportador e reagentes, volume entre os pontos de mistura dos fluxos e a deteç̧ão e o volume e construção da célula. Como a velocidade dessa reação aumenta (podendo ser muito rápida, de alguns segundos) com a concentração de cloro, o intervalo de linearidade pode ser maior quando os experimentos são realizados no modo estático (figura 7 ).

$\mathrm{Na}$ ausência de cloro, o sinal aumentou em pH acima de 7,5 e a intensidade de radiação emitida depende da acidez da amostra.

O método proposto pode ser utilizado para determinação de cloro em água de torneira, com interferências de cloramina e clorito e menor interferência de $\mathrm{Cu}(I I)$ e $\mathrm{Mn}$ (II) $\left(1,0 \times 10^{-6} \mathrm{~mol} \mathrm{I}^{-1}\right)$. Comparado com o método DPD, cujo limite de deteç̧ão é de $50 \mu \mathrm{g} . \mathrm{I}^{-1}$, o presente método tem um limite de deteç̧ão de $\left.52 \mu \mathrm{g} . \mathrm{I}^{-1}\right)$. Entretando, pelo método $\mathrm{DPD}$, cloro e cloramina presentes em uma mesma amostra podem ser determinados.

A reatividade do TCPO é bastante afetada pelo grau de hidrólise do reagente e a reação com cloro, dependendo da concentração, é muito rápida, mas mesmo com estas limitações, uma amostra aquosa pode ser analisada pelo método FIA desenvolvido.

A complexidade do sistema não permitiu que suposiçōes sobre as espécies envolvidas fossem realizadas. A interpretação de dados cinéticos é muito complexa e os dados obtidos por sistemas FIA não são adequados. O tempo de reação e a reatividade de TCPO dependem da concentração dos reagentes e do grau de 
reatividade de TCPO dependem da concentração dos reagentes e do grau de hidrólise do reagente. Melhores informações poderiam ser obtidas por experimentos realizados no modo estático equipados com programa de aquisição de dados "on line", para reaçōes rápidas.

A intensidade de emisão da reação de TCPO com cloro é muito menor que com peróxido de hidrogênio. O mecanismo da reação QL com peróxido de hidrogênio, por apresentar rendimento quântico QL maior tem sido vastamente estudado por vários autores.

\section{IV-Perspectivas futuras}

Com a aquisição de novo equipamento em nosso laboratório, será possível a realização de experimentos no modo estático, empregando-se pequenos volumes

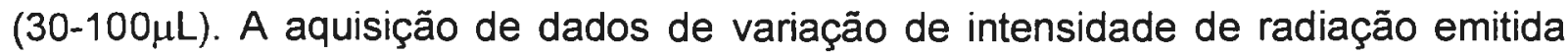
com o tempo será efetuada com computador acoplado. Os seguintes estudos serão realizados como continuidade do presente trabalho:

- Efeito de surfactantes na reação de TCPO e 2-NPO com peróxido de hidrogênio em meio tamponado, com o objetivo de estudar o efeito da natureza do tampão, acidez do meio e tipo do surfactante e,

- Efeito da presença de oxigênio na reação de TCPO com hipoclorito em meio de diferentes acidez. 


\section{$\underline{\text { V-Referências bibliográficas }}$}

1. M. J. Cormier, D. M. Hercules e J. Lee, "Chemiluminescence and bioluminescence", Plenun Press, New York, 1973

2. W. R. Seitz e M .P. Neary, Chemiluminescence and bioluminescence in chemical analysis, Anal. Chem., 46, 188A-202A, 1974

3. U. Isacsson e G. Wettermark, Chemiluminescence in analytical chemistry, Anal. Chim. Acta, 68, 339-362, 1974

4. D. B. Paul, Recent analytical developments using chemiluminescence in solution, Talanta, 25, 377-382, 1978

5. P. A. Sherman, J. Holzbecher e D. E. Ryan, Analytical applications of peroxyoxalate chemiluminescence, Anal. Chim. Acta, 97, 21-27, 1978

6. L. J. Kricka e G. H. G. Thorpe, Chemiluminescent and bioluminescent methods in analytical chemistry, Analyst, 108, 274-1296, 1983

7. J. N. Miller, Recent developments in fluorescence and chemiluminescence analysis, Analyst, 109, 191-198, 1984

8. S. G. Shulman, "Molecular Luminescence Spectroscopy - Methods and Applications: Part 1 em Chemical Analysis", v. 77, John Wiley and Sons, New York, 1985, p.17

9. K. D. Gundermann e F. McCapra, "Chemiluminescence in Organic Chemistry", Springer Verlag, Berlin, 1987 
10. M. L. Grayeski, Chemiluminescence analysis, Anal. Chem., 59, 1243A-1256A, 1987

11. A. K. Campbell, "Chemiluminescence - Principles and applications in biology and medicine", Ellis Horwood, Chichester, 1988

12. D. Pérez-Bendito, M. Silva, "Kinetic Methods in Analytical Chemistry", Ellis Horwood, Chichester, 1988

13. G. J. Jong e P. J. M. Kwakman, Chemiluminescence detection for high performance liquid chromatography of biomedical samples, J. Chromatogr., 492, $319-343,1989$

14. A. Townshend, Solution chemiluminescence-some recent analytical developments: plenary lecture, Analyst, 115, 495-500, 1990

15. K. Robards e P. J. Worsfold, Analytical applications of liquid-phase chemiluminescence, Anal. Chim. Acta, 266, 147-173, 1992

16. A. R. Bowie, M. G. Sanders e P. J. Worsfold, Analytical applications of liquid phase chemiluminescence reactions - a review, J. Biolumin. Chemilumin., 11, 61-90, 1996

17. L. P. Palilis e A. C. Calokerinos, Analytical applications of chemiluminogenic reactions, Anal. Chim. Acta, 413, 175-186, 2000

18. W. L. Hinze, N. Srinivasan, T. K. Smith, S. Igarashi e H. Hoshino, Organized assembles in analytical chemiluminescence spectroscopy: an overview, In: "Advances in Multidimensional Luminescence", vol.1, JAI Press, 149-206, 1991 
19. M. M. Rauhut, A. M. Semsel e B. G. Roberts, Reaction rates quantum yields and partial mechanism for chemiluminescent reaction of 3-aminophthalhydrazide with aqueous alkaline hydrogen peroxide and persulfate, J. Org. Chem, 31, 2431- 2436, 1966

20. G. B. Schuster, Chemiluminescence of organic peroxides - conversion of ground-state reactants to excited-state products by the chemically-initiated electronexchange luminescence mechanism, Acc. Chem. Res., 12, 366-373, 1979

21. J. L. Burguera, A. Townshend e S. Greenfield, Flow-injection analysis for monitoring chemiluminescent, Anal. Chim.Acta, 114, 209-214, 1980

22. J. Ruzicka e E. H. Hansen, Flow injection analysis. New concept of fast continuous-flow analysis, Anal. Chim. Acta, 78, 145-157, 1975

23. S. Stieg e T. A. Nieman, Experimental and theoretical considerations of flow cell design in analytical chemiluminescence, Anal. Chem., 50, 401-404, 1978

24. R. Albertin, M. A. G. Arribas, E. L. Bastos, S. Röpke, P. N. Sakai, A. M. M. Sanches, C. V. Stevani, I. S. Umezu, J. Yu e W. J. Baader, Organic chemiluminescence: some classroom demonstration experiments, 21, 772-779, 1998

25. B. Del Castillo, M. A. Martin, P. Martin, B. Lin e P. Portillo, Chimicoggi 5, 55, 1988

26. B. Radziszewski, Chem. Ber., 10, 70, 1877

27. E. Wiedemann, Ann. Phys. Chem., 34, 446, 1888

28. R. Dubois, C. R. Acad. Sci., 132, 431, 1901

29. M. Trautz, Z. Phys. Chem. 53, 1, 1905 
30. H. Kautski e H. Zochar, Z. Phys., 9, 267, 1922

31. L. Mallet, Comp. Rend., 185, 352, 1927

32. H. O. Albrecht, Z. Phys. Chem., 136, 321, 1928

33. K. Gleu e W. Petsch, Angew. Chem., 48, 57, 1935

34. E. A. Chandross, A new chemiluminescent system, Tetrahedron Lett., 12, 761765,1963

35. M. M. Rauhut, B. G. Roberts e A. M. Semsel, A study of chemiluminescence from reactions of oxalyl chloride hydrogen peroxide and fluorescent compounds, J. Am. Chem. Soc., 88, 3604-3617, 1966

36. T. G. Curtis e W. R. Seitz, Chemiluminescence - new method for detecting fluorescent compounds separated by thin-layer chromatography, J. Chromatogr., 134, 343-350, 1977

37. S. Kobayashi e K. Imai, Determination of fluorescent compounds by highperformance liquid-chromatography with chemiluminescence detection, Anal. Chem., $52,424-427,1980$

38. E. H. White, O. Zafiriou, H. H. Kagi e J. H. M. Hill, Chemiluminescence of luminol: the chemical reaction, J. Am. Chem. Soc., 86, 940-941, 1964

39. T. G. Burdo e W. R. Seitz, Mechanism of cobalt catalysis of luminol chemiluminescence, Anal. Chem., 47, 1639-1643, 1975

40. G. Merényi, J. Lind e T. E. Eriksen, Luminol chemi-luminescence - chemistry, excitation, emitter, J. Biolum. Chemilum, 5, 53-56, 1990 
41. E. C. Ferreira e A. V. Rossi, A quimiluminescência como ferramenta analítica: do mecanismo a aplicações da reação do luminol em métodos cinéticos de análise, Quim. Nova, 25, 1003-1011, 2002

42. V. V. S. E. Dutt e H. A. Mottola, Some analytical applications of reaction-ratepromoting effects, Anal. Chem., 46, 1090-1094, 1974

43. C. B. Xiao, D. W. King, D. A. Palmer e D. J. Wesolowski, Study of enhancement effects in the chemiluminescence method for $\mathrm{Cr}(I I I)$ in the $\mathrm{ng} 1(-1)$ range, Anal. Chim. Acta, 415, 209-219, 2000

44. M. M. Rauhut, D. Sheehan, R. A. Clarke e A. M. Semsel, Photochem Photobiol, 4, 1097-1110, 1965

45. M. M. Rauhut, D. Sheehan, R. A. Clarke, B. G. Roberts e A. M. Semsel, Chemiluminescence from reaction of 9-chlorocarbonyl-10-methylacridinium chloride with aqueous hydrogen peroxide, J Org Chem, 30, 3587-3592, 1965

46. A. G. Hadd e J. W. Birks, Peroxyoxalate chemiluminescence: mechanism and analytical detection, Em: "Selective Detectors", vol. 131, p. 209-240, John Wiley, New York, 1995

47. P. J. M. Kwakman e U. T. Th. Brinkman, Peroxyoxalate chemiluminescence detection in liquid chromatography, Anal. Chim. Acta, 266, 175-192, 1992

48. G. B. Schuster e S. P. Schimidt, Chemiluminescence of organic compounds, Adv. Phys. Org. Chem., 18, 187-238, 1982 
49. A. L. P. Nery e W. J. Baader, Quimiluminescência de peróxidos orgânicos: geração de estados eletronicamente excitados na decomposição de 1,2-dioxetanos, Quím. Nova, 24, 626-636, 2001

50. K. W. Sigvardson e J. W. Birks, Peroxyoxalate chemiluminescence detection of polycyclic aromatic amines in liquid chromatography, Anal. Chem., 56, 1096-1102, 1984

51. F. Mc Capra, Prog. Org. Chem., 8, 231, 1973

52. C. V. Stevani, S. M. Silva, W. J. Baader, Studies on the mechanism of the excitation step in peroxyoxalate chemiluminescence, Eur. J. Org. Chem. 4037-4046, 2000

53. N. Hanaoka, R. S. Givens, R. L. Schowen e T. Kuwana, Stopped flow determination of the parameters affecting the application of peroxyoxalate chemiluminescence to high-performance liquid chromatographic detection, Anal. Chem, 60, 2193-2197, 1988.

54. F. J. Alvarez, N. J. Parekh, B. Maruszewski, R. S. Givens, T. Higuchi e R. L. Schowen, Multiple intermediates generate fluorophore derived light in the oxalate/peroxide chemiluminescence system, J. Am. Chem. Soc., 108, 6435-6437, 1986

55. C. V. Stevani, D. F. Lima, V. G. Toscano e W. J. Baader, Kinetic studies on the peroxyoxalate chemiluminescent reaction: imidazole as a nucleophilic catalyst, J. Chem. Soc. Perkin Trans, 989-995, 1996

56. H. Neuvonen, A two-intermediate model for imidazole-promoted peroxyoxalate chemiluminescence, J. Biolumin. Chemilumin., 12, 241-248, 1997 
57. A. G. Hadd, A. Seeber e J. W. Birks, Kinetics of two pathways in peroxyoxalate chemiluminescence, J. Org. Chem., 65, 2675-2683, 2000

58. C. C. West e J. H. Harwell; Surfactants and subsurface remediation, Environ. Sci. Technol., 26, 2324-2330, 1992

59. G. L. Mclntire, Micelles in analytical chemistry, Crit. Rev. Anal. Chem. 21, 257278,1990

60. E. Pelizzetti e E. Pramauro, Analytical applications of organized molecular assemblies, Anal. Chim. Acta, 169, 1-29, 1985

61. F. H. Quina e W. L. Hinze; Surfactant-mediated cloud point extractions: An environmentally benign alternative separation approach, Ind. Eng. Chem. Res., 38, $4150-4168,1999$

62. N. Maniasso, Ambiente micelares em química analitica, Química Nova, 24, $87-93,2001$

63. L. Saunders, Molecular aggregation in aqueous dispersions of phosphatidyl and lysophosphatidylcholines, Biochim. Biophys. Acta, 125, 70, 1966

64. D. Attwood, P. H. Elworthy e S. B. Kayne, Membrane osmometry of aqueous micellar solutions of pure nonionic and ionic surfactants, J. Phys.Chem., 74, 35293534,1970

65. R. D. Geer, E. H. Eylar e E. W. Anacker, Dependence of micelle aggregation number on polar head structure. Light scattering by aqueous solutions of decylammonium salts and related surfactants, J. Phys. Chem., 75, 369-374, 1971 
66. J. L. Kurz, Effects of micellization on kinetics of hydrolysis of monoalkyl sulfates, J. Phys. Chem., 66, 2239-2246, 1962

67. E. J. Fendler, C. L. Day e J. H.Fendler, Proton magnetic resonance investigation of the environment of aromatic compounds in aqueous zwitterionic micellar solutions, J. Phys. Chem. 76, 1460-1466,1972.

68. E. Pramauro e E. Pelezetti, Surfactants in Analytical Chemistry - Applications of Organized Amphiphilic Media; vol. XXXI, in 'Wilson \& Wilson's Comprehensive Analytical Chemistry", Elsevier Science, B.V., Amsterdam, 1996

69. J. H. Fendler, Membrane Mimetic Chemistry, Caracterizations and Applications or Micelles, Microemulsions, Monolayers, Bilayers, Vesicles, Host-Guest Systems, and Polyons, John Wiley \& Sons, New York, 1982

70. J. Lasovsky e F. Grambal, Micellar complexes of energy-transfer, Bioelectrochem. Bioenerg., 15, 95-102, 1986

71. H. Karatani, Effects of cyclodextrin on enhancement for chemiluminescence of the luminol related compound, Chem. Lett., 377-380, 1986

72. S. Igarashi e W. L. Hinze, Enzymatic assay with detection by enhanced luminol chemiluminescence in a reversed micellar system - determination of I-aminoacids and glucose, Anal. Chim. Acta, 225, 147-157, 1989

73. C. L. Malehorn, T. E. Riehl e W. L. Hinze, Improved determination of hydrogen-peroxide or lucigenin by measurement of lucigenin chemiluminescence in organized assemblies, Analyst, 111, 941-947, 1986 
74. W. L. Hinze, T. E. Riehl, H. N. Singh e Y. Baba, Micelle-enhanced chemiluminescence and application to the determination of biological reductants using lucigenin, Anal. Chem., 56, 2180-2191, 1984

75. A. Ingvarsson, C. L. Frurer, T. E. Riehl, K. N. Thimmaiah, J. M. Williams e W. L. Hinze, Improvement in 10,10'-dimethyl-9,9'-biacridinium dinitrate analytical chemiluminescence measurements by use of reactive hydroxide counterion alkyltrimethylammonium micellar surfactants, Anal. Chem., 60, 2047-2055, 1988

76. E. J. Woolf e M. L. Grayeski, Effect of cyclodextrin solutions on aqueous peroxyoxalate chemiluminescence, J. Lumin., 39, 19-27, 1987

77. S. Koyo, S. Tokumaru e I. Tsukamoto, Peroxyoxalate chemiluminescent assay in aqueous solution with $\gamma$-cyclodextrin, Clin. Chem., 38, 788, 1992

78. O. M. Steijger, H. M. Van Mastbergen e J. J. M. Holthuis, Chemiluminescence of bis(2,4,6-trichlorophenyl)oxalate in aqueous micellar systems, Anal. Chim. Acta, $217,229-237,1989$

79. N. Dan, M. L. Lau e M. L. Grayeski, Micellar-enhanced aqueous peroxyoxalate chemiluminescence, Anal. Chem. 63, 1766-1771, 1991

80. N. Dan e M. L. Grayeski, Effects of reversed micelles on peroxyoxalate chemiluminescence and analytical implications for determination of fluorophors, Langmuir, 10, 447-453, 1994.

81. M. M. Rauhut, L. J. Bollyky, B. G. Roberts, M. Loy, R. H. Whitman, A. V. lannotta, A. M. Semsel e R. A. Clarke, Chemiluminescence from reactions of eletronegatively substituted aryl oxalates with $\mathrm{H}_{2} \mathrm{O}_{2}$ and fluorescent compounds, J. Am. Chem. Soc., 89, 6515-6522, 1967 
82. J. H. Lee, S. Y. Lee e K. J. Kim, The relative significance of multiple pathways in peroxyoxalate chemiluminescence reactions, Anal. Chim. Acta, 329, 117-126, 1996

83. H. Neuvonen, Kinetics and mechanisms of reactions of pyridines and imidazoles with phenyl acetates and trifluoroacetates in aqueous acetonitrile with low content of water: nucleophilic and general base catalysis in ester hydrolysis, J. Chem. Soc. Perkin Trans II, 159-166, 1987

84. T. Jonsson e K. Irgum, New nucleophilic catalysts for bright and fast peroxyoxalate chemiluminescence, Anal. Chem., 72, 1373-1380, 2000

85. M. Ishii, M. Yamada e S. Suzuki, Didodecyldimethylammoniumbromide vesicle-catalyzed and uranine-sensitized chemiluminescence for determination of free cyanide at picogram levels by flow injection analysis, Anal. Lett., 19, 1591-1601, 1986

86. M. Kishida, Y. Makita, T. Suzuki, M. Yamada e T. Hobo, Cobalt (II)-catalyzed chemiluminescence in a dioctadecyldimethylammonium chloride bilayer membranous medium for the flow injection determination od phenylpyruvic acid, Anal. Chem, 63, 2301-2305, 1991

87. A. Kuniyoshi, K. Hatta, T. Suzuki, A. Masuda e M. Yamada, Chemiluminescence sensor with Mn (III)-tetrakis(4-sulfonatophenyl)-phorphiri immobilized on dioctadecyldimethylammonium chloride bilayer membranes incorporated into PVC film, Anal. Lett., 29, 673-685, 1996 
88. American Public Health Association and Water Pollution Control Federation, "Standard Methods for the Examination of Water and Wastewater", $18^{\text {th }}$ Edition, American Public Health Association, Washington, DC, 1992, p.4-36.

89. L. C. Adam, I. Fábián, K. Suzuki e G. Gordon, Hypochlorous acid decomposition in the $\mathrm{pH}$ 5-8 region, Inorg. Chem., 31, 3534-3541,1992

90. T. Nakagama, M. Yamada, T. Hobo, Chemiluminescence sensor with uranine immobilized on an anion-exchange resin for monitoring free chlorine in tap water, Anal. Chim. Acta, 231, 7-12, 1990

91. E. M. Aieta e J. D. Berg, A review of chlorine dioxide in drinking water treatment, Jour. AWWA, 78, 62-72, 1986

92. D. F. Shriver, P. W. Atkins in Inorganic Chemistry, Oxford University Press, U.K., third Edition, 1999, p. 197-198, 424

93. M. W. Lister, Decomposition of sodium hypochlorite: the uncatalyzed reaction, Can. J. Chem., 34, 465-478, 1956

94. T. Yokoyama e O. Takayasu, Kogyo Kagaku Zasshi, 1619-1624, 70, 1967

95. L. C. Adam e G. Gordon, Hypochlorite ion decomposition: effects of temperature, ionic strength, and chloride ion, Inorg. Chem., 38, 1299-1304,1999

96. M. W. Lister, Decomposition of sodium hypochlorite: the catalyzed reaction, Can. J. Chem., 34, 479-488, 1956.

97. M. W. Lister e R.C. Petterson, Oxygen evolution from sodium hypochlorite solutions, Can. J. Chem., 40, 729-733, 1962 
98. A. T. Palin, The determination of free and combined chlorine in water by the use of diethyl-p-phenylene diamine, J. Amer. Water Works Assoc., 49, 873-880,1957

99. A. F. Danet, M. C. Cheregi, M. Badea, A. Radu e H. Y. Aboul-Enein, Automated flow injection analysis device and methods for determination of chlorine in drinking waters, Rev. Chim., 54, 3-6, 2003

100. D. J. Leggett, N. H. Chen e D. S. Mahadevappa, Rapid-determination of residual chlorine by flow-injection analysis, Analyst, 107, 433-441, 1982

101. J. D. Johnson, R. Overly, Stabilized neutral o-tolidine, SNORT, colorimetric method for chlorine, Anal. Chem., 41, 1744-1750, 1969

102. M. C. Cheregi e A. F. Danet, Method for free chlorine determination in water, using the flow - Injection analysis principle, Rev. Chim., 51, 566-571, 2000

103. G. Gordon, D. L. Sweetin, K. Smith, G. E. Pacey, Improvements in the N,Ndiethyl-p-phenylenediamine method for the determination of free and combined residual chlorine through the use of FIA, Talanta, 38, 145-149, 1991

104. D. J. Leggett, N. H. Chen, D.S. Mahadevappa, A flow-injection method for analysis of residual chlorine by the DPD procedure, Fresenius' Z. Anal. Chem., 315, $47-50,1983$

105. M. Zenki, H. Komatsubara, K. Toei, Determination of residual chlorine in tap water by flow-injection spectrophotometry, Anal. Chim. Acta, 208, 317-320, 1988

106. K. K. Verna, A. Jain, A. Townshend, Determination of free and combined residual chlorine by flow-injection spectrophotometry, Anal. Chim. Acta, 261, 233240,1992 
107. M. Trojanowicz, W. Matuszewski, A. Hulanicki, Flow-injection potentiometric determination of residual chlorine in water, Anal. Chim. Acta, 136, 85-92, 1982

108. D. Midgley, A bromide-selective electrode-redox electrode cell for the potentiometric determination of bromine and free residual chlorine, Talanta, 30, 547554,1983

109. A. N. Tsaousis, C. O. Huber, Flow-injection amperometric determination of chlorine at a gold electrode, Anal. Chim. Acta, 178, 319-323, 1985

110. Y. Ellis e P. L. Brown, Determination of residual chlorine by derivatisation with 2,6-dimethylphenol and gas chromatographic separation, Anal. Chim. Acta, 124, 431-436, 1981

111. P. Chen, W. Z. Wei e S. Z. Yao, Different valency chlorine species analysis by non-suppressd ion chromatography with double cell quartz crystal detector, Talanta, 49, 571-576, 1999

112. M. Biesaga, M. Kwiatkowska e M. Trojanowicz, Separation of chlorinecontaining anions by ion chromatography and capillary electrophoresis, J. Chromatogr. A, 777, 375-381, 1997

113. U. Isaccson e G. Wettermark, Determination of inorganic chlorine compounds by chemiluminescence reactions, Anal. Chim. Acta, 83, 227-239, 1976

114. U. Isaccson e G. Wettermark, Selective analysis of chlorine (hypochlorous acid) and chlorine dioxide using chemiluminescence, Anal. Lett.,11, 13-25, 1978 
115. D. E. Marino e J. D. Ingle Jr, Determination of free chlorine in water by chemiluminescence reaction with hydrogen peroxide, Anal. Chim. Acta, 123, 247253,1981

116. W. R. Seitz, Chemiluminescence from reaction between hypochlorite and Iuminol, J. Phys. Chem., 79, 101-115, 1975

117. D. E. Marino e J. D. Ingle Jr, Determination of chlorine in water by luminol chemi-luminescence, Anal. Chem., 53, 455-458, 1981

118. J. R. Gord, G. Gordon e G. E. Pacey, Selective chlorine determination by gasdiffusion flow injection analysis with chemiluminescent detection, Anal. Chem., 60, 24, 1988.

119. N. Ishimaru, J. M. Lin e M. Yamada, Luminol-free chlorine chemiluminescence in an oil-in-water microemulsion medium, Anal. Commun., 35, 67-69,1998

120. M. Yamada, T. Hobo e S. Suzuki, Xanthene dye chemiluminescence for determination of free chlorine in water, Anal. Lett., 21, 1887-1900, 1988

121. T. Nakagama, M. Yamada e T. Hobo, Rhodamine-6G chemiluminescence for the determination of free chlorine in tap water by a flow-injection method, Analyst, $114,1275-1278,1989$

122. G. Irons e G. M. Greenway, Investigation into the detection of chlorine species by rhodamine $6 \mathrm{G}$ chemiluminescence with electrochemical modification, Analyst, $120,477-483,1995$ 
123. M. M. Nakamura, N. Coichev, J. M. Lin e M. Yamada, Flow injection investigation of the chemiluminescent reaction of bis(2,4,6-trichlorophenyl)oxalate with free chlorine, Anal. Chim. Acta, 484, 101-109, 2003

124. J. Basset, R. C. Denney, G. H. Jeffery, J. Mendham in Vogel Análise Inorgânica Quantitativa, Editora Guanabara, RJ, 1981, p. 284

125. A. C. Capomacchia, R. N. Jennings, S. M. Hemingway, P. D'Souza, W. Prapaitrakul e A. Gingle, Native peroxyoxalate chemiluminescence from the reaction of bis(2,4,-dinitrophenyl)oxalate and hydrogen peroxide perturbed by nonfluorophores, Anal. Chim. Acta, 196, 305-310, 1987

126. N. Imaizumi, K. Hayakawa e M. Miyazaki, Stability of bis $(2,4,6-$ trichlorophenyl)oxalate in high-performance liquid chromatography for chemiluminescence detection, Analyst, 114, 161-164, 1989

127. R. Weiberger, C. A. Mannan e M. Cerchio, Noise and background in peroxyoxalate chemiluminescence detection for liquid chromatography, 288, 445450,1984

128. N. W. Barnett, R. Bos, S. W. Lewis e R. A. Russel, Postulation of a phenoxyl radical intermediate as the species responsible for the background emission observed with certain peroxyoxalate chemiluminescence reagents, Anal. Communic., $34,17-20,1997$

129. N. W. Barnett, R. N. Evans e R. A. Russel, Observations of the chemiluminescent background emission from the reaction of bis $(2,4,6$ trichlorophenyl)oxalate with hydrogen peroxide in aqueous tetrahydrofuran $(1+1)$ Anal. Proc. In. Anal. Communic., 31, 241-244, 1994 
130. R. N. Jennings e A. C. Capomacchia, Solution kinetics of the degradation of the chemiluminescent reagent bis(2,4-dinitrophenyl)oxalate in water/acetonitrile, Anal. Chim. Acta, 205, 207-213, 1988

131. H. Neuvonen, Kinetics of the decomposition of a chemiluminescent reagent bis(2,4-dinitrophenyl)oxalate in aqueous acetonitrile, J. Chem. Soc. Perkin Trans 2, $89-95,1994$

132. H. Neuvonen, Neutral hydrolysis and imidazole-catalysed decomposition of bis(4-nitrophenyl)oxalate. 1,1'- oxalyldiimidazole as an intermediate, J. Chem. Soc. Perkin Trans 2, 945-949, 1995

133. D. C. Williams, G. F. Huff e W. R. Seitz, Evaluation of peroxyoxalate chemiluminescence for determination of enzime generated peroxide, Anal. Chem. 48, 1003-1006, 1976

134. R. Weinberger, Solvent and $\mathrm{pH}$ effects on peroxyoxalate chemiluminescence detection for liquid chromatography, J. Chromatogr., 314, 155-165, 1984

135. K. Hayakawa, E. Minogawa, T. Yokoyama, M. Miyazawa, K. Imai, A universal peroxyoxalate-chemiluminescence detection system for mobile phases of differing pH, Biomed Chromatogr. 6, 84-87, 1992

136. M. M. Nakamura, S. A. Saraiva, N. Coichev, Parameters affecting the peroxyoxalate chemiluminescence, Anal. Lett., 32, 2471-2487, 1999

137. K. W. Sigvardson e J. W. Birks, Peroxyoxalate chemiluminescence detection of polycyclic aromatic hydrocarbons in liquid chromatography, Anal. Chem., $55432-$ 435,1983 
138. B. Mann e M. L. Grayeski, Background emission from the peroxyoxalate chemiluminescence reaction in the absence of fluorophors, Anal. Chem., 62, 15321536,1990

139. N. Hanaoka, H. Tanaka, A. Nakamoto e M. Tanaka, Kinetic study of background emission from peroxyoxalate chemiluminescence reaction and application to the improvement of detection limits in liquid chromatography, Anal. Chem., 63, 2680-2685, 1991

140. G.N.R.Tripathi e R. H. Schuler, The resonance Raman spectrum of phenoxyl radical, J. Chem. Phys., 81, 113-121, 1984

141. J. Magonski, Z. Pawlak e T. Jasinki, Dissociation constants of substituted phenols and homoconjugation constants of the corresponding phenol-phenolate systems in acetonitrile, J. Chem. Soc. Faraday Trans, 89, 119-122, 1993. 